Prepared in cooperation with the

Massachusetts Department of Environmental Protection, the U.S. Environmental Protection Agency, and the City of Cambridge

\title{
Potential Reductions of Street Solids and Phosphorus in Urban Watersheds from Street Cleaning, Cambridge, Massachusetts, 2009-11
}
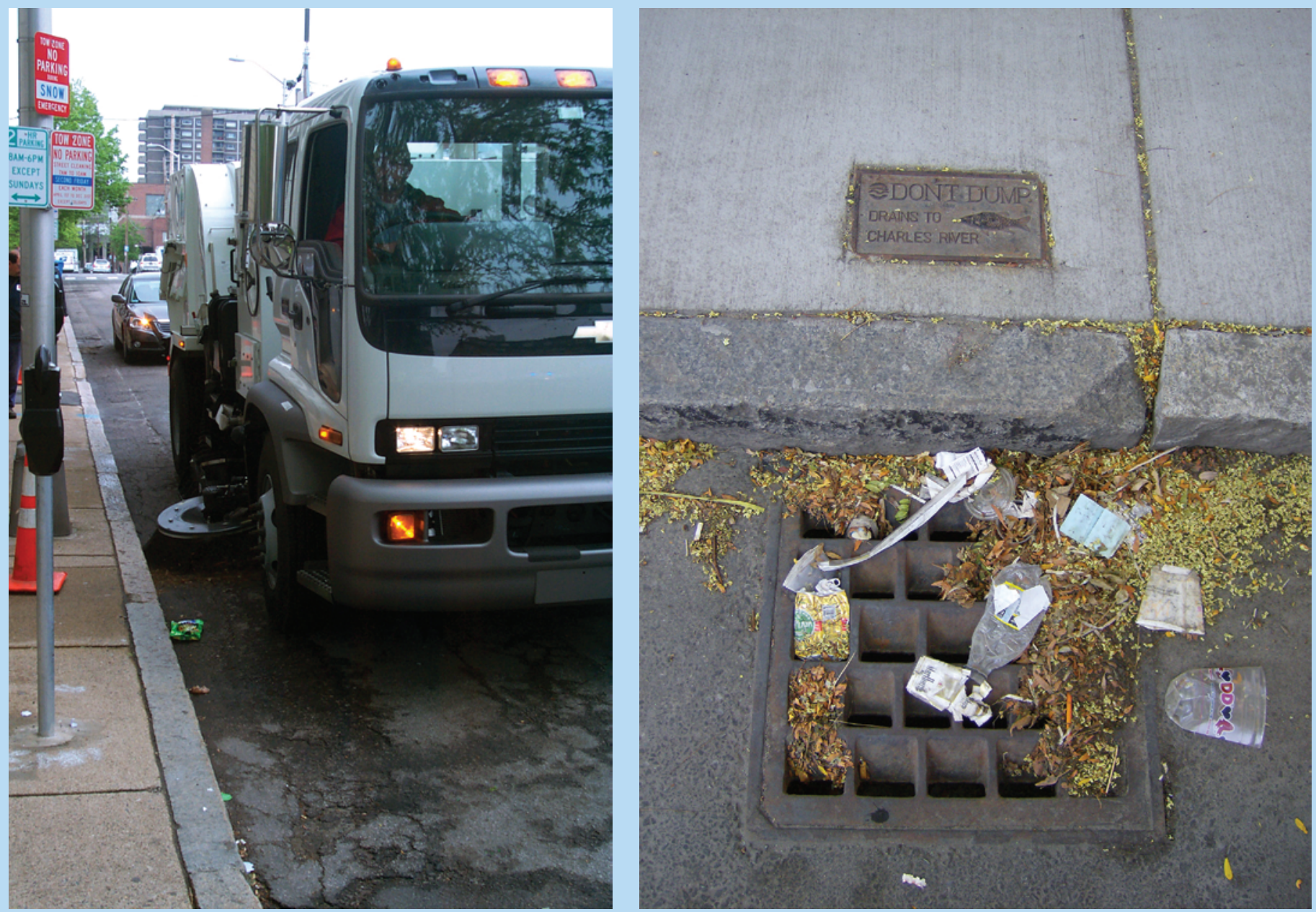

Scientific Investigations Report 2012-5292 
Front cover. Photographs showing regenerative-air street cleaner and storm drain.

Back cover. Photograph of rotary gutter broom of a regenerative-air street cleaner in action. 


\section{Potential Reductions of Street Solids and Phosphorus in Urban Watersheds from Street Cleaning, Cambridge, Massachusetts, 2009-11}

By Jason R. Sorenson

Prepared in cooperation with the

Massachusetts Department of Environmental Protection, the

U.S. Environmental Protection Agency, and the City of Cambridge

Scientific Investigations Report 2012-5292 


\section{U.S. Department of the Interior \\ KEN SALAZAR, Secretary \\ U.S. Geological Survey \\ Marcia K. McNutt, Director}

U.S. Geological Survey, Reston, Virginia: 2013

For more information on the USGS — the Federal source for science about the Earth, its natural and living resources, natural hazards, and the environment, visit http://www.usgs.gov or call 1-888-ASK-USGS.

For an overview of USGS information products, including maps, imagery, and publications, visit http://www.usgs.gov/pubprod

To order this and other USGS information products, visit http://store.usgs.gov

Any use of trade, firm, or product names is for descriptive purposes only and does not imply endorsement by the U.S. Government.

Although this information product, for the most part, is in the public domain, it also may contain copyrighted materials as noted in the text. Permission to reproduce copyrighted items must be secured from the copyright owner.

Suggested citation:

Sorenson, J.R., 2013, Potential reductions of street solids and phosphorus in urban watersheds from street cleaning, Cambridge, Massachusetts, 2009-11: U.S. Geological Survey Scientific Investigations Report 2012-5292, 66 p., plus appendix 1 on a CD-ROM in pocket. (Also available at http://pubs.usgs.gov/sir/2012/5292/.) 


\section{Acknowledgments}

This work was supported in part by the Massachusetts Department of Environmental Protection (08E4MA2441101801), the U.S. Environmental Protection Agency (DW-14-95772401-0), and the City of Cambridge as American Recovery and Reinvestment Act Grantee 2009-08/ARRA 60 (10E4MA24410120).

The author wishes to extend his gratitude to Owen O'Riorden, John Nardone, Paul Tulley, George Stylianopoulis, John Fitzgerald, Lenny Silva, and Wendy Robinson of the Cambridge Department of Public Works; Gary Gonyea and Tom Maguire of the Massachusetts Department of Environmental Protection; Mark Voorhees and Michael Borst of the U.S. Environmental Protection Agency; Kenneth Young, Gary Young, Bryan Young, Bob Hatfield, and Jeff O'Malley of TYMCO Regenerative Air Sweepers, Inc.; Jon Casey, Warren Leonard, and Joseph Arena, of Casey and Dupuis; student intern Eli Yuan-Vogel of the University of Massachusetts at Amherst; and Northeastern Co-op students Andrew Ingalls, Marine Langreney, A.J. Spiers, and Melissa Weil. Many thanks to Sgt. James Crowley, Alicia Popovics, and the many police officers of the Cambridge Police Department who helped maintain traffic safety. Special thanks to Roger Bannerman of the Wisconsin Department of Natural Resources for his insight and guidance.

The author also wishes to thank Paul Buono, Tony Cannarsa, Leslie DeSimone, Gregory Granato, Jennifer Savoie, Marcus Waldron, Phillip Zarriello, and Robert Breault of the U.S. Geological Survey (USGS). Many thanks also to USGS Volunteers for Science Mary Gowins and Sandra Petrakis. Special thanks to Judy Horwatich, William Selbig, and Kirk Smith of the USGS for their guidance and thoughtful reviews. 
THIS PAGE INTENTIONALLY LEFT BLANK 


\section{Contents}

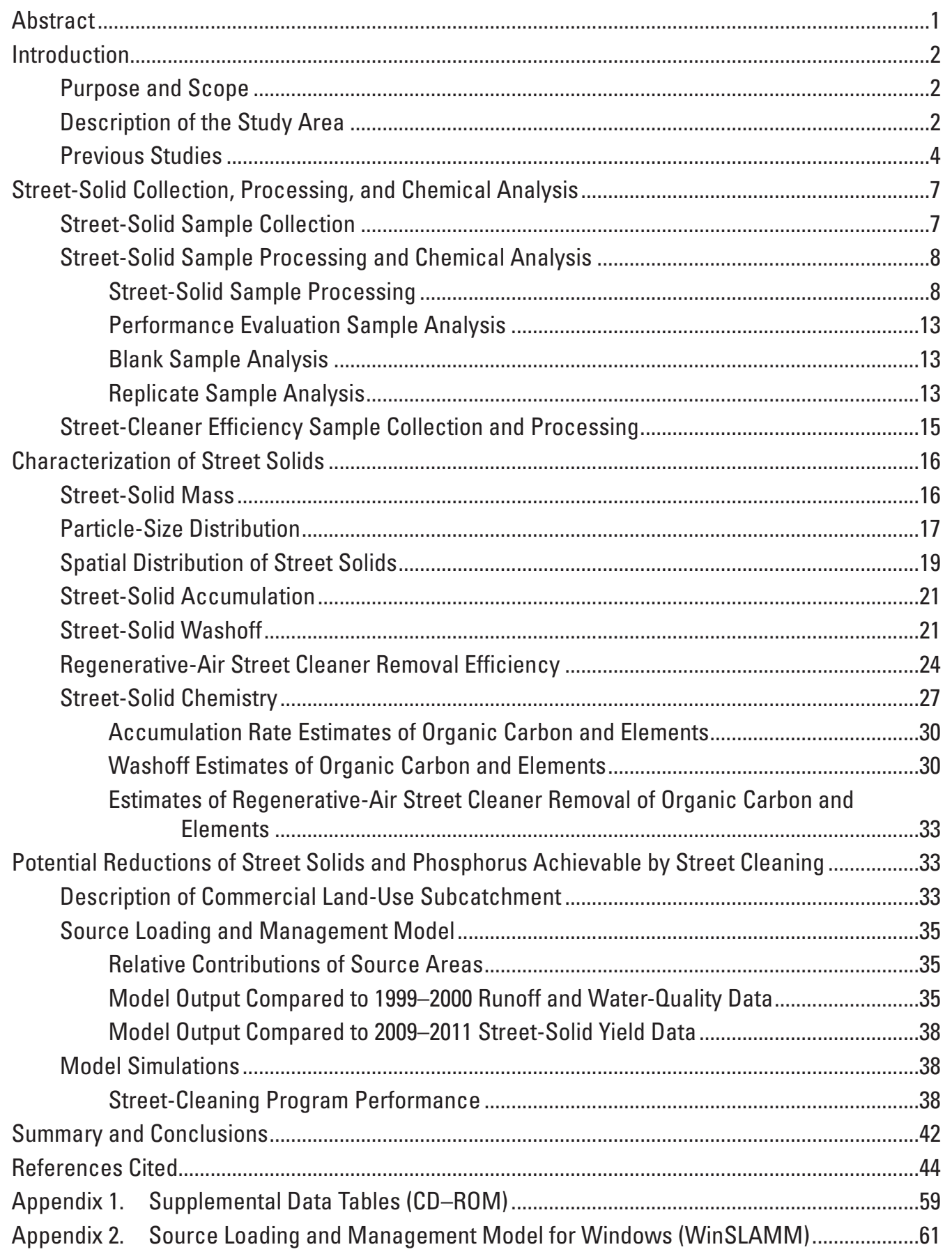




\section{Figures}

1. Location map of $A$, the City of Cambridge, Massachusetts, and $B$, land-use distribution, and municipal street-cleaning districts.

2. Aerial photograph showing the boundary between municipal street-cleaning districts $\mathrm{D}$ and $\mathrm{E}$, approximate location of multifamily and commercial study street sections, locations of city construction and private development, and location of the predominantly commercial land-use subcatchment used in the Source Loading and Management Model, Cambridge, Massachusetts...

3. Photograph of curb-to-curb street-solid composite sampling equipment and municipal police detail to ensure traffic safety, Cambridge, Massachusetts.

4. Photograph of $A$, two cleaned vacuumed paths typical of street-solid composite sampling, and examples of a rough street-surface and a poor street-surface condition, and $B$, a smooth street surface with good street-surface condition, curband-gutter drainage system, and an example of unusual loading avoided during sampling, Cambridge, Massachusetts

5. Photograph of $A$, a street-solid composite sample contained within a 0.1 micrometer paper filter bag being extracted from the vacuum, folded, and placed into a labeled clear plastic ziplock bag, Cambridge, Massachusetts, and $B$, stainless steel riffle splitter and receiving pans used for large volumes or heterogeneous street-solid sample

6. Photograph of a TYMCO Dustless Sweeping Technology-6 regenerative-air street cleaner in Cambridge, Massachusetts...

7. Graph showing daily precipitation and average street-solid yields between March 2010 and 2011 measured within multifamily and commercial land-use types during periods of dry weather and bracketed rainstorms from curb-to-curb composite samples, and estimated yields during removal-efficiency experiments from single side composite samples.

8. Boxplot showing seasonal and end-of-winter street-solid yields, in pounds per curb-mile from streets in $A$, multifamily, and $B$, commercial land-use types, Cambridge, Massachusetts

9. Boxplot showing accumulation rates by grain-size fraction and total solids, in pounds per curb-mile per day from streets in $A$, multifamily and $B$, commercial landuse types, Cambridge, Massachusetts.

10. Graphs showing street-solid yield by grain-size fraction and total yield, in pounds per curb-mile per day as a function of time in days since the last rain or street cleaning on streets in multifamily and commercial land-use types, Cambridge, Massachusetts.

11. Boxplot showing percent washoff of street solids by grain-size fraction estimated for storms with a recorded rainfall volume range of 0.32 to 1.71 inches, from streets in $A$, multifamily and $B$, commercial land-use types, Cambridge, Massachusetts.

12. Graphs showing average percent washoff for each grain-size fraction, and average total washoff for storms with a recorded rainfall volume range of 0.32 to 1.71 inches as a function of $A$, total rain depth, and $B$, rainfall intensity from streets in multifamily and commercial land-use types, Cambridge, Massachusetts.

13. Boxplot showing street-solid yields before and after a single pass of a regenerative-air street cleaner on streets in $A$, multifamily and $B$, commercial land-use types, Cambridge, Massachusetts. 
14. Graphs showing $A$, removal efficiency plot of a regenerative-air street cleaner making a single pass on streets with smooth to rough street-surface conditions and heavy on-street parking with monthly parking controls, in multifamily and commercial land-use types Cambridge, Massachusetts

15. Boxplot showing total phosphorus yields, in pounds per curb-mile, by season from streets representing predominantly $A$, multifamily and $B$, commercial land-use types in Cambridge, Massachusetts

16. Predominantly commercial land-use subcatchment in Cambridge, Massachusetts, and U.S. Geological Survey flow and water-quality monitoring station (USGS ID: 01104677), over a 0.5-meter color orthophoto obtained from MassGIS

17. Graphs showing cumulative relative percent contributions of major source areas within the $A$, multifamily, $B$, institutional, and $C$, commercial land-use types contained in the modeled commercial subcatchment, Cambridge, Massachusetts.

18. Plots of $A$, rainfall depth as compared to runoff depth, and $B$, runoff coefficient as compared to rainfall depth from commercial subcatchment observations, March to December 2000, Cambridge, Massachusetts (USGS ID: 01104677)

19. Graph showing simulated runoff depth as compared to observed runoff depth, March to December 2000, Cambridge, Massachusetts (USGS ID: 01104677)

20. Graph showing time series of simulated outfall discharge from the commercial land-use subcatchment as compared to observed runoff volume, March to December 2000, Cambridge, Massachusetts (USGS ID: 01104677)

21. Graph showing simulated as compared to observed street-solid yields for multifamily and commercial land-use areas, Cambridge, Massachusetts (2010 data only) .............40

22. Graphs showing simulated and observed street-solid yields, April 2010 to March 2011 for $A$, multifamily and $B$, commercial land-use types within the modeled subcatchment, Cambridge, Massachusetts

\section{Tables}

1. Land-use types and percent of total area for Cambridge, Massachusetts ........................

2. Characteristics of study-street sections, Cambridge, Massachusetts ...............................5

3. Target analytes and analytical techniques for samples submitted to SGS Laboratories, Toronto, Ontario, Canada

4. Median values and relative standard deviations for selected concentrations of total and total-recoverable trace elements in quality-control samples.

5. Selected analytical results of graded unground silica sand used as blank material sourced from Ottawa, Illinois

6. Summary of Cambridge, Massachusetts, street-solid yields by land-use type and grain-size fraction.

7. Comparison of Cambridge, Massachusetts, street-solid yields by land-use type to those in other areas of the United States.

8. Average, median, maximum, and minimum removal efficiency, in percent, of a regenerative-air street cleaner on multifamily and commercial land-use streets in Cambridge, Massachusetts.

9. Total and grain-size fraction median constituent total-recoverable concentrations and masses constituent masses from composite street-solid samples collected from streets representing $A$, multifamily and $B$, commercial land-use types in Cambridge, Massachusetts. 
10. Street-solid composite sample collection dates, sample type, antecedent rain conditions, sampled storm volume, street-solid yield, and total phosphorus yields from streets in Cambridge, Massachusetts

11. Accumulation rates for constituents measured in street-solid composite samples, by grain-size fraction and land-use type collected before and after precipitation events in pounds per curb-mile per day, Cambridge, Massachusetts.

12. Percent washoff of constituent masses in terms of grain-size fraction and land-use type from street-solid composite samples collected before and after 6 storms with a recorded rainfall volume range of 0.32 to 1.71 inches, Cambridge, Massachusetts.......54

13. Median percent reductions for total and grain-size fractions of constituents measured in seasonal composite of street-solid yields collected before and after a single pass of a regenerative-air street cleaner on streets representing multifamily and commercial land-use types in Cambridge, Massachusetts

14. Source Loading and Management Model estimated percent reductions of total and particulate solids and phosphorus using single passes by three different streetcleaning technologies at various frequencies in a predominantly commercial subcatchment, Cambridge, Massachusetts. 


\section{Conversion Factors, Datum, and Abbreviations}

Inch/Pound to SI

\begin{tabular}{|c|c|c|}
\hline Multiply & By & To obtain \\
\hline \multicolumn{3}{|c|}{ Length } \\
\hline inch (in.) & 2.54 & centimeter $(\mathrm{cm})$ \\
\hline inch (in.) & 25.4 & millimeter (mm) \\
\hline foot $(\mathrm{ft})$ & 0.3048 & meter (m) \\
\hline mile (mi) & 1.609 & kilometer $(\mathrm{km})$ \\
\hline \multicolumn{3}{|c|}{ Area } \\
\hline square mile $\left(\mathrm{mi}^{2}\right)$ & 2.59 & square kilometer $\left(\mathrm{km}^{2}\right)$ \\
\hline acre & 0.4047 & hectare (ha) \\
\hline acre & 4046.94 & square meter $\left(\mathrm{m}^{2}\right)$ \\
\hline \multicolumn{3}{|c|}{ Volume } \\
\hline gallon (gal) & 3.79 & $\operatorname{liter}(\mathrm{L})$ \\
\hline gallon (gal) & 0.003785 & cubic meter $\left(\mathrm{m}^{3}\right)$ \\
\hline cubic inch $\left(\mathrm{in}^{3}\right)$ & 0.01639 & liter $(\mathrm{L})$ \\
\hline cubic foot $\left(\mathrm{ft}^{3}\right)$ & 0.02832 & cubic meter $\left(\mathrm{m}^{3}\right)$ \\
\hline \multicolumn{3}{|c|}{ Mass } \\
\hline ounce, avoirdupois (oz) & 28.35 & $\operatorname{gram}(\mathrm{g})$ \\
\hline pound avoirdupois (lb) & 0.4535 & kilogram (kg) \\
\hline pounds per curb-mile (lbs/curb-mi) & 0.2819 & grams per curb-meter (g/curb-m) \\
\hline tons per day (ton/d) & 0.9075 & metric ton per day $(\mathrm{mt} / \mathrm{d})$ \\
\hline \multicolumn{3}{|c|}{ Flow } \\
\hline cubic foot per second $\left(\mathrm{ft}^{3} / \mathrm{s}\right)$ & 0.02832 & cubic meter per second $\left(\mathrm{m}^{3} / \mathrm{s}\right)$ \\
\hline cubic feet per minute $\left(\mathrm{ft}^{3} / \mathrm{min}\right)$ & 0.02831685 & cubic meter per minute $\left(\mathrm{m}^{3} / \mathrm{min}\right)$ \\
\hline \multicolumn{3}{|c|}{ Speed } \\
\hline miles per hour (mph) & 1.609 & kilometer per hour (kmph) \\
\hline
\end{tabular}

Temperature in degrees Celsius $\left({ }^{\circ} \mathrm{C}\right)$ may be converted to degrees Fahrenheit $\left({ }^{\circ} \mathrm{F}\right)$ as follows:

$$
{ }^{\circ} \mathrm{F}=\left(1.8 \times{ }^{\circ} \mathrm{C}\right)+32
$$

Vertical coordinate information is referenced to the North American Vertical Datum of 1988 (NAVD 88).

Altitude, as used in this report, refers to distance above the vertical datum.

Concentrations of chemical constituents in water are given either in milligrams per liter (mg/L) or micrograms per liter $(\mu \mathrm{g} / \mathrm{L})$.

Concentrations of chemical constituents in solids are given either in milligrams per kilogram $(\mathrm{mg} / \mathrm{kg})$, or as a percent $(\%)$. 


\section{List of Abbreviations}

$\begin{array}{ll}\text { COV } & \text { coefficient of variation } \\ \text { CTC } & \text { curb-to-curb } \\ \text { EIA } & \text { effective impervious area } \\ \text { HE } & \text { high efficiency } \\ \text { NIST } & \text { National Institute of Science and Technology } \\ \text { NOAA } & \text { National Oceanic and Atmospheric Administration } \\ \text { NRCS } & \text { National Resource Conservation Service } \\ \text { NURP } & \text { National Urban Runoff Program } \\ \text { PES } & \text { performance evaluation sample } \\ \text { RA } & \text { regenerative air } \\ \text { RPD } & \text { relative percent differences } \\ \text { SCM } & \text { stormwater control measures } \\ \text { SLAMM } & \text { Source Loading and Management Model } \\ \text { SS } & \text { single sided } \\ \text { SSC } & \text { suspended solids concentration } \\ \text { TMDL } & \text { total maximum daily load } \\ \text { USEPA } & \text { U.S. Environmental Protection Agency } \\ \text { USGS } & \text { U.S. Geological Survey }\end{array}$




\title{
Potential Reductions of Street Solids and Phosphorus in Urban Watersheds from Street Cleaning, Cambridge, Massachusetts, 2009-11
}

\author{
By Jason R. Sorenson
}

\section{Abstract}

Material accumulating and washing off urban street surfaces and ultimately into stormwater drainage systems represents a substantial nonpoint source of solids, phosphorus, and other constituent loading to waterways in urban areas. Cost and lack of usable space limit the type and number of structural stormwater source controls available to municipalities and other public managers. Non-structural source controls such as street cleaning are commonly used by cities and towns for construction, maintenance and aesthetics, and may reduce contaminant loading to waterways. Effectiveness of street cleaning is highly variable and potential improvements to water quality are not fully understood. In 2009, the U.S. Geological Survey, in cooperation with the Massachusetts Department of Environmental Protection, the U.S. Environmental Protection Agency, and the city of Cambridge, Massachusetts, and initiated a study to better understand the physical and chemical nature of the organic and inorganic solid material on street surfaces, evaluate the performance of a street cleaner at removing street solids, and make use of the Source Loading and Management Model (SLAMM) to estimate potential reductions in solid and phosphorus loading to the lower Charles River from various street-cleaning technologies and frequencies.

Average yield of material on streets collected between May and December 2010, was determined to be about 740 pounds per curb-mile on streets in multifamily land use and about 522 pounds per curb-mile on commercial landuse streets. At the end-of-winter in March 2011, about 2,609 and 4,788 pounds per curb-mile on average were collected from streets in multifamily and commercial land-use types, respectively. About 86 percent of the total street-solid yield from multifamily and commercial land-use streets was greater than or equal to 0.125 millimeters in diameter (or very fine sand). Observations of street-solid distribution across the entire street width indicated that as much as 96 percent of total solids resided within 9 feet of the curb. Median accumulation rates of street solids and median washoff of street solids after rainstorms on multifamily and commercial land-use streets were also similar at about 33 and 22 pounds per curb-mile per day, and 35 and 40 percent, respectively. Results indicate that solids on the streets tested in Cambridge, Mass., can recover to pre-rainstorm yields within 1 to 3 days after washoff. The finer grain-size fractions tended to be more readily washed from the roadway surfaces during rainstorms. Street solids in the coarsest grain-size fraction on multifamily streets indicated an average net increase following rainstorms and are likely attributed to debris run-on from trees, lawns, and other plantings commonly found in residential areas.

In seven experiments between May and December 2010, the median removal efficiency of solids from street surfaces following a single pass by a regenerative-air street cleaner was about 82 percent on study sites in the multifamily landuse streets and about 78 percent on the commercial land-use streets. Median street-solid removal efficiency increased with increasing grain size. This type of regenerative-air street cleaner left a median residual street-solid load on the street surface of about 100 pounds per curb-mile.

Median concentrations of organic carbon and total phosphorus (P) on multifamily streets were about 35 and 29 percent greater, respectively, than those found on commercial streets. The median total mass of organic carbon and total $\mathrm{P}$ in street solids on multifamily streets was 68 and 75 percent greater, respectively, than those found on commercial streets. More than 87 percent of the mass of total $\mathrm{P}$ was determined to be in solids greater than or equal to 0.125 millimeters in diameter for both land-use types. The median total accumulation rate for total $\mathrm{P}$ on multifamily streets was about 5 times greater than on commercial streets. Total $\mathrm{P}$ accumulation in the medium grain-size fraction was nearly the same for streets within both land-use types at 0.004 pounds per curb-mile per day. Accumulation rates within the coarsest and finest grain-size fractions on multifamily streets were about 11 and 82 times greater than those on the commercial streets. Median washoff of total $\mathrm{P}$ was 58 and 48 percent from streets in multifamily and commercial land-use types, respectively, and generally increased with decreasing grain size. Total $\mathrm{P}$ median reductions resulting from a single pass of a regenerative-air street cleaner on streets in multifamily and commercial landuse types were about 82 and 62 percent, respectively, and were similar in terms of grain size between both land-use types. 
A Source Loading and Management Model for Microsoft Windows (WinSLAMM) was applied to a 21.8 acre subcatchment in Cambridge, Mass. The subcatchment area consists of mostly commercial and multifamily land-use types to evaluate the potential reductions of total and particulate solids, and $\mathrm{P}$ attributed to street cleaning. Rainwater runoff from rooftops represented between 20 and 50 percent of the total basin runoff. Street surfaces only accounted for about 20 percent of the total basin runoff.

Monthly applications of mechanical-brush and vacuumassisted street cleaners within the subcatchment as defined by SLAMM for areas with long-term (24-hour) on-street parking and monthly parking controls using five average climatic years resulted in total solid reductions of about 3 and 5 percent, respectively. Simulating the regenerative-air street cleaner tested as part of this study resulted in total solid reductions of about 16 percent. Increasing street cleaning frequency to three times weekly increased total solids removal for mechanicalbrush, vacuum-assisted, and regenerative-air street cleaners to about 6,14, and 19 percent, respectively. Monthly applications of mechanical-brush, vacuum-assisted, and regenerative-air street cleaners within the subcatchment resulted in total $\mathrm{P}$ reductions of about 1,3 , and 8 percent, respectively. A street cleaning frequency of three times each week for each of the three street-cleaner types increased total P removal to about 3, 7 , and 9 percent, respectively.

\section{Introduction}

A TMDL (Total Maximum Daily Load) for total phosphorus (P) has been established for the lower Charles River basin (Massachusetts Department of Environmental Protection and others, 2007). To meet the total P criteria in this TMDL, the city of Cambridge, Massachusetts, is expected to achieve more than a 65-percent reduction in total P loading contributed to the Charles River from all city sources. Part of this reduction is expected from the management of stormwater runoff. Structural stormwater control measures (SCMs) are one type of nonpoint source runoff management, but urban areas are limited by the lack of usable space and high installation costs, thus making nonstructural SCMs, such as street cleaning (or street sweeping) a more practical alternative. Street cleaning may provide some load reduction, but monitoring these reductions in urban runoff as a result of a street cleaning program is difficult. Moreover, in Cambridge, Mass., which receives rain about every 3.5 days (National Oceanic and Atmospheric Administration, 2011), the effectiveness of street cleaning to reduce phosphorus loads to the lower Charles River is further minimized. To better quantify the potential benefits and limitations of street cleaning programs in urban areas at reducing total solids and P loads, a study was initiated in 2009 with the U.S. Geological Survey (USGS), in cooperation with the Massachusetts Department of Environmental Protection (MassDEP), the U.S. Environmental Protection Agency (USEPA), and the city of Cambridge, Mass.

\section{Purpose and Scope}

This report describes the physical characteristics of the solids found on street surfaces in predominantly high-density/ multifamily residential and commercial land-use areas within Cambridge, Mass., during 10 months of sampling between August 2009 and March 2011. Analytical results of organic carbon and 32 elements including total $\mathrm{P}$ for selected samples also are presented. The report contains discussions of the physiochemical characteristics of street-solid samples before and after rain storms and during periods of dry weather to estimate street-solid accumulation and washoff because of precipitation. The development of removal efficiency coefficients based on street solids collected before and after a single pass of a regenerative-air street cleaner as part of a monthly streetcleaning program is presented. The report also documents the construction and evaluation of the model WinSLAMM version 9.4.0 (Pitt and Voorhees, 2002) to provide total and particulate solids and total and particulate P load reduction estimates resulting from three street-cleaning technologies operated at various frequencies within a predominantly commercial landuse subcatchment.

\section{Description of the Study Area}

The city of Cambridge is a 7.1 square mile $\left(\mathrm{mi}^{2}\right)$ urban municipality located in eastern Massachusetts along the northern bank of the Charles River (fig. 1A). The city of Boston borders Cambridge to the south and east. The cities of Watertown, Belmont, Arlington, and Somerville also border Cambridge. Watertown lies to its southwest, Belmont and Arlington border the west, and Somerville borders Cambridge to the north. Topographically, the city generally slopes upward toward the west. Elevation to the northwest at Porter Square and to the southwest at Fresh Pond are about 47 to 40 feet (ft) above sea level, respectively, (Porter Square observation point, Weather Underground, 2011), and USGS Fresh Pond gage (USGS ID: 422302071083801). Fresh Pond, located in southwest Cambridge (fig. 1B) is a kettle pond with a 2,000 to 3,000 foot-wide moraine to its south that trends northwest. The surficial geology of the remainder of the city is characterized as outwash sands and gravels overlying tills associated with drumlins (Skeehan, 2001). Based on Boston climatic data between 1872 and 2002, the average annual temperature range for the area is about -6.1 to 27.2 degrees Celsius $\left({ }^{\circ} \mathrm{C}\right)(21$ to 81 degrees Fahrenheit). Total annual precipitation is about 42 inches (in.), which is evenly distributed throughout the year as rainfall and snow (National Oceanic and Atmospheric Administration, 2011).

The 2000 census determined there were about 15,936 persons per square mile in Cambridge, making it the fifth most densely populated city in the United States at that time (U.S. Census Bureau, 2010, table C-1), and the fifth most populated city in the State. High-density/multifamily residential and commercial land-use areas make up more than 

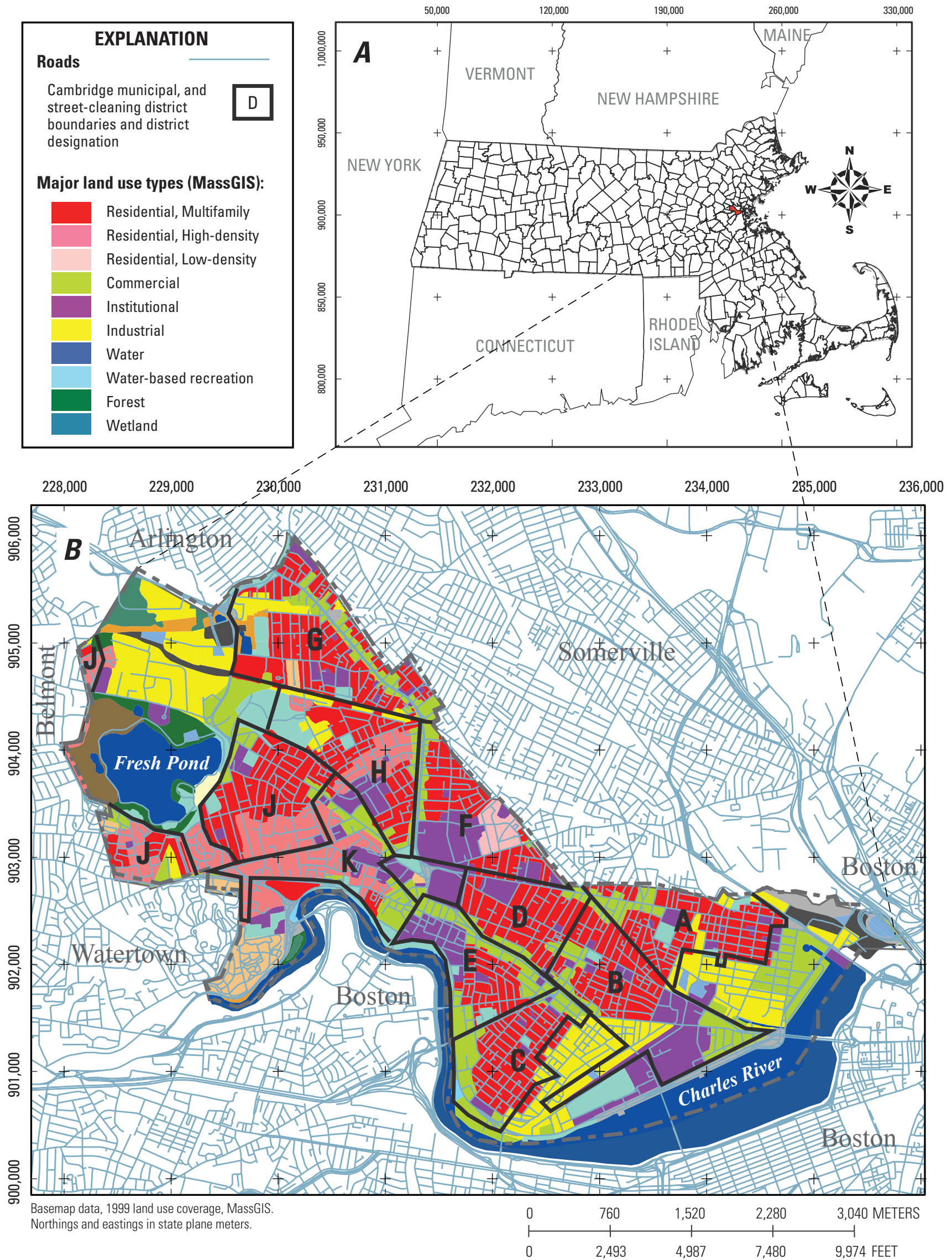

Figure 1. Location map of $A$, the City of Cambridge, Massachusetts, and $B$, land-use distribution, and municipal street-cleaning districts. 
40 percent of the total area of the city of Cambridge (table 1 , fig. 1B). Three streets representing predominantly highdensity/multifamily residential (referred to as multifamily) and three streets representing predominantly commercial land-use types were selected within municipal street-cleaning districts $\mathrm{D}$ and $\mathrm{E}$ based on cleaning frequency, geographic orientation, traffic volume, street-surface condition, proximity to locations with existing stormwater loading data, and overall safety (table 2, fig. 2). Institutional and industrial, and residential and institutional land-use types also were present in the multifamily and commercial study street sections, respectively. Basic characteristics of the three multifamily and three commercial land-use street sections, including pavement condition index and 24-hour daily traffic count data where available (written commun., city of Cambridge), are listed in table 2 . The lengths of the street sections ranged from 750 to $1,304 \mathrm{ft}$. The average street width was between 25 and $43 \mathrm{ft}$. In addition, observations of pavement texture and condition, and measurements of percent canopy closure were made at each of the six asphalt streets.

Table 1. Land-use types and percent of total area for Cambridge, Massachusetts (Based on 1999 land-use coverage).

$[<$, less than]

\begin{tabular}{lrc}
\hline \multicolumn{1}{c}{ Land-use type } & $\begin{array}{c}\text { Area } \\
\text { (acres) }\end{array}$ & $\begin{array}{c}\text { Percent } \\
\text { of total } \\
\text { area }\end{array}$ \\
\hline Cropland & 1.0 & 0.0 \\
Forest & 71.7 & 1.6 \\
Wetland & 42.5 & 0.9 \\
Open land & 33.3 & 0.7 \\
Participation recreation & 245.3 & 5.4 \\
Water-based recreation & 5.9 & 0.1 \\
Residential, multifamily & $1,304.6$ & 28.5 \\
Residential, high density (lots $<0.25$ acre) & 360.2 & 7.9 \\
Residential, median density (lots $0.25-0.5$ acre) & 34.2 & 0.7 \\
Commercial & 590.9 & 12.9 \\
Industrial & 551.5 & 12.0 \\
Urban open & 31.0 & 0.7 \\
Transportation & 105.0 & 2.3 \\
Waste disposal & 10.4 & 0.2 \\
Water & 460.9 & 10.1 \\
Golf & 67.1 & 1.5 \\
Urban public (schools, churches, govt offices) & 505.4 & 11.0 \\
Transportation facilities & 68.3 & 1.5 \\
Cemeteries & 95.0 & 2.1 \\
\hline Total & $4,584.2$ & 100 \\
\hline & & \\
\hline
\end{tabular}

The city uses a monthly street-cleaning program between April and December making use of primarily mechanicalbrush sweepers, but during April and November, a tandem approach using a mechanical-brush followed by a regenerative-air street cleaner as a means to pick up extra street load associated with end-of-winter (EOW) and leaf-fall seasons. Monthly cleaning is scheduled such that even- and oddnumbered sides of the streets in a district are usually cleaned throughout the course of two days. Street cleaning activities are carried out by contractors and the public works department. Although certain squares, commercial streets, and surrounding areas with limited or no on-street parking are swept weekly or more, most city streets are grouped into welldefined monthly street-cleaning districts (fig. 1). In calendar years 2009 and 2010, about 1,605 and 1,042 tons of material were removed from Cambridge streets, respectively (written commun., Cambridge Department of Public Works, 2011).

\section{Previous Studies}

The National Urban Runoff Program (NURP) conducted from the late 1970s and through the early 1980s provided the basis for understanding of street cleaning effects on urban stormwater runoff. Sartor and Boyd (1972) performed the earliest direct experiments to determine street-solid accumulation and washoff. Pitt (1979) developed sampling techniques to better understand the nature of street-surface solids that are essentially still used. As part of the NURP projects, the U.S. Environmental Protection Agency (USEPA; 1983) determined that urban stormwater runoff contains high concentrations of $\mathrm{P}$ that contribute to eutrophication. The USEPA (1983) and Pitt (1987) reported that mechanical-brush sweepers were determined to be only 10 to 30 percent effective at removal of street solids. Since the NURP era, an increasing number of studies have examined the physical and chemical nature of urban runoff and the potential environmental benefits of street cleaning. Pitt and others (2004) provide tables of selected studies and their respective results in terms of material accumulation and washoff from street surfaces. Discussion of several selected studies investigating $\mathrm{P}$ in runoff and water-quality benefits of street cleaning follows below.

Steuer and others (1997) determined that Marquette, Michigan lawns were the dominant source (26 percent) of total $P$ loading in the basin, yet only represented 6 percent of the total runoff. Waschbusch and others (1999) determined lawns and streets in Madison, Wisconsin, were the largest sources of total and dissolved $\mathrm{P}$ and total $\mathrm{P}$ loads from these source areas and were proportional to the percentage of runoff at one site (37 percent) and about one-half the percentage of runoff at the second site (14 percent). They also observed that 75 percent of the street-dirt mass was greater than 250 micrometers $(\mu \mathrm{m})$ in diameter, and less than 5 percent was less than $63 \mu \mathrm{m}$ in diameter. 


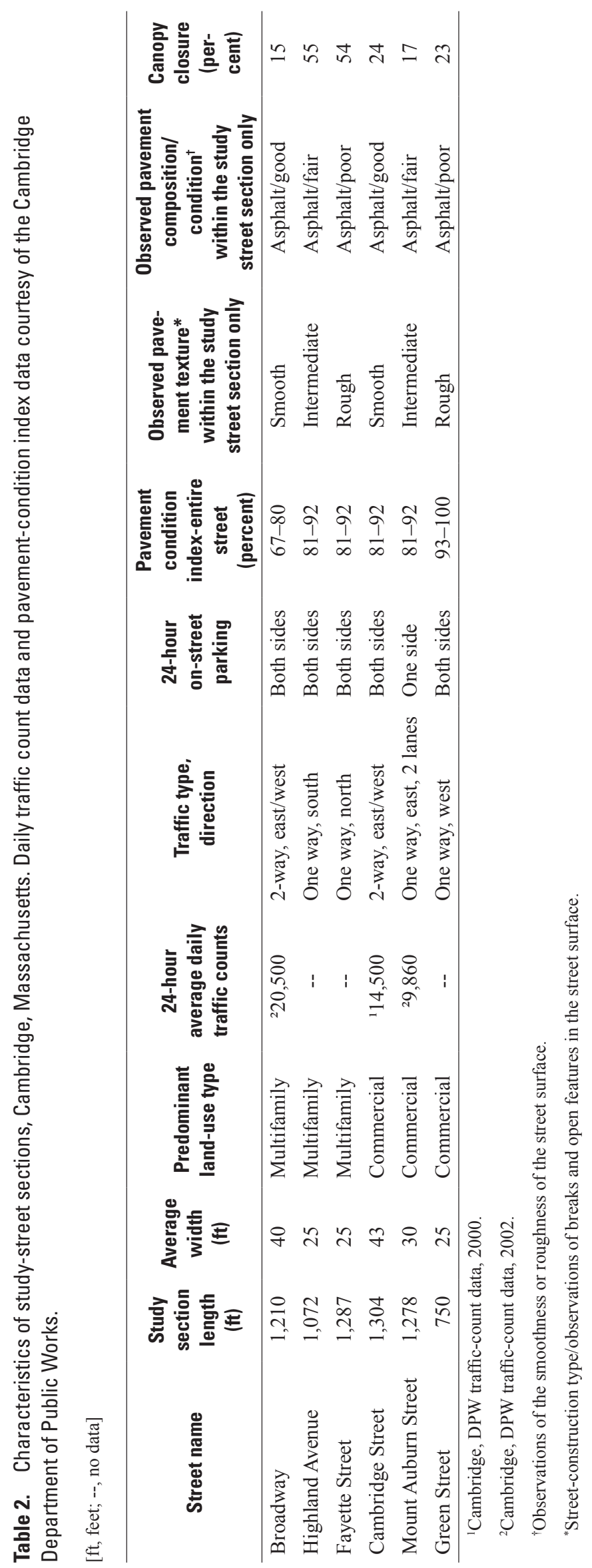




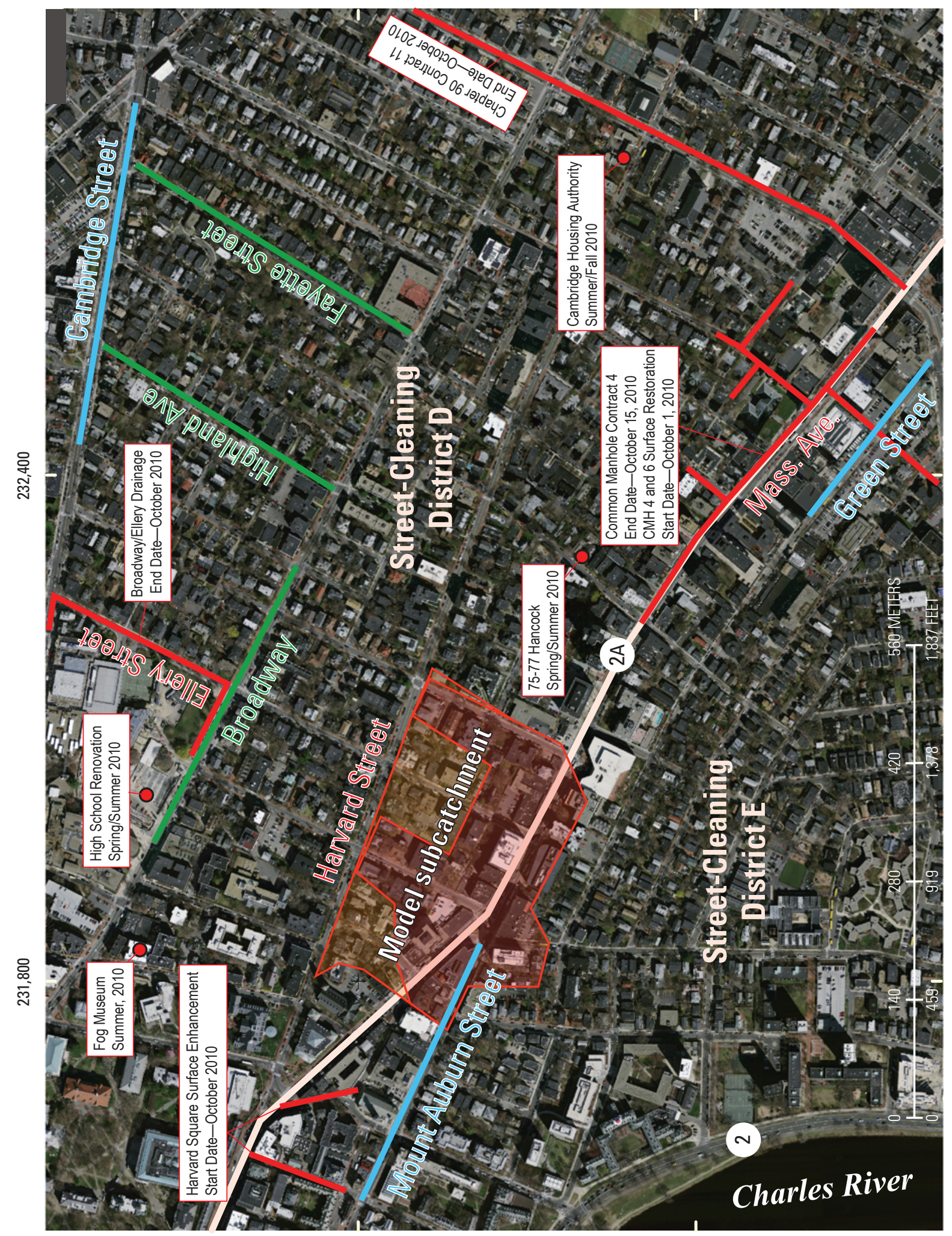


Breault and others (2005) conducted a study examining the organic and inorganic chemistry and accumulation rates of street dirt in residential areas, and evaluated the relative performance of a mechanical-brush and vacuum street cleaners as part of a pilot study in New Bedford, Mass. (not shown). An accumulation rate of about 50 pounds per curbmile per day (lbs/curb-mi/day) was reported, and coarser size fractions between 2.0 and 0.250 millimeter $(\mathrm{mm})$ appeared to accumulate most rapidly. About 93 percent of the material was determined to be greater than very fine sand (greater than $0.125 \mathrm{~mm}$ ). Organic and inorganic constituent concentrations of street solids were similar to those reported in other studies, and total $\mathrm{P}$ was about 3.60 milligrams per kilogram $(\mathrm{mg} / \mathrm{kg})$ with the highest concentrations attributed to size fractions less than $0.125 \mathrm{~mm}$ in diameter. The vacuum street cleaner removal efficiencies were between 62 and 92 percent compared to removal efficiencies between 20 and 31 percent observed for the mechanical-brush street cleaner.

Selbig and Bannerman (2007) used a paired-basin approach (Clausen and Spooner, 1993) in Madison, Wis., to evaluate street-dirt particulate and stormwater loading under control conditions without street cleaning and under streetcleaning conditions using multiple frequencies and three different street-cleaning technologies. Average and median residential street-dirt yields were reported to be about 614 and $569 \mathrm{lbs} /$ curb-mi, respectively, or about 1.6 times the national average reported by Sartor and Boyd (1972). Comparison of paired-basin results indicated that potential load reductions from street cleaning are likely limited by the extreme variability in stormwater runoff loads. The removal efficiency of street cleaners was determined to increase with increasing street-dirt yield. Average street-dirt removal efficiencies of regenerative-air and vacuum-assist cleaners were 25 and 30 percent, respectively. Weekly operation of mechanical-brush sweepers reduced average street-dirt loads by 5 percent. An increase in street-dirt particles less than $0.250 \mathrm{~mm}$ in diameter was reported after street cleaning. The largest and most evenly distributed yield of street dirt was measured during the spring.

Law and others (2008) conducted sampling and chemical analysis of street solids from streets in a control and treatment subcatchment in Baltimore, Md. A conceptual model of pollutant removal rates for weekly and monthly frequencies of mechanical and regenerative/vacuum-assist treatments was developed. A street cleaner removal efficiency of 14 percent was reported, and the lower value was attributed to frequent and intense storms and the twice weekly cleaning frequency during their experimental period. An average street-solid load of $645 \mathrm{lbs} /$ curb-mi for their treatment area and an average street-solid load of 1,100 lbs/curb-mi was estimated from the control area, which was not swept. Law and others (2008) determined that particle-size distribution was similar for before- and after-cleaning street-solid load samples. They reported about 40 percent of sampled street-solid load particles were between 0.250 to $1.0 \mathrm{~mm}$ in diameter, and 70 percent of the total street-solid load consisted of particles larger than $0.250 \mathrm{~mm}$ in diameter. Lead $(\mathrm{Pb})$ and total $\mathrm{P}$ concentrations were determined to be significantly higher in their unswept control basin. The concentration of total P and total Kjeldahl nitrogen (TKN) was greater for solids larger than $0.250 \mathrm{~mm}$ in diameter. This tendency was attributed to organic matter, such as leaf litter that often contains substantial amounts of these constituents, in their samples. The resulting estimated range of reductions for total solids, total nitrogen, and total $\mathrm{P}$ as a result of street cleaning were 9 to 31,3 to 8 , and 3 to 7 percent, respectively.

Seattle Public Utilities and Department of Transportation (2009) sponsored a 1-year paired-basin study in 2006 to determine the effectiveness of street cleaning to reduce the mass of organic and inorganic constituents to urban waterways and the effectiveness of reducing the frequency of catch-basin cleaning. Median yields of street solids that included organic matter ranged from 69 to 2,200 lbs/curb-mi on streets that were swept twice per month. Analysis of grain-size fractions of street solids showed between 43 and 95 percent of the total mass was greater than $0.250 \mathrm{~mm}$ in diameter. Monthly samples of solids from streets in residential land-use areas had organic carbon concentrations between 6 and 38 percent. TKN and total P dry-weight concentrations in street-solid samples ranged from 49 to 36,600 , and 191 to $1,610 \mathrm{mg} / \mathrm{kg}$, respectively. Although reductions in street-solid yields resulting from bi-monthly street cleaning ranged from 48 to 90 percent in Seattle, no significant reductions in constituent concentrations or reductions in catch-basin cleaning were reported.

\section{Street-Solid Collection, Processing, and Chemical Analysis}

Street-solid samples were collected from the surfaces of six street sections (table 2 and fig. 2). Three streets were selected in predominantly high-density/multifamily residential land-use areas (referred to as multifamily) and three streets were selected in predominantly commercial land-use areas. Study street sections were selected based on land-use designation, safety considerations, and street-cleaning frequency. Samples were collected to characterize the accumulation of street solids, the washoff of street solids because of rainfall runoff, the removal efficiency of street solids by a regenerative-air street cleaner, and the concentrations of organic carbon and 32 elements including $\mathrm{P}$ in street solids.

\section{Street-Solid Sample Collection}

Samples were collected to represent average street-solid characteristics found in the two land-use types. Sampling methods were the similar to those used by Pitt (1979) and Burton and Pitt, (2002), and the same equipment used in this study was used by Selbig and others (2007). Four 9-gallon, stainless steel wet/dry vacuums with a maximum air flow of 92 cubic feet per minute were used to collect the samples. 
Potential Reductions of Street Solids and Phosphorus from Street Cleaning, Cambridge, Massachusetts, 2009-11

Each street had a dedicated intake-hose setup that included a 6-inch wide aluminum intake nozzle attached to a 6-foot long stainless steel wand connected to the vacuum by a 2 -in. diameter reinforced black neoprene hose between 15 and $35 \mathrm{ft}$ long (fig. 3). All equipment was kept in the bed of a pickup truck and covered with a hard cap. Aluminum nozzles wore down and their intake width narrowed with use over the rough street surfaces. Nozzle widths were measured before each sampling event and recorded on field sheets. When nozzle widths were less than 5 inches, they were replaced.

Ten subsamples also were collected from each street and weighed individually to determine the variability in street-solid yields (Selbig and others, 2007), and were used to calculate the number of subsamples needed in a composite sample to accurately represent street-solid yields as described by Hansen and others (1984). Using an allowable error of 0.50 (or plus or minus $( \pm) 50$ percent), the calculated number of samples needed was less than 7; however, if the allowable error was reduced to 0.25 , the number of subsamples increased to 49 . For this study 10 subsamples were collected for all composites on all streets. Unusual loading conditions such as piles of debris, potholes or areas near construction track out were avoided during sampling to maintain the representativeness of the composite sample. Although 10 markers were painted on the vertical side of the curb on each street section, the sampling locations varied for each sampling event because of the heavy on-street parking, which often limited where sampling crews could collect subsamples. The reproducibility of the street-solid sample collection procedures was evaluated using a Mann-Whitney/rank-sum test. Twelve street-solid composite sample pairs were used and results indicated no significant difference between the pairs of samples $(p=0.68)$. The good precision between sample pairs indicates that sources of variability in street-solid yields were not introduced by samplecollection techniques.

A single subsample involved vacuuming from curb to curb across the street moving at about 1 foot per second or less with increasing street surface roughness. It was common to see a cleaned path where material was removed following a vacuumed pass (fig. 4A). Autumn brought a large amount of leaf material to street surfaces that would often clog the intake nozzle. Under these conditions, leaves along the sample path were manually sampled and placed into pre-weighed and labeled plastic bags. Eleven composite samples were collected during the summer of 2009, and were collected in a manner similar to the procedure described by Selbig and others (2007) where street-dirt material was collected directly into the vacuum stainless steel canisters, its cloth filter was brushed off, shaken into the canister, then all material was brushed out into preweighed clear plastic bags. Sample collection was modified for all 2010-2011 vacuumed composite samples, which were collected in pre-weighed $0.1 \mu \mathrm{m}$ paper filter bags. Paper filter bags were chosen to limit field crew exposure to particulate matter, minimize loss of finer fraction to the air, and reduce overall time spent in the field. Composite samples contained in the $0.1 \mu \mathrm{m}$ paper filter bags were removed from the vacuum canisters, the intake port closed, and material within the bag was allowed to settle to the bottom before it was folded and sealed inside a labeled clear plastic ziplock bag (fig. 5A).

\section{Street-Solid Sample Processing and Chemical Analysis}

Street-solid samples were processed and prepared for shipment to SGS Environmental Services Laboratory in Ontario, Canada for analysis of 32 elements and organic carbon. Performance evaluation samples (PESs), equipment blank samples, and replicate samples also were prepared and submitted for analysis. Street solids in this study are defined as all material collected on street surfaces including all gravel and asphalt and all organic material to as much as about $50 \mathrm{~mm}$ in diameter. All visible anthropogenic material such as plastic, metal, and cigarette butts was not included.

\section{Street-Solid Sample Processing}

Samples were taken to the USGS Northborough, Massachusetts laboratory, where they were weighed and dried within the paper filter bags for 14 hours at $105^{\circ} \mathrm{C}$. Dried samples were weighed again and separated into three grainsize fractions herein designated as: "coarse," or material greater than or equal to $2 \mathrm{~mm}$, "medium," or material less than $2 \mathrm{~mm}$ to greater than or equal to $0.125 \mathrm{~mm}$, and "fine," or material less than $0.125 \mathrm{~mm}$ in diameter using stainless steel sieves. A 4-mm stainless-steel sieve was used to screen out larger material before sieving; when the sample material was too great for a single set of sieves, multiple sets were used. Sieves were washed using phosphate-free detergent and rinsed with tap water, followed by three rinses with deionized water, then dried before each use. Emptied paper filter bags were weighed again and the difference between its tare weight and the weight of the emptied bag was added to the less than $0.125-\mathrm{mm}$ size fraction (defined as very fine sand). The sample mass results for each street are listed in appendix tables 1-15 and 1-16 (on CD-ROM at back of report). Data were omitted if the relative percent difference between the sum of the three grain-size fraction masses and the initial total dry mass was more than 15 percent.

About 10 to 20 grams (g) of representative street-solids material was subsampled from each of the three separated grain-size fractions, placed into labeled Whirl-pak bags and shipped to SGS laboratories for analysis of organic carbon, total P, and 31 other elements (table 3 ). In cases where there were large amounts of material or the material was too heterogeneous to be subsampled representatively, a riffle splitter (fig. 5B) was used to yield representative subsamples for analysis. Although leaves and organic debris were not removed from street-solid subsamples, all visible anthropogenic debris and litter was removed before submission for chemical analysis. Resulting total-recoverable concentrations of all curbto-curb (CTC; composite samples collected by vacuuming 


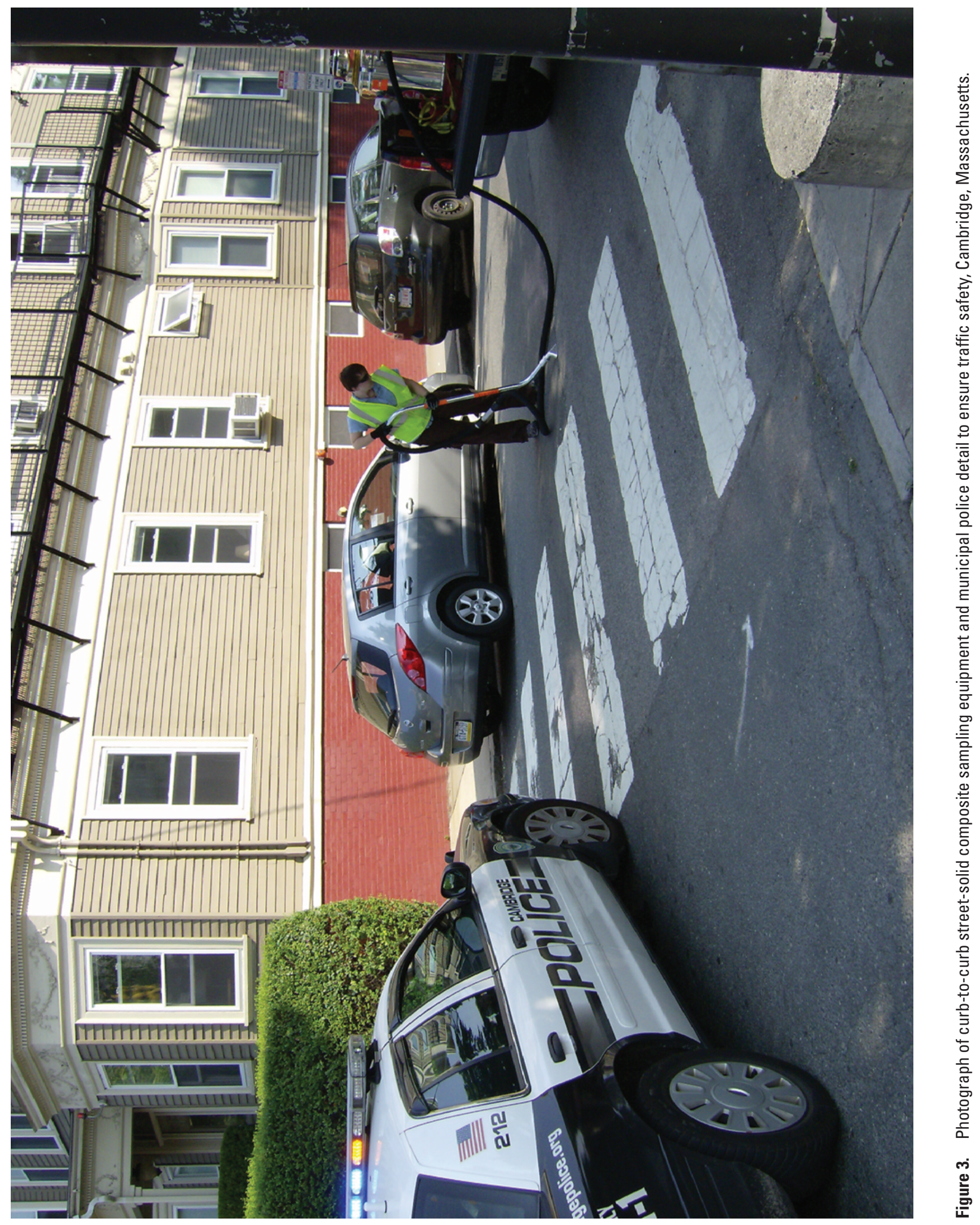



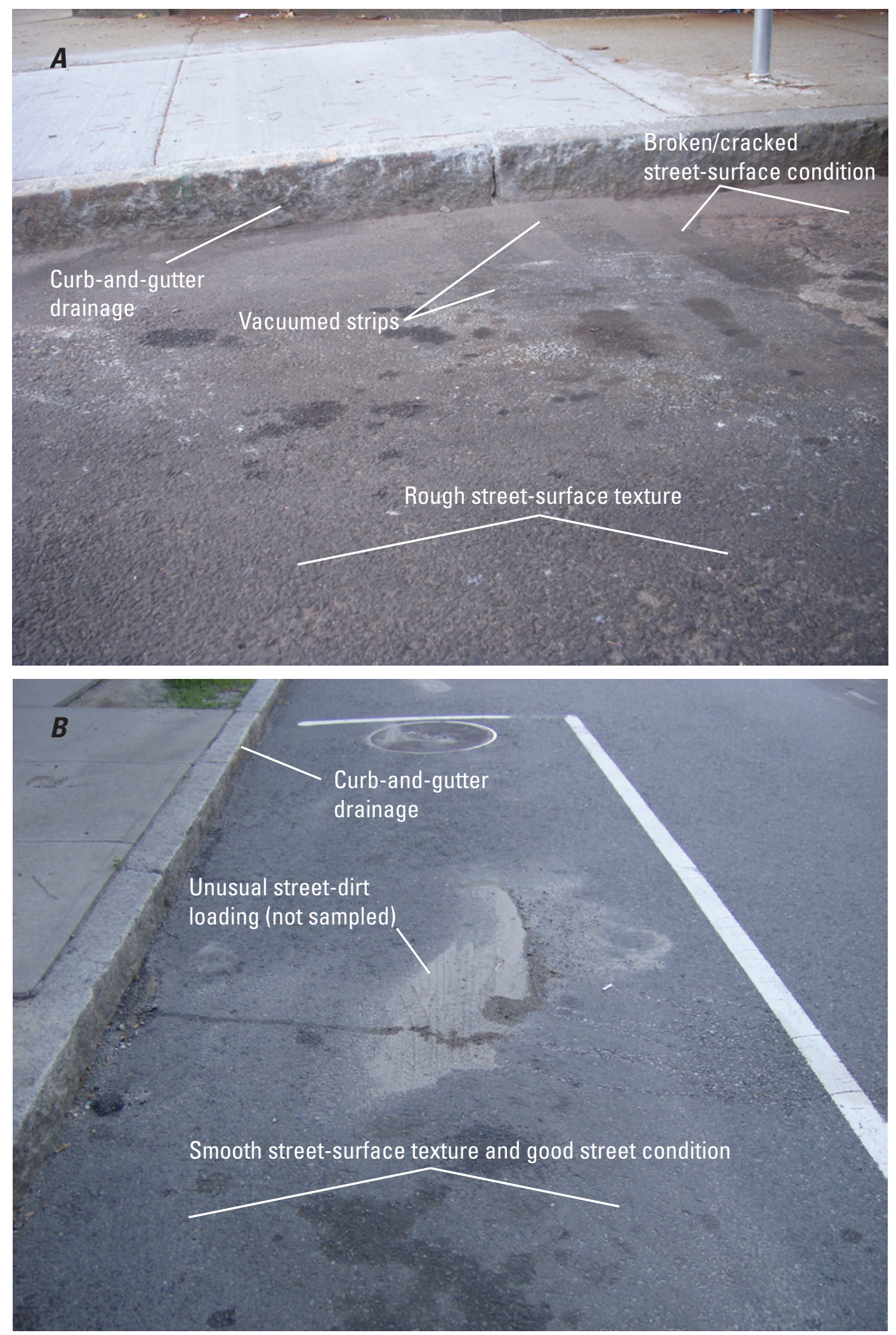

Figure 4. Photograph of $A$, two cleaned vacuumed paths typical of street-solid composite sampling, and examples of a rough street-surface and a poor street-surface condition (photo courtesy of Tom Maguire, MassDEP), and $B$, a smooth street surface with good street-surface condition, curb-and-gutter drainage system, and an example of unusual loading avoided during sampling, Cambridge, Massachusetts. 

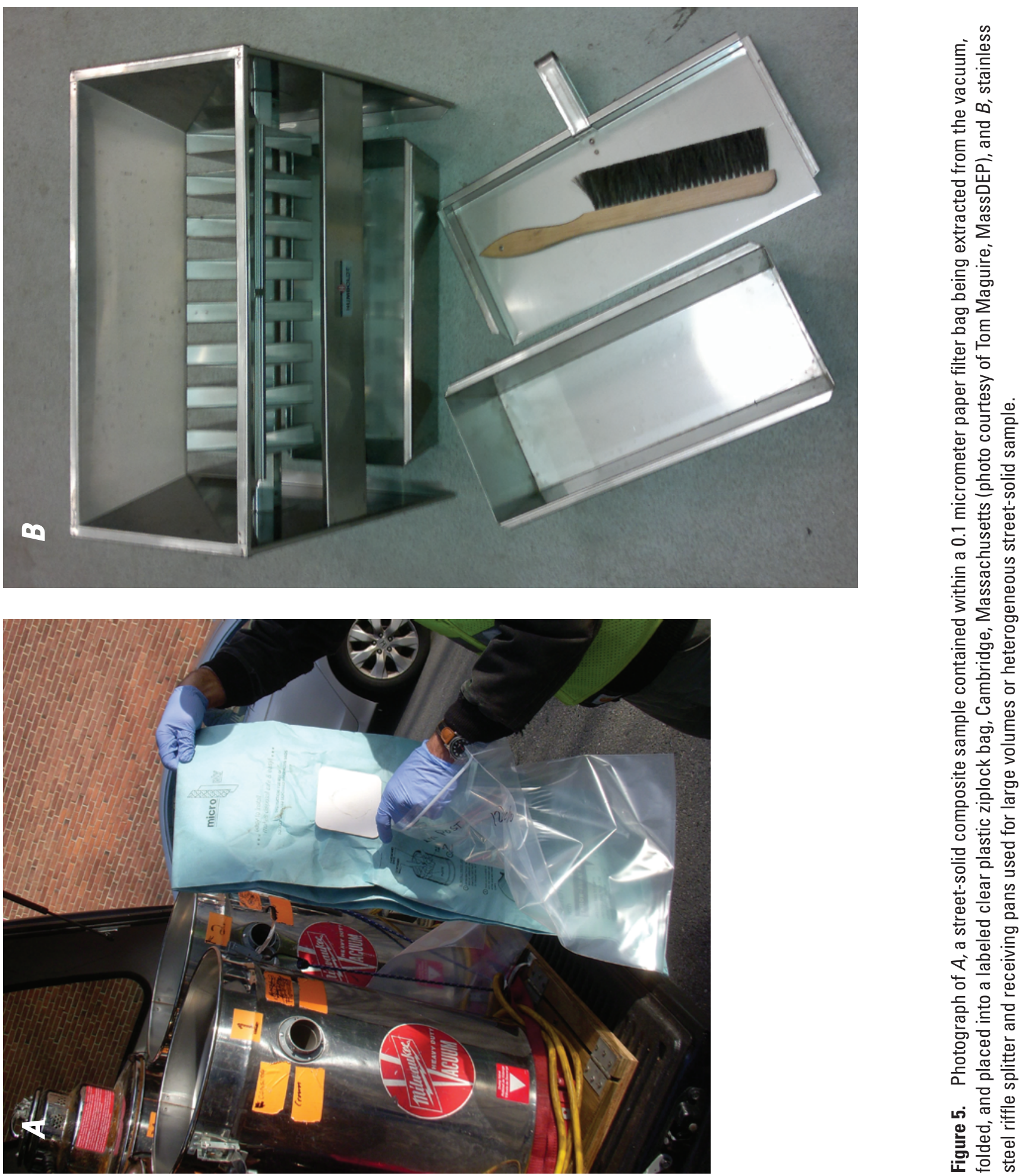


\section{Potential Reductions of Street Solids and Phosphorus from Street Cleaning, Cambridge, Massachusetts, 2009-11}

Table 3. Target analytes and analytical techniques for samples submitted to SGS Laboratories, Toronto, Ontario, Canada.

[MDL, method detection limit; USEPA, U.S. Environmental Protection Agency; ICP-MS, Inductively Coupled Plasma-Mass Spectrometry; ppm, parts per million]

\begin{tabular}{|c|c|c|c|c|}
\hline Analyte & Units & $\begin{array}{l}\text { Analytical } \\
\text { techniques }\end{array}$ & MDL & USEPA method \\
\hline Aluminum, recoverable & ppm & ICP-MS & 100 & EPA IC3050B/ICP40 \\
\hline Antimony, recoverable & percent & ICP-MS & 5 & EPA IC3050B/ICP40 \\
\hline Arsenic, recoverable & ppm & ICP-MS & 3 & EPA IC3050B/ICP40 \\
\hline Barium, recoverable & ppm & ICP-MS & 1 & EPA IC3050B/ICP40 \\
\hline Beryllium, recoverable & ppm & ICP-MS & 0.5 & EPA IC3050B/ICP40 \\
\hline Bismuth, recoverable & ppm & ICP-MS & 5 & EPA IC3050B/ICP40 \\
\hline Cadmium, recoverable & percent & ICP-MS & 1 & EPA IC3050B/ICP40 \\
\hline Calcium, recoverable & ppm & ICP-MS & 100 & EPA IC3050B/ICP40 \\
\hline Chromium, recoverable & ppm & ICP-MS & 1 & EPA IC3050B/ICP40 \\
\hline Cobalt, recoverable & ppm & ICP-MS & 1 & EPA IC3050B/ICP40 \\
\hline Copper, recoverable & ppm & ICP-MS & 0.5 & EPA IC3050B/ICP40 \\
\hline Iron, recoverable & percent & ICP-MS & 100 & EPA IC3050B/ICP40 \\
\hline Lanthanum, recoverable & percent & ICP-MS & 0.5 & EPA IC3050B/ICP40 \\
\hline Lead, recoverable & ppm & ICP-MS & 2 & EPA IC3050B/ICP40 \\
\hline Lithium, recoverable & ppm & ICP-MS & 1 & EPA IC3050B/ICP40 \\
\hline Magnesium, recoverable & percent & ICP-MS & 0.01 & EPA IC3050B/ICP40 \\
\hline Manganese, recoverable & ppm & ICP-MS & 2 & EPA IC3050B/ICP40 \\
\hline Molybdenum, recoverable & ppm & ICP-MS & 1 & EPA IC3050B/ICP40 \\
\hline Nickel, recoverable & percent & ICP-MS & 1 & EPA IC3050B/ICP40 \\
\hline Phosphorus, recoverable & ppm & ICP-MS & 100 & EPA IC3050B/ICP40 \\
\hline Potassium, recoverable & percent & ICP-MS & 100 & EPA IC3050B/ICP40 \\
\hline Scandium, recoverable & ppm & ICP-MS & 0.5 & EPA IC3050B/ICP40 \\
\hline Silver, recoverable & ppm & ICP-MS & 0.2 & EPA IC3050B/ICP40 \\
\hline Sodium, recoverable & ppm & ICP-MS & 100 & EPA IC3050B/ICP40 \\
\hline Strontium, recoverable & ppm & ICP-MS & 0.5 & EPA IC3050B/ICP40 \\
\hline Tin, recoverable & ppm & ICP-MS & 10 & EPA IC3050B/ICP40 \\
\hline Titanium, recoverable & percent & ICP-MS & 100 & EPA IC3050B/ICP40 \\
\hline Tungsten, recoverable & ppm & ICP-MS & 10 & EPA IC3050B/ICP40 \\
\hline Vanadium, recoverable & ppm & ICP-MS & 2 & EPA IC3050B/ICP40 \\
\hline Yttrium, recoverable & ppm & ICP-MS & 0.5 & EPA IC3050B/ICP40 \\
\hline Zinc, recoverable & ppm & ICP-MS & 0.5 & EPA IC3050B/ICP40 \\
\hline Zirconium, recoverable & ppm & ICP-MS & 0.5 & EPA IC3050B/ICP40 \\
\hline Total organic carbon & percent & Coulometric titration & 0.01 & EPA 9060 \\
\hline
\end{tabular}


across the street from one curb to the opposite curb) and single sided (SS; composite samples collected by vacuuming $9 \mathrm{ft}$ out from the curb) street-solid composite samples can be seen in appendix tables 1-17, 1-18, 1-19, and 1-20 (on CD-ROM at back of report).

\section{Performance Evaluation Sample Analysis}

Six National Institute of Standards and Technology (NIST) standard reference soil 2710 samples and five NIST standard reference soil 2781 samples served as PESs, and were submitted to SGS laboratories with street-solid samples to determine potential contamination bias and overall method performance. The median analytical results and relative standard deviations shown in table 4 are of selected constituents for two types of analyses performed on standard reference soil samples consist of the following: total concentrations, measured in samples fully digested by hydrofluoric acid, and totalrecoverable concentrations, measured in samples digested by less aggressive acid mixtures. The USEPA has determined that the total-recoverable concentration represents the bioavailability of elements in the environment (U.S. Environmental Protection Agency, 1986). Most analytical results included in this report were obtained using the total-recoverable digestion.

Concentrations certified by the NIST are based on several measurements using two or more techniques from multiple laboratories using hydrofluoric acid to achieve a complete digestion. About 26 percent of the median total concentrations of elements associated with the NIST reference soil 2710 certified values, and about 12 percent of the median total concentrations of elements associated with NIST reference soil 2781 certified values that were measured were within their respective certified concentration ranges (table 4). The elements with median concentrations outside the certified concentration ranges were within 16 percent or less of the lower range of certified values of NIST reference soil 2710 , and within 15 percent or less of the lower range of certified values of NIST reference soil 2781 (table 4). The relative standard deviations for blind sample concentrations of total $\mathrm{P}$ and six other elements of concern (shaded values seen in table 4) were between 4 and 16 percent for the NIST 2710 results and between 2 and 20 percent for the NIST 2781 results.

Total-recoverable element concentrations obtained using the milder digestion described above resulted in concentrations that were generally lower than the totalrecoverable concentrations for both NIST standard soils 2710 and 2781 (table 4). However, median total-recoverable concentrations of all constituents in NIST standard 2710 were within about 30 percent or less of the lower range of certified values except for aluminum $(\mathrm{Al})$, barium $(\mathrm{Ba})$, calcium $(\mathrm{Ca})$, potassium $(\mathrm{K})$, sodium $(\mathrm{Na})$, antimony $(\mathrm{Sb})$ and titanium (Ti), which were between 45 and 94 percent less than the lower range of certified values. All median total-recoverable concentrations of constituents in NIST standard 2710 were within the recovery range except for $\mathrm{K}, \mathrm{P}, \mathrm{Ti}$, and vanadium (V). Concentrations of Ti, K, and V were 18, 14, and 4 percent greater than the upper limit of the recovery range, respectively. The median concentration of $\mathrm{P}$ was about 18 percent less than the lower limit of the recovery range for analyses of NIST standard 2710, indicating a potential negative bias in the totalrecoverable concentrations for P. Median total-recoverable concentrations of all constituents in NIST standard 2781 were within about 9 percent or less than the upper limit of the recovery range except for $\mathrm{Al}$, cadmium $(\mathrm{Cd})$, chromium $(\mathrm{Cr})$, iron $(\mathrm{Fe})$, magnesium $(\mathrm{Mg})$, and manganese $(\mathrm{Mn})$, which were 1 to 28 percent greater than the upper limit of the recovery range. Total $\mathrm{P}$ was about 7 percent less than the noncertified value of NIST standard 2781, supporting the potential negative bias in the total-recoverable concentrations for total $\mathrm{P}$ indicated by the results for NIST standard 2710 .

\section{Blank Sample Analysis}

Analyses of organic carbon, total P, and 31 other elements also were done on samples of graded unground silica sand. Median results of selected elements were at or below the method detection limit, indicating the silica sand was an appropriate blank material (table 5). The silica sand was then exposed to a precleaned aluminum intake nozzle, neoprene hose, and a preweighed $0.1-\mu \mathrm{m}$ paper filter bag weighed and dried and then stored for more than 48 hours in a similar manner as street-solid samples collected in the field. The samples were then emptied into stainless steel sieves and shaken for 30 minutes. Analytical results of total P and other selected elements in the equipment blank silica sand were also at or below the method detection limit and demonstrate the sampling equipment, filter bags, and processing equipment were not a source of sample contamination.

\section{Replicate Sample Analysis}

Mean and median RPDs between the sum of the sieved fractions and the total dried mass were 5.6 and 0.87 percent, and ranged between 0.02 and 70 percent. However, there were only five instances where the RPD was greater than 25 percent.

Replicate samples of the PESs (NIST 2710 and 2781 described above) were analyzed using the total and totalrecoverable digestions. Median relative percent differences (RPDs) between certified values and resulting total concentrations were about 8 percent using NIST standard reference soil 2710 and about 15 percent using NIST standard reference soils 2781. Total P median concentration RPDs using NIST 2710 and 2781 were about 6 and 3.4 percent, respectively. These results are within the 25-percent limit established by the quality assurance project plan (Sorenson, Quality Assurance Project Plan, written commun., accepted May 2010)

Thirty replicate splits of street-solid samples were submitted for analysis and the median RPD of resulting total concentrations for all elements was about 2 percent and about 10 percent for total-recoverable concentrations of all 


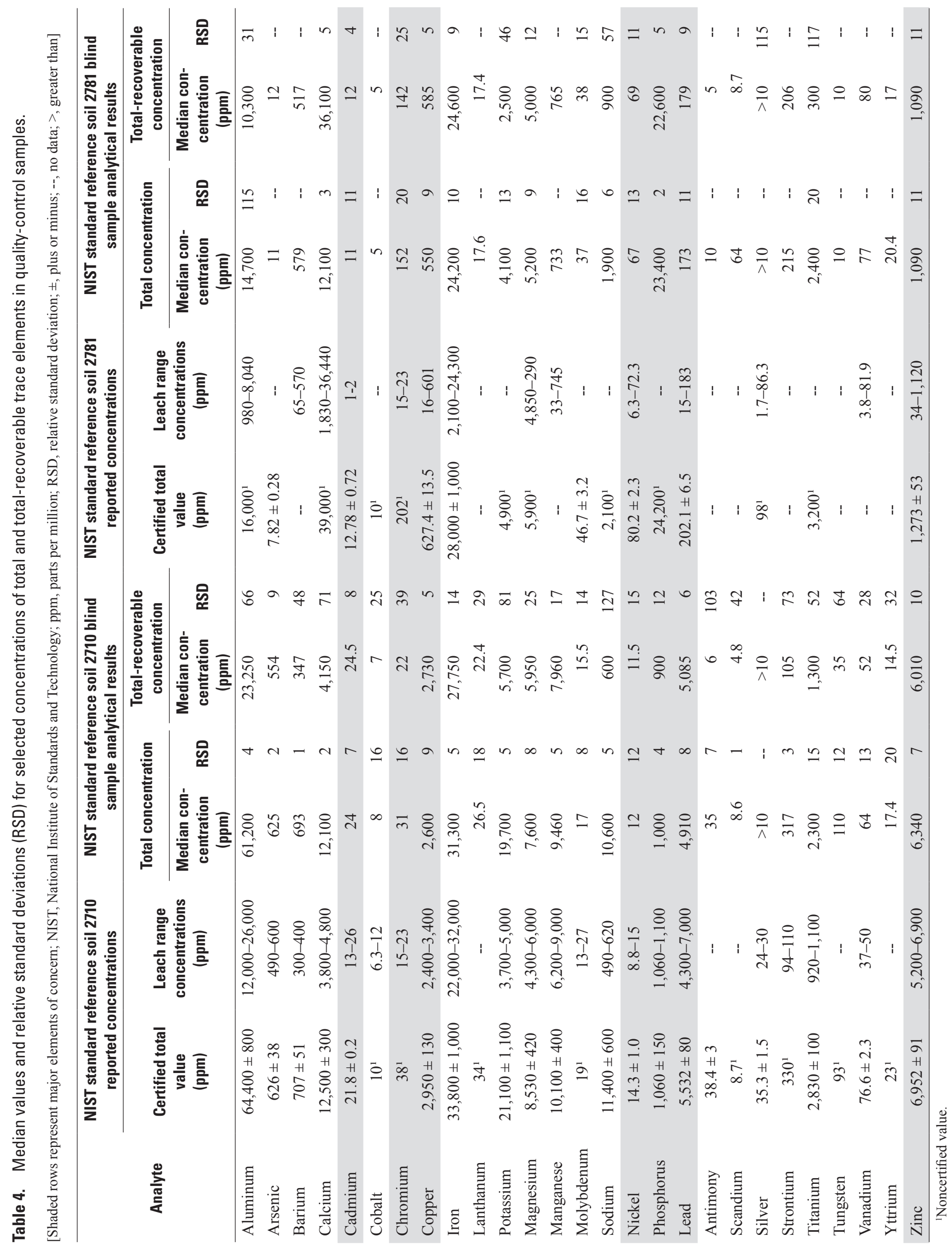


Table 5. Selected analytical results of graded unground silica sand used as blank material (determined using one-half the detection limit for "Iess than" values) sourced from Ottawa, Illinois (U.S. Silica Company).

[ppm, parts per million; n, number of samples; E, estimated]

\begin{tabular}{lrrrrrrrr}
\hline $\begin{array}{c}\text { Constituent in ppm } \\
\mathbf{n = 1 5}\end{array}$ & $\begin{array}{c}\text { Organic } \\
\text { carbon }\end{array}$ & Cadmium & Chromium & Copper & Nickel & Phosphorus & Lead & Zinc \\
\hline Detection level & 500 & 1.00 & 1.00 & 0.50 & 1.00 & 100 & 2.00 & 1.00 \\
Maximum & E250 & E0.05 & 3.00 & 0.90 & 1.00 & E50 & 2.00 & 4.70 \\
Median & E250 & E0.05 & 4.00 & 0.25 & 1.00 & E50 & 1.00 & 1.80 \\
Average & E250 & E0.05 & 2.78 & 0.40 & 0.94 & E50 & 1.22 & 1.94 \\
Minimum & E250 & E0.05 & 1.00 & E0.25 & E0.50 & E50 & 1.00 & E0.25 \\
\hline
\end{tabular}

32 elements. The median RPD for organic carbon analyses was about 8 percent. Evaluation of replicate sample RPDs by grain-size fraction indicate median RPDs of the greater than or equal to $2 \mathrm{~mm}$ (coarse), less than $2 \mathrm{~mm}$ to greater than or equal to $0.125 \mathrm{~mm}$ (medium), and less than $0.125 \mathrm{~mm}$ (fine) size fractions of about 23,15 , and 5 percent, respectively. Smaller RPDs are likely due to the more homogeneous material of the smaller grain-size fractions. Gravel and organic debris such as leaves or sticks were common in the larger grain-size fraction material. Median RPDs of total P for all samples were near zero, but ranged from zero to about 111 percent. The larger RPD was associated with the coarse size fraction. The median RPDs for total $\mathrm{P}$ by grain size from coarse to fine were about 26,11 , and 7 percent, respectively.

\section{Street-Cleaner Efficiency Sample Collection and Processing}

Both sides of Mount Auburn Street (fig. 2) were swept in a single day each month after the city adjusted the cleaning schedule of the southern side of the street from weekly to monthly cleaning for consistency. However, street sweepers were seen operating on Mount Auburn Street by field crews at a frequency greater than the established monthly schedule on two occasions, which may have affected street-solid accumulation observations. Washoff sampling was done within 24 hours or less and removal-efficiency sampling was typically done within 4 hours or less, minimizing the effect of unscheduled street cleaning operations.

On days scheduled for cleaning, the sampling crew would collect single-sided subsamples from 10 locations along each street before the street cleaner made a single pass. Each vacuumed strip was 108 in (9 ft) from the curb, which represents the width of the street affected by the street cleaner in a single pass. Following the collection of the "pre-treatment" samples, a regenerative-air street cleaner was operated over the street at 5 miles per hour (mph) or less using a single gutter broom (fig. 6). Although waterless operation would have provided the most effective removal of all particles, water was applied to the gutter broom, not to the street surface, to minimize pedestrian dust exposure. Immediately following the single street cleaner pass (within about 30 minutes), a second composite sample was collected and labeled as a "post-treatment" sample. The difference between the pre- and post-sample masses allowed the determination of the street cleaner removal efficiency. All samples were collected after the street cleaner made a single pass except for samples collected on November 9 and 12, 2010, when the leaf load on the streets required two passes by the regenerative-air street cleaner. On the same dates on non-study streets, mechanical-brush sweepers made two to four passes before a smaller vacuum-assist machine, operating in tandem with the brush sweeper, made its single pass. No samples were collected on November 10, 2010, because of rain.

Post-treatment samples contained about $48 \mathrm{~g}$ of material and when separated into three grain-size fractions, did not yield sufficient material to subsample for submission to the laboratory for analysis. Seasonal composite samples were created to provide sufficient material by combining and thoroughly mixing pre- and post-treatment street-cleaner efficiency samples within the following spring, summer and fall periods: May to June, July to September, and October to December. Samples were combined into large labeled clear plastic ziplock bags and sealed. The seasonal composite sample was then shaken and rotated until a homogeneous color and texture was achieved. Representative subsamples of these seasonal composites were obtained using the riffle splitter (fig. 5B) and were submitted for chemical analysis as described above. 


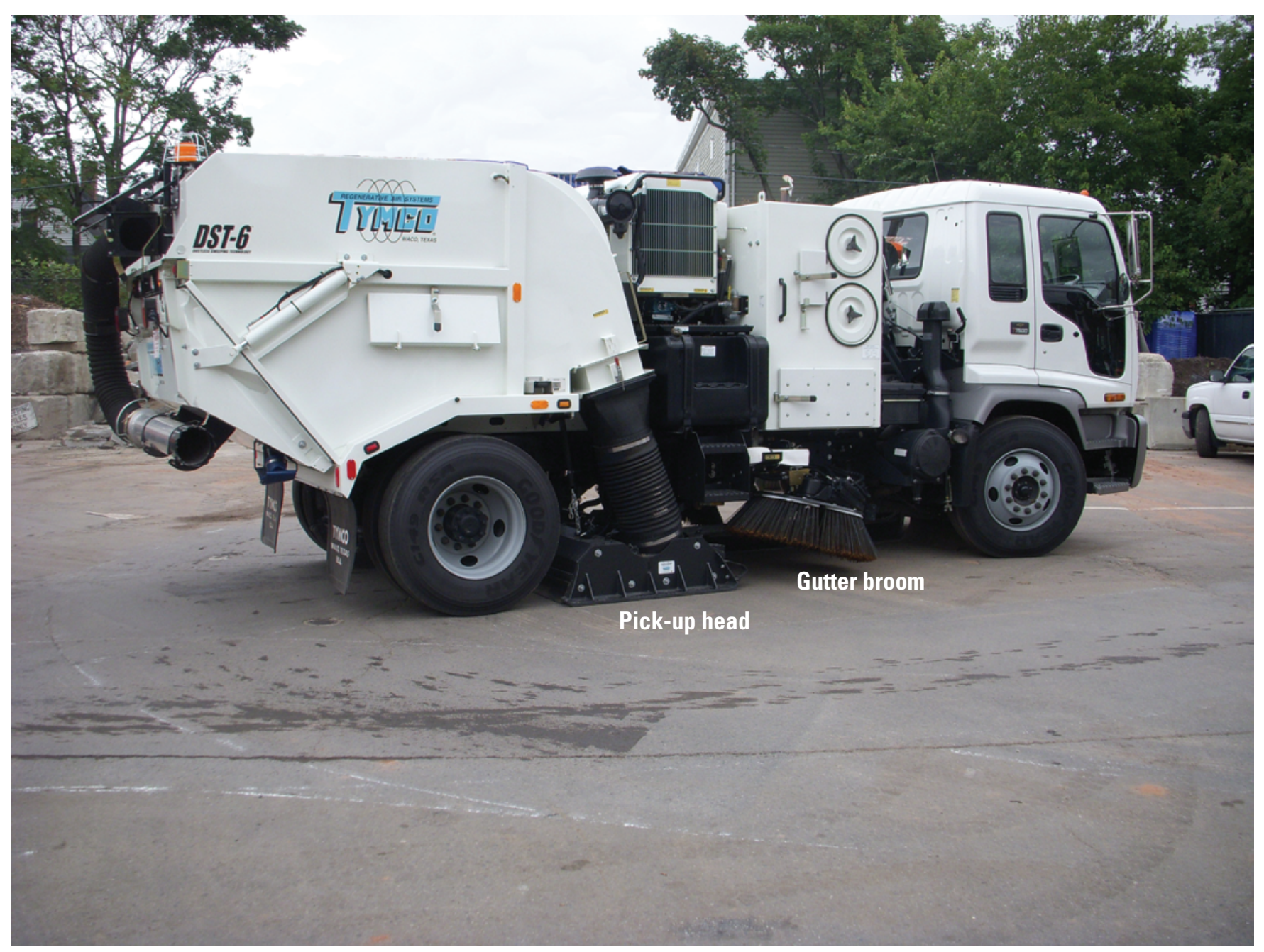

Figure 6. Photograph of a TYMCO Dustless Sweeping Technology-6 (DST-6) regenerative-air street cleaner in Cambridge, Massachusetts (photo courtesy of Tom Maguire, MassDEP).

\section{Characterization of Street Solids}

Street-solid loadings are the result of deposition and removal rates plus "permanent storage" and seasonal components such as leaf-fall and accumulation of material including winter deicing and maintenance materials (Pitt and others, 2004). Thirty-five CTC street-solid sampling events yielded 195 total mass composite samples collected in July and August 2009, between May and December 2010, and March 2011. Another 98 single sided (SS) street-solid sampling events yielded 194 total mass composite samples collected between May and December 2010. Estimates of accumulation and washoff of street solids were determined using the CTC street-solid sample composites, and removal efficiency estimates were calculated using street-solid sample composites collected from one side of the street (SS) before and after a single pass of a regenerative-air street cleaner.
Although some samples were collected from late July to early September 2009, most samples were collected between May and December 2010. The two additional sampling events in early March 2011 represent an end-of-winter (EOW) load. SS street-solid composite samples representing pre- and post-street cleaning street-solid yields were used to develop a productivity function, or removal efficiency equation for the regenerative-air street cleaner.

\section{Street-Solid Mass}

The average mass of CTC street-solids composite samples for 132 selected composite samples from multifamily and commercial streets between May and December 2010 was $612 \pm 8$ and $427 \pm 3$ g, respectively. With the inclusion of the large amounts of street solids collected in March 2011, the average mass of street solids for the two land-use 
types increased to $742 \pm 10$ and $720 \pm 13 \mathrm{~g}$, respectively. Comparison of initial sample mass and the mass following 14 hours at $105^{\circ} \mathrm{C}$ in samples from multifamily and commercial streets indicate the street solids had an average moisture content of about 21 and 14 percent, respectively. Although sampling protocols required street surfaces to be dry for the collection of composite samples, and areas where water ponded were avoided, substantial water content was observed within organic debris along curb areas and during several cold-weather sampling events, water was frozen to the streetsolid material itself.

Pitt (1979) reported that street-dirt yield was a better unit of measure for street cleaner performance as it represents the actual mass removed from the street surface. In keeping with this convention, all collected street-solid mass composites were converted to a composite street-solid yield lbs/curb-mi using the following expression:

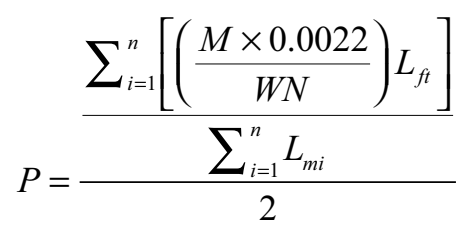

where

\begin{tabular}{|c|c|}
\hline$P$ & $\begin{array}{l}\text { is the mass of the dirt on a street, in pounds } \\
\text { per curb-mile; }\end{array}$ \\
\hline$n$ & is the total number of streets in each basin; \\
\hline$i$ & $\begin{array}{l}\text { is an index to each street sampled in the study } \\
\text { area; }\end{array}$ \\
\hline$M$ & $\begin{array}{l}\text { is the total mass of sampled street-dirt, in } \\
\text { grams; }\end{array}$ \\
\hline$W$ & is the width of the vacuum nozzle, in feet; \\
\hline$N$ & $\begin{array}{l}\text { is the number of individual strips vacuumed } \\
\text { per street; }\end{array}$ \\
\hline$L_{f t}$ & is the length of each street, in feet; and \\
\hline & the length of eac \\
\hline
\end{tabular}

0.0022 is the unit conversion factor between grams and pounds, and dividing by 2 accounts for two curblanes. This expression also was used to determine yields from singlesided street-solid composite masses but the numerator was not divided by two.

Sample composite yields and rain events that occurred from May 2010 to March 2011 are shown in figure 7. Street solids sampled in Cambridge, Mass., by land-use type and grain-size fraction are summarized in table 6. Street-solid yields for multifamily and commercial streets in Cambridge, Mass., are compared to other studies in the United States in table 7. Average multifamily street-solid yield was about $740 \mathrm{lbs} /$ curb-mi. Median multifamily street-solid yield was about $602 \mathrm{lbs} /$ curb-mi. Commercial land-use average and median street-solid yields were about 522 and 467 lbs/curbmi, respectively. Average multifamily and commercial yields are about 1.9 and 1.7 times the national average (Sartor and
Boyd, 1972), respectively (table 7). Average and median multifamily and commercial street-solid yields increased to about 898 and 615, and 887 and 498 lbs/curb-mi, respectively when including the large amounts of EOW material collected in March 2011. Including the EOW samples increased average multifamily and commercial yields to about 2 to 3 times the reported national average, respectively. Evaluation of average street-solid yields on a seasonal basis required combining results between May and June, July to September, October to December 2010, and March 2011, street solid yields from each land-use type to represent spring, summer, fall, and EOW periods, respectively. The distribution of these seasonal sample groups are seen as boxplots in figure 8. Although there are only two sampling events on each street in March to represent the EOW, an annual street-solid yield cycle is seen in both land-use types that is lowest in the spring following spring washoff and EOW cleanup, then yields increase through the summer and into autumn before the end of the street-cleaning season in December, which allows yields to reach their peak levels at the EOW. Median street-solid yields from commercial streets were about 16 and 22 percent greater than those from multifamily streets for spring and EOW periods, respectively. Summer yields from both land-use types were within 2 percent of each other. However, multifamily median streetsolid yields were about 42 percent greater than those in commercial streets in the fall. Individual CTC sample dates and resulting masses and yields for streets in both multifamily and commercial land-use types are seen in appendix table 1-15 (on CD-ROM at back of report).

\section{Particle-Size Distribution}

Samples were split into three grain-size fractions: coarse, medium, and fine, using stainless-steel sieves and sieve shaker. The median percent distribution of material in the three grainsize fractions found on the multifamily and commercial streets from coarse to fine was about 30,61, and 9 percent and about 15,71 , and 14 percent, respectively. It is likely the greater proportion of coarse street solids in multifamily street samples is due to the tree density and other plantings on those streets compared to commercial streets (table 1). In addition, median organic carbon yields on multifamily streets were about 2.5 times greater than those from commercial streets. About 87 percent of the composite samples from both land-use types consisted of material coarser than very fine sand (or greater than $0.125 \mathrm{~mm}$ ). These results are similar to those determined in other studies. Waschbusch and others (1999) reported about 75 percent of sampled street-solid mass in Madison, Wis., was greater than $0.250 \mathrm{~mm}$ and less than 5 percent was less than $0.063 \mathrm{~mm}$ in diameter; Breault and others (2005) reported more than 93 percent of the street solids was greater than $0.125 \mathrm{~mm}$ in diameter in New Bedford, Mass.; and Law and others (2008) reported about 70 percent of the street solids was greater than $0.250 \mathrm{~mm}$ in diameter in Baltimore, $\mathrm{Md}$. 


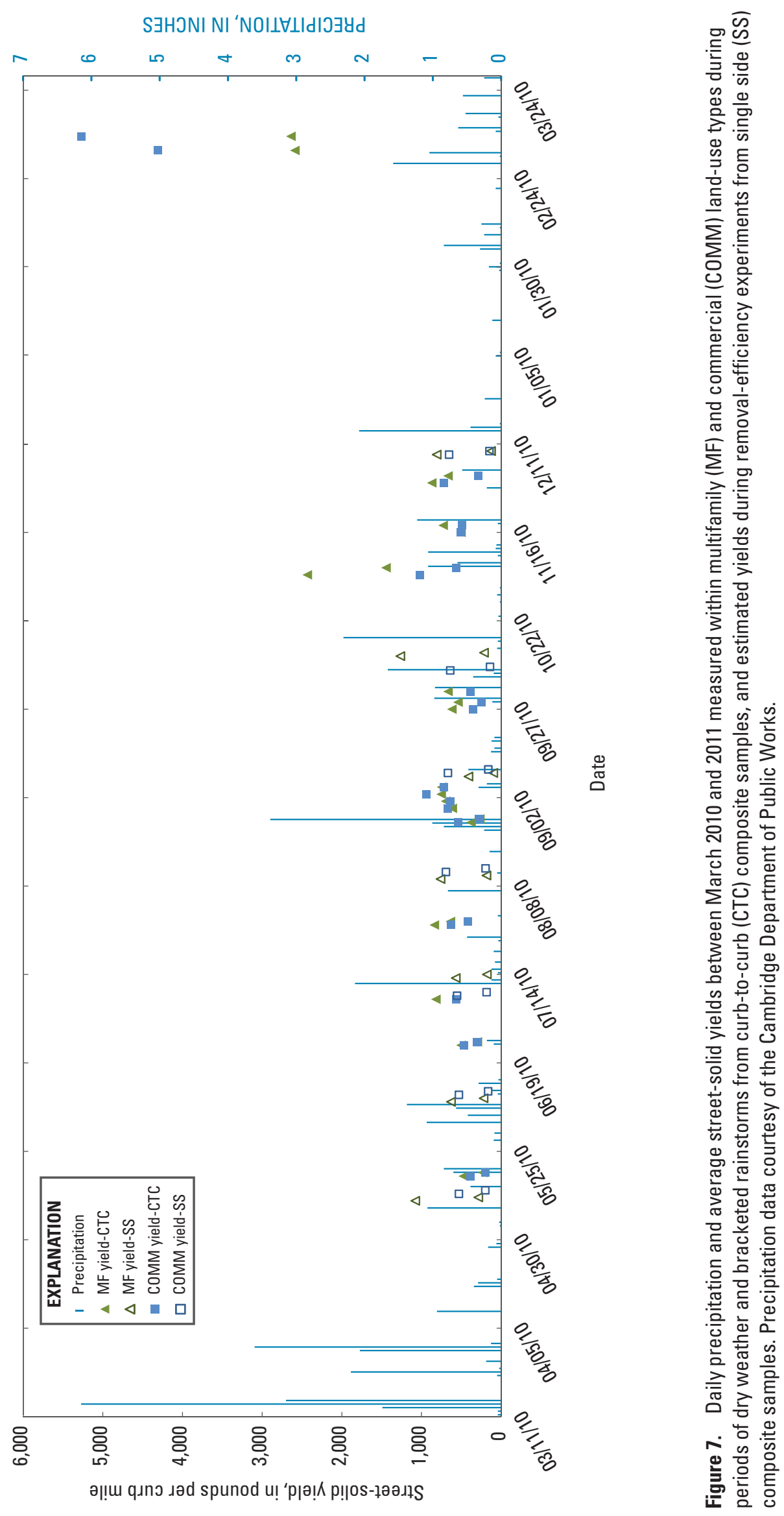


Table 6. Summary of Cambridge, Massachusetts, street-solid yields by land-use type and grain-size fraction.

[n, number of samples; mm, millimeters; coarse, greater than or equal to $2 \mathrm{~mm}$; medium, less than $2 \mathrm{~mm}$ greater than or equal to $0.125 \mathrm{~mm}$; fine, less than $0.125 \mathrm{~mm}$ in diameter]

\begin{tabular}{|c|c|c|c|c|}
\hline \multicolumn{5}{|c|}{ Street-solid yield, in pounds per curb-mile } \\
\hline Statistic & Total & Coarse & Medium & Fine \\
\hline \multicolumn{5}{|c|}{$\begin{array}{l}\text { Multifamily } \\
n=65\end{array}$} \\
\hline Mean & 740.1 & 301.0 & 346.9 & 63.6 \\
\hline Median & 601.5 & 129.2 & 277.4 & 37.9 \\
\hline Minimum & 168.8 & 11.7 & 95.1 & 6.1 \\
\hline Maximum & $3,847.5$ & $2,935.1$ & 974.6 & 280.9 \\
\hline \multicolumn{5}{|c|}{$\begin{array}{c}\text { Commercial } \\
n=64\end{array}$} \\
\hline Mean & 521.5 & 111.6 & 331.2 & 64.5 \\
\hline Median & 466.7 & 65.1 & 305.0 & 60.7 \\
\hline Minimum & 179.7 & 21.0 & 126.6 & 4.2 \\
\hline Maximum & $1,471.0$ & 707.3 & 918.7 & 307.2 \\
\hline
\end{tabular}

Table 7. Comparison of Cambridge, Massachusetts, street-solid yields by land-use type to those in other areas of the United States (Modified from Selbig and Bannerman, 2007).

[--, no data; all values in pounds per curb-mile]

\begin{tabular}{|c|c|c|c|c|c|c|c|c|}
\hline Statistic & $\begin{array}{c}\text { Cambridge, } \\
\text { Massachusetts }\end{array}$ & $\begin{array}{l}\text { Madison, } \\
\text { Wisconsin }^{1}\end{array}$ & $\begin{array}{l}\text { Champaign, } \\
\text { Illinois }^{2}\end{array}$ & $\begin{array}{c}\text { Bellevue, } \\
\text { Washington }^{3}\end{array}$ & $\begin{array}{c}\text { Seattle, } \\
\text { Washington }^{4}\end{array}$ & $\begin{array}{l}\text { San Jose, } \\
\text { California }^{5}\end{array}$ & $\begin{array}{l}\text { Baltimore, } \\
\text { Maryland }^{6}\end{array}$ & U.S. Nationwide ${ }^{7}$ \\
\hline \multicolumn{9}{|c|}{ Multifamily } \\
\hline Mean & 740 & 614 & 408 & 815 & 970 & 310 & 645 & 391 \\
\hline Median & 602 & 569 & -- & 705 & 1,060 & -- & -- & -- \\
\hline \multicolumn{9}{|c|}{ Commercial } \\
\hline Mean & 522 & -- & -- & -- & -- & 509 & -- & 302 \\
\hline Median & 467 & -- & -- & -- & -- & -- & -- & -- \\
\hline
\end{tabular}

'Selbig and Bannerman, 2007.

${ }^{2}$ Bender and Terstriep, 1984

${ }^{3}$ Pitt, 1985.

${ }^{4}$ Seattle Public Utilities and Herrera Environmental, 2009.

${ }^{5}$ Pitt, 1979.

${ }^{6}$ Law and others, 2008.

${ }^{7}$ Sartor and Boyd, 1972.

\section{Spatial Distribution of Street Solids}

Distribution of material on street surfaces is highly variable and controlled by many factors including presence of berms or curbing, condition of street-surface texture, prevailing winds, traffic density, on-street parking, and parking controls. Sartor and Boyd (1972) and Pitt (1979) observed that on smooth streets with moderate to heavy traffic without on-street parking, about 90 percent of the material was located within 1 foot of the curb. Pitt (1979) also reported street dirt on rough-textured streets typically is distributed more evenly as more material is retained within cracks and pits on the surface. In addition, they reported on-street parking can act to buffer traffic action and prevailing winds to further limit consolidation of street solids near the curb. Seasonal effects also determine street solids distribution. This is demonstrated in areas with relatively cold winters requiring street maintenance during snow events in the form of deicers or sand. Although the Cambridge Department of Public Works (DPW) does not apply maintenance sand to their streets during snowstorms, maintenance sand tracked into the city from daily traffic and use of sand to improve traction on sidewalks and other pedestrian areas may be available to "wash on" to street surfaces.

Selbig and Bannerman (2007) collected curb samples from $3 \mathrm{ft}$ out from the curb in addition to the crown (or center lane). Their streets had minimal on-street parking, and they reported an even distribution of street material at the EOW such that the crown contained a greater proportion of material than the curb lanes; however, by early summer 75 percent of the street dirt was confined to within $3 \mathrm{ft}$ of the curb. 

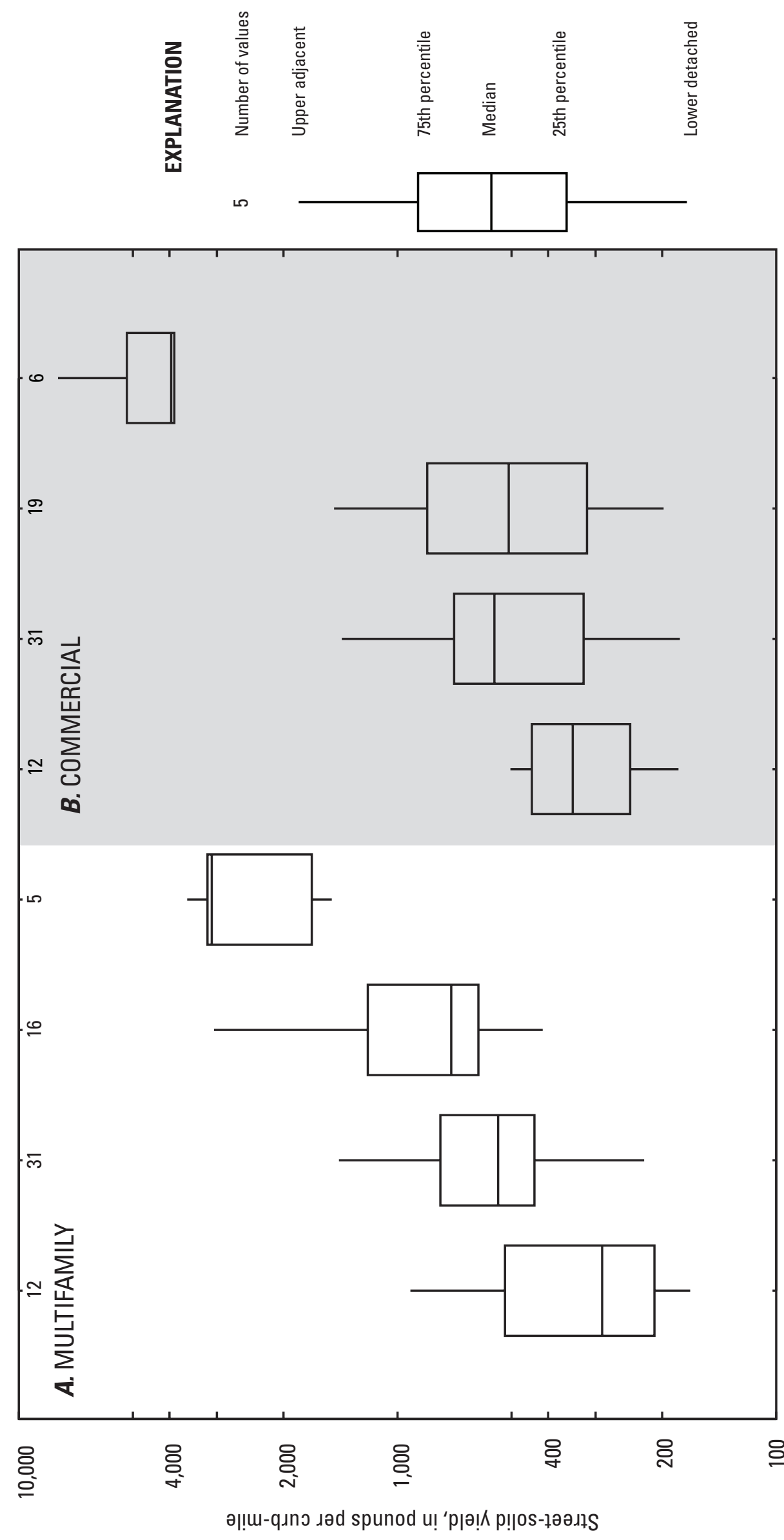

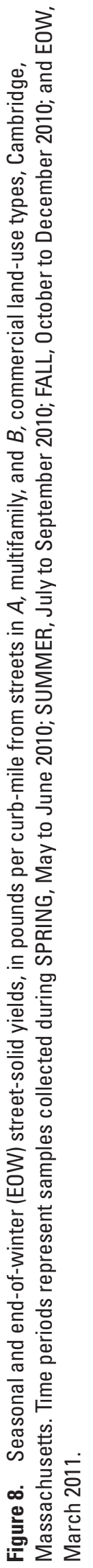


Three sets of street-solid distribution samples were collected on each street in Cambridge in July and October 2010, and in March 2011, such that one portion of the composite represented a curb lane and a second composite represented the remaining center lane or crown of the street. July composite samples represented street-solids within $3 \mathrm{ft}$ of the curb and the remaining street crown. About 57 percent of the total street-solids was found within $3 \mathrm{ft}$ of the curb and about 43 percent of the total street-solids was found in the street crown. About 67, 55, and 63 percent of street solids from the coarse, medium, and fine grain-size fractions were within $3 \mathrm{ft}$ of the curb, respectively. Within the crown, the distribution of street solids from coarse to fine grains were about 33, 45, and 37 percent, respectively. Samples were collected from the curb extending $9 \mathrm{ft}$ towards the crown in October 2010. About 95 percent of total street solids were observed within $9 \mathrm{ft}$ of the curb, and the remaining 5 percent resided within the crown. Distribution of street solids by grain size indicated 97, 91, and 94 percent of material in the coarse, medium, and fine grain-size fractions were within $9 \mathrm{ft}$ of the curb, respectively. The remaining 3, 9, and 6 percent of the coarse to fine grain-size fractions were within the crown, respectively. EOW samples were collected $6 \mathrm{ft}$ from the curb in March 2011, and about 74 percent of the total material was within this area. From coarse to fine grain-size fractions, 81, 72 , and 75 percent of street solids was within $6 \mathrm{ft}$ of the curb, respectively. These samples suggest a fairly even distribution of street solids throughout the year in Cambridge on the smooth to rough-textured streets with heavy on-street parking. The most even distribution was observed within the two grain-size fractions greater than or equal to $0.125 \mathrm{~mm}$, which represents more than 86 percent of the total mass of street solids on both multifamily and commercial streets.

\section{Street-Solid Accumulation}

Street-solid composite samples from each street were used to estimate the accumulation rate (build-up rate or deposition loading) of street solids on street surfaces by dividing the difference in total yields between successive samples before and after a rainstorm by the number of days between sampling events. Accumulation results for Mount Auburn Street were negative, indicating a loss of material with time rather than a buildup, although results from the five other streets were positive. Considering the additional street cleaning by mechanical-brush street cleaners observed outside the monthly schedule on this street, commercial accumulation-rate estimates exclude data from Mount Auburn Street, which may exhibit a negative bias resulting from additional street cleaning activity.

Accumulation rates from streets in each land-use type are shown in figure 9. Overall accumulation patterns were similar between land-use types by grain-size fraction and total yield. Median total accumulation rates were 33 and $22 \mathrm{lbs} /$ curb-mi/day, and ranged between -43 to 84 and -23 to
$308 \mathrm{lbs} /$ curb-mi/day for multifamily and commercial land-use streets, respectively (extreme values truncated in figure 9). Median multifamily accumulation rates were largest within the medium grain-size fraction at about $19 \mathrm{lbs} /$ curb-mi/day, though the coarse and fine grain-size fractions accumulate similarly at about $7 \mathrm{lbs} /$ curb-mi/day. Median commercial accumulation rates for the medium grain-size fraction were about $15 \mathrm{lbs} /$ curb-mi/day, the fine grain-size fraction was about $6 \mathrm{lbs} /$ curb-mi/day and the coarse grain-size fraction was the smallest at about $2 \mathrm{lbs} /$ curb-mi/day.

The average accumulation of street solids on the study streets increased quickly within a few days of a street cleaning or rainstorm in both multifamily and commercial land-use types (fig. 10). The drop in yields after nearly two days on streets in both plots is attributed to sample loss during processing that resulted in an average accumulation value based on only one street for multifamily and commercial streets. These results indicate that the street solids on multifamily and commercial streets in Cambridge can accumulate to near median yields within 1 to 3 days after the streets are cleaned or following a rainstorm (fig. 10). After this steep increase, the estimated street-solid yield in each land-use type remained somewhat consistent. The overall accumulation pattern of these data is similar to the early research of Sartor and Boyd (1972) for both land-use types with a steep increase within the first few days of a washoff or street-cleaning event, then increasing more slowly and reaching maximum yields in about 5 days. Yields also became constant after about 7 days in Bellevue, Washington, an area where rainfall occurs about every 3 days (Pitt, 1985). Burton and Pitt (2002) suggest that yields of street solids on roadways in areas such as Bellevue, Wash., remain close to the initial yields and do not increase with time.

\section{Street-Solid Washoff}

The washoff of street solids from roadway surfaces and mobilization of local soils adjacent to streets are dependent on the initial load, and the rainfall intensity or volume of stormwater on the roadway to loosen dirt and other solids from the pavement and transport it off/from the street (Pitt and others, 2004). Pitt and others (2004) also suggest that urban stormwater runoff during small and less intense rainstorms represent most of the solid load resulting from wear of the road surface and the deposition of traffic-related materials. Furthermore, Pitt and others (2004) reported that washoff is affected by distribution of street solids on road surfaces and extent of armoring (or the sheltering of smaller particles by larger ones).

Street-solid composite samples were collected before and after rainstorms. The time between the end of a rainstorm and when samples were collected varied, and percent washoff from streets in the two land-use types was estimated based on samples collected between 3 and 23 hours of the end of six rainstorms. The narrow window between the collection 

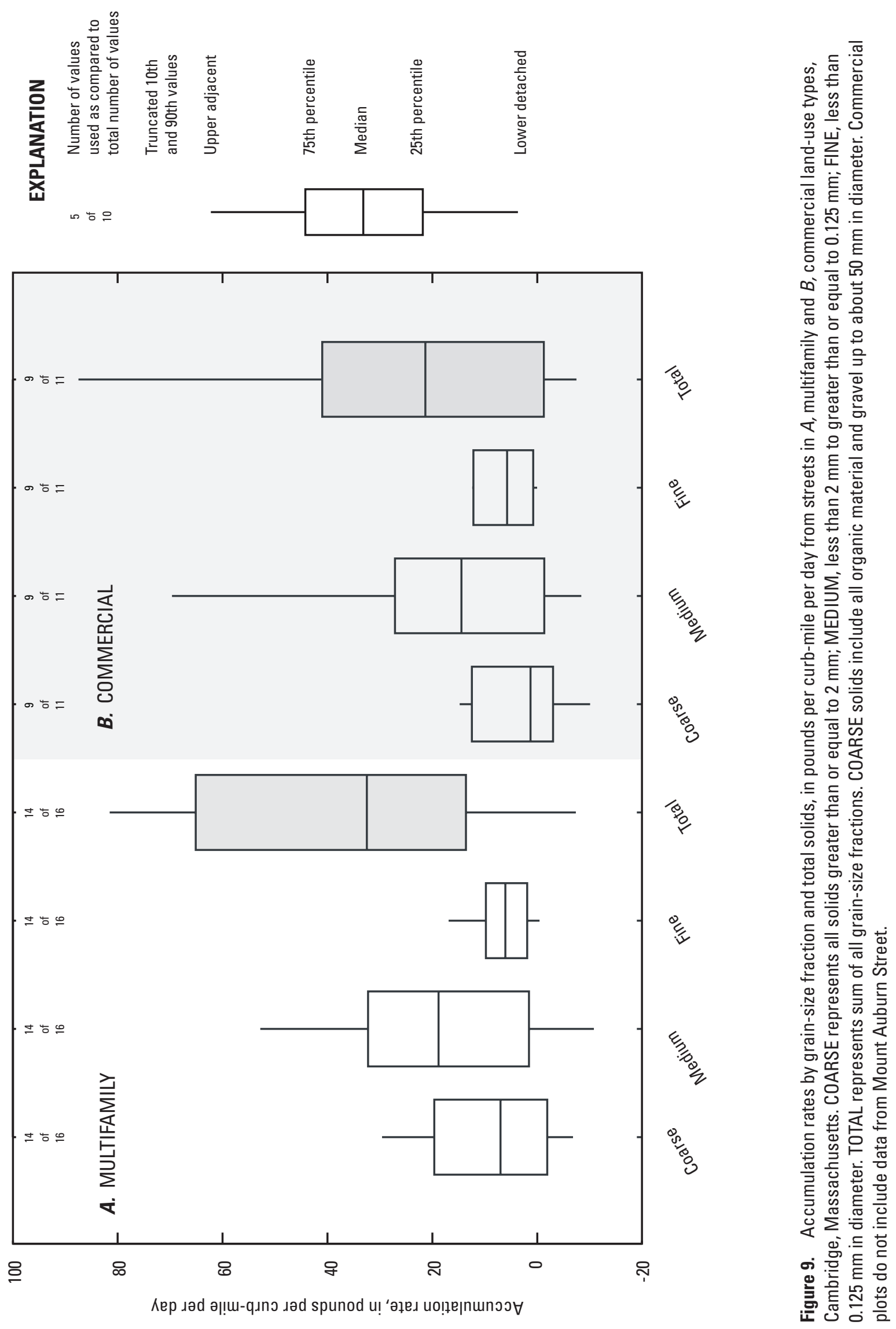


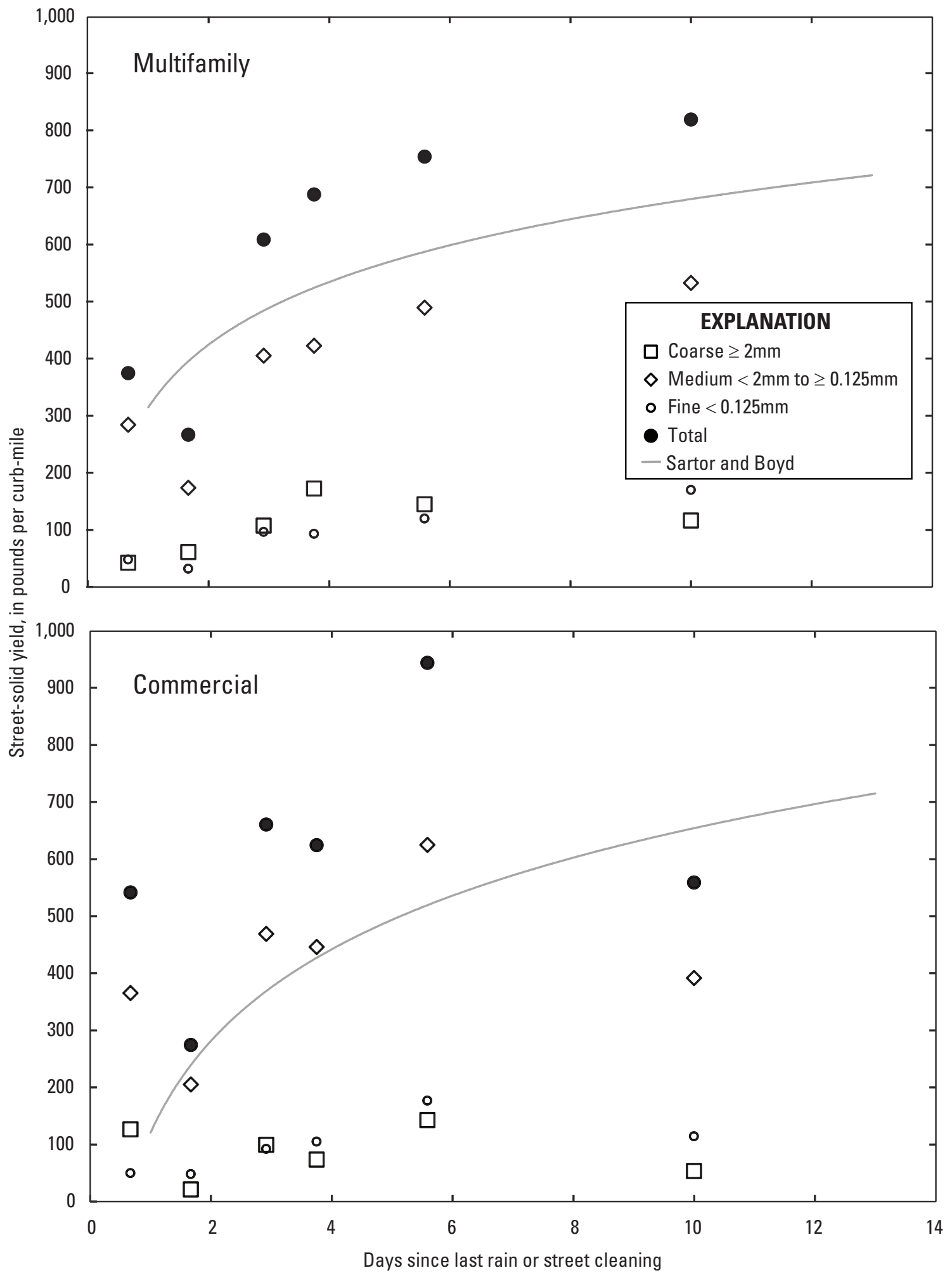

Figure 10. Street-solid yield by grain-size fraction and total yield, in pounds per curb-mile per day as a function of time in days since the last rain or street cleaning on streets in multifamily and commercial land-use types, Cambridge, Massachusetts. U.S. nationwide residential and commercial results from Sartor and Boyd (1972) also are shown. Commercial plots do not include data from Mount Auburn Street. 
of prestorm and poststorm samples likely eliminated effects of unscheduled street cleaning on Mount Auburn Street. The average amount of street solids removed from the roadway by rainfall (washoff) was calculated by subtracting the difference of street-solid mass in total composite samples and by grain-size fraction before and after a rainstorm for six sample pairs. Total storm volumes and rainfall intensities based on the Cambridge DPW rain gage on Hampshire Street ranged between 0.32 to 1.71 inch and 0.027 to 0.185 inches per hour (in/hr), respectively. Net increases of street solids following rainstorms result in negative washoff values. One of the six composite sample pairs bounds a rainstorm during heavy leaffall season, which may explain the negative washoff values. Deposition of leaves/seeds/woody debris from trees, dirt, soils, and other debris transported from impervious surfaces or saturated pervious surfaces adjacent to the street surface, and dirt and soils tracked in from construction vehicles (track-out) are possible sources that may increase the amount of street solids after a rainstorm. Every effort was made to avoid areas with unusual loading or obvious additional street solids from active construction sites (fig. 2) during sampling.

The percent washoff of street solids from each street in terms of grain-size fraction, and an average percent washoff of all three grain-size fractions from each street as a result of the six rainstorms are presented as boxplots in figure 11. Percent washoff of solids from streets in multifamily and commercial areas increased similarly with decreasing grain-size. Median average street-solid washoff also was similar between land-use types at about 36 and 42 percent for multifamily and commercial streets, respectively.

An average percent washoff for each grain-size fraction and an average total washoff from both land-use types for each of the six storms were calculated and plotted as a function of rainfall volume and intensity (fig. 12). Plots in figure 12A show the percent washoff is generally highest in the fine grain-size fraction, and there were two instances with negative washoff of primarily coarse street solids on multifamily streets and one instance of negative washoff of fine size fraction street solids on commercial streets. Observed storm intensities in figure 12B were less than $0.20 \mathrm{in} / \mathrm{hr}$, and the highest percent washoff values are seen in the fine fraction at intensities less than $0.10 \mathrm{in} / \mathrm{hr}$. Negative washoff of primarily coarse street solids are observed only from streets in the multifamily landuse type and washoff occurs at lower intensities compared to negative washoff from streets in commercial land use.

\section{Regenerative-Air Street Cleaner Removal Efficiency}

The removal efficiency of a TYMCO Dustless Sweeping Technology-6 (DST-6) regenerative-air street cleaner, herein referred to as the "RA street cleaner," was determined by comparing the difference between street-solid composite samples collected before and after the streets were cleaned by a single pass of the machine in multifamily and commercial land-use areas.

The difference between pre- and post-median yields of total street solids from multifamily streets was 82 and 78 percent on commercial streets (table 8). Removal efficiency of the RA street cleaner decreased with smaller grain-size fractions, and was nearly the same for streets in both land-use types. The median percent removal efficiency for the machine on multifamily and commercial streets was 92,83 , and 53 percent, and 92, 79, and 51 percent for the coarse, medium, and fine grain-size fractions, respectively. Negative values, or net increases in material were occasionally observed within the fine grain-size fraction. However, this typically occurred on streets with rough surfaces, and is possibly a result of the action of the street cleaner's gutter broom removing coarse dirt and other material from cracks and holes near the curb, exposing finer material in addition to fine-grained material left behind by the wet gutter broom. Median street-solid yields before a single RA street cleaner pass within $9 \mathrm{ft}$ of the curb on multifamily and commercial streets were 735 and $521 \mathrm{lbs} /$ curb-mi, respectively. Street-solid yields before street cleaning ranged from about $269 \mathrm{lbs} /$ curb-mi in both land-use types to 1,685 to $1,377 \mathrm{lbs} /$ curb-mi on multifamily and commercial streets, respectively (fig. 13). Median residual yields after the street was cleaned were nearly identical for streets in both land-use types at about $100 \mathrm{lbs} / \mathrm{curb}$-mi, but ranged between 18 and $513 \mathrm{lbs} /$ curb-mi, and 46 and $222 \mathrm{lbs} /$ curb-mi on multifamily and commercial land-use streets, respectively. Individual removal efficiency (or single-sided) sample dates and resulting masses and yields for streets in both multifamily and commercial land-use types are seen in appendix table 1-16 (on CD-ROM at back of report).

A residual yield of street solids always remained on the street surface following a single street cleaner pass in the study sections as a function of the initial yield. Evaluation of the removal efficiency data based on season, individual streets, land-use type, street condition, and traffic volume did not present any clear patterns, and resulted in poor relations. Closer inspection of available removal efficiency data indicate a nonnormal, cloud-like pattern without a strong linear relation, whether or not the data was corrected for the whole street or not. The Kendall-Thiel robust line, described by Helsel and Hirsch (2002), is a nonparametric regression technique that is less affected by outliers and nonnormality of residuals that commonly characterize hydrologic datasets (Granato, 2006). The Kendall-Thiel Robust Line program (KTRLine-version 1.0; Granato, 2006) was used to develop a regression of residual yield (post-street cleaning) and initial yield (prestreet cleaning) or productivity function data corrected for the whole street for the regenerative-air street cleaner. The slope is calculated as the median of all possible pairwise slopes and the intercept is calculated so that the line will run through the median of the input data (Granato, 2006). The slope of the regression between street-solid yield before and after street cleaning is low, and the data indicate that the efficiency of the street cleaner increased with increasing initial yields, but also 

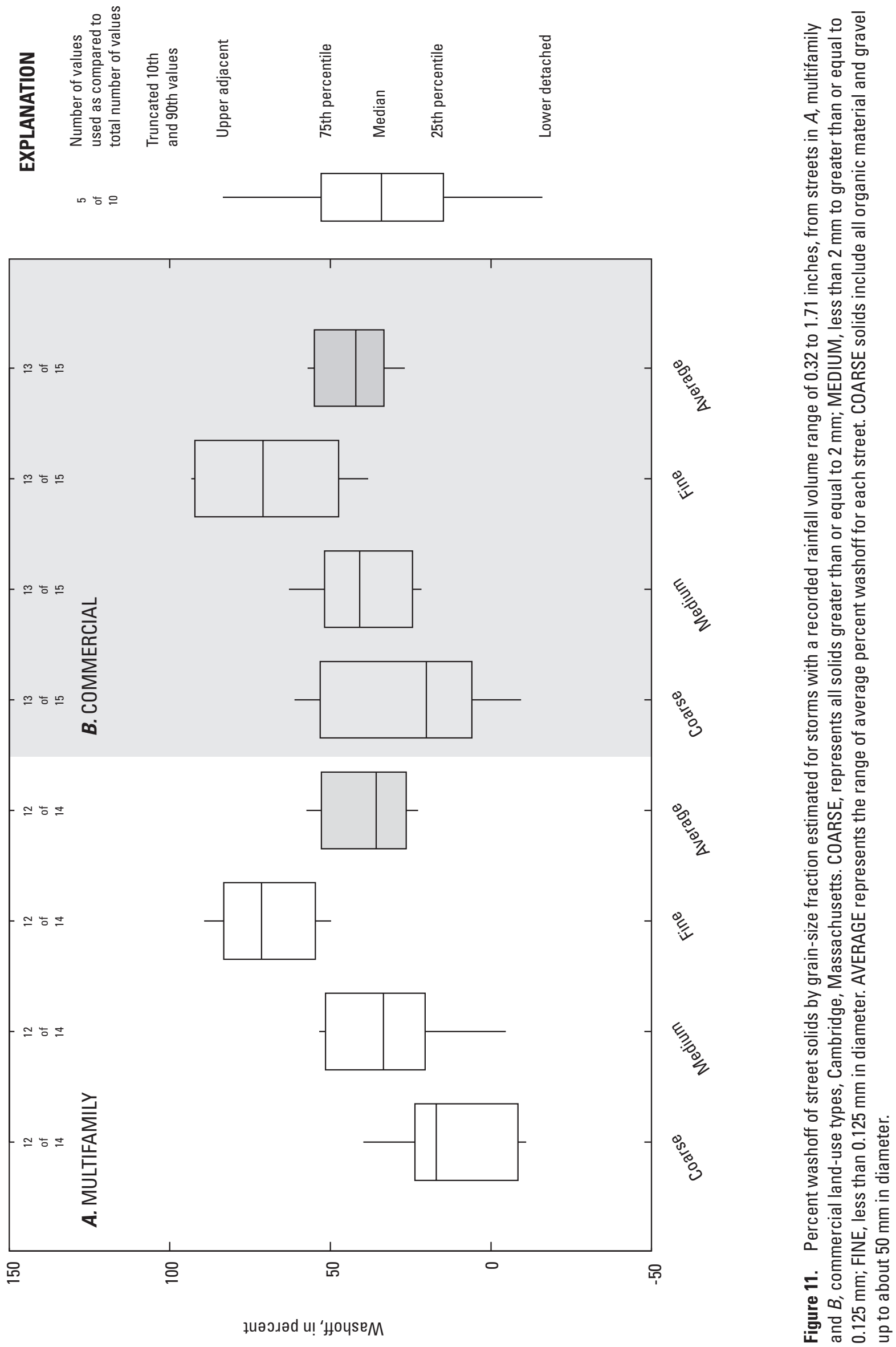

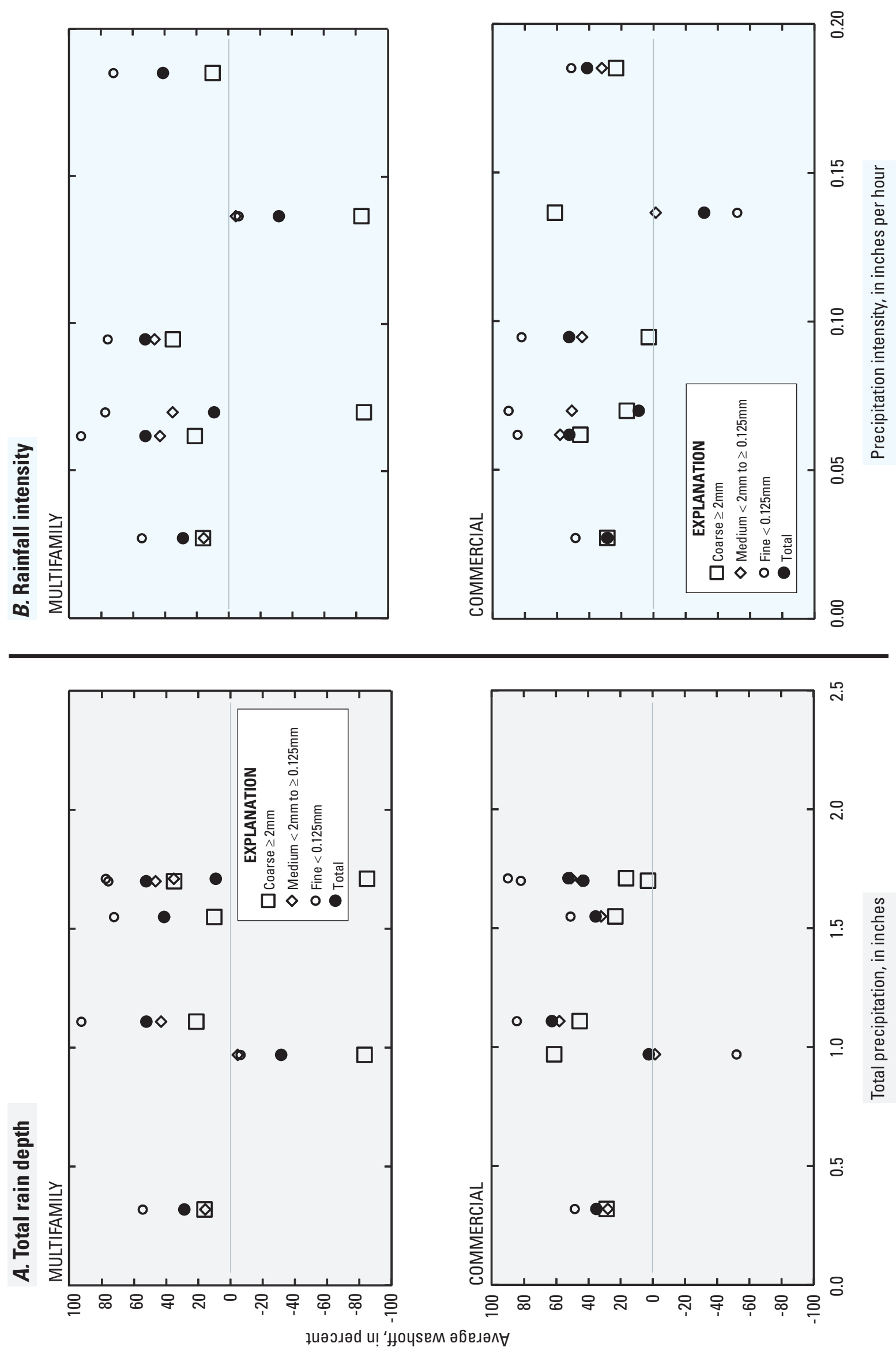

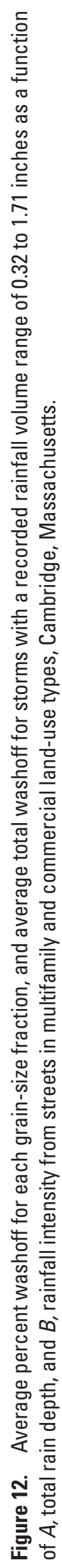


Table 8. Average, median, maximum, and minimum removal efficiency, in percent, of a regenerative-air street cleaner on multifamily and commercial land-use streets in Cambridge, Massachusetts.

[Negative values indicate an increase in material following a single regenerative-air street-cleaner pass; $\mathrm{n}$, number of samples; mm, millimeter; coarse, greater than or equal to $2 \mathrm{~mm}$; medium, less than $2 \mathrm{~mm}$ greater than or equal to $0.125 \mathrm{~mm}$; fine, less than $0.125 \mathrm{~mm}$ in diameter]

\begin{tabular}{lcccc}
\hline & \multicolumn{4}{c}{ Removal efficiency, in percent } \\
\cline { 2 - 5 } & Total & Coarse & Medium & Fine \\
\hline \multicolumn{5}{c}{ Multifamily } \\
$\mathrm{n}=33$ \\
\hline Average & 83.3 & 89.5 & 82.6 & 49.8 \\
Median & 86.2 & 95.8 & 88.5 & 65.9 \\
Maximum & 98.3 & 99.8 & 96.9 & 94.9 \\
Minimum & 35.7 & 75.1 & 42.8 & -87.1 \\
\hline \multirow{5}{*}{ Commercial } \\
& 78.2 & $\mathrm{n}=39$ & \\
\hline Average & 99.7 & 94.1 & 80.1 & 63.6 \\
Median & 92.6 & 99.3 & 95.9 & 92.8 \\
Maximum & 43.8 & 63.9 & 45.3 & -86.7 \\
Minimum & \multicolumn{5}{c}{}
\end{tabular}

left a consistent residual yield regardless of the initial streetsolid yield. The slope (0.066), and y-intercept (69.57) of the KTRLine (fig. 14) represent the productivity function coefficients applied in the SLAMM model to simulate the performance of the regenerative-air street cleaner evaluated in 2010.

\section{Street-Solid Chemistry}

Constituents on street surfaces in urban areas may come from a variety of sources and may vary depending upon the age of the materials used for construction. For example, fiberglass and asphalt roof types are known to have better runoff quality than slate tile, rubber, or galvanized metal (Davis and others, 2000). Average concentrations of copper $(\mathrm{Cu}), \mathrm{Pb}$, and zinc $(\mathrm{Zn})$ in samples of bulk rainfall collected from a rubberized roof in Ipswich, Mass., were 2.8, 5.9, and 7.9 micrograms per liter $(\mu \mathrm{g} / \mathrm{L})$, respectively (Zimmerman and others, 2010). The concentrations of total P in bulk rainfall were 0.01 milligrams per liter $(\mathrm{mg} / \mathrm{L})$. Average concentrations of $\mathrm{Cu}, \mathrm{Pb}$, and $\mathrm{Zn}$ in samples of rainfall runoff from the rubberized roof were about 53, 692, and $514 \mu \mathrm{g} / \mathrm{L}$, respectively, and about $0.10 \mathrm{mg} / \mathrm{L}$ was reported for total P. In addition, roofing and siding materials from buildings has been associated with substantial concentrations of $\mathrm{Cd}, \mathrm{Cu}, \mathrm{Pb}$, and Zn (Davis and others, 2000).
Smith (2010) conducted an extensive study of stormwater runoff from Massachusetts highways of various traffic densities. In addition to exhaustive stormwater sampling, samples of maintenance sand, maintenance salt (sodium chloride), liquid calcium chloride, berm soil, and grass clippings were submitted for analysis of elements, polyaromatic hydrocarbons, and phthalates. Grasses were determined to possess relatively high concentrations of $\mathrm{Ca}, \mathrm{K}$, and $\mathrm{P}$. Washed off solids greater than $0.250 \mathrm{~mm}$ in diameter, including sands and gravels, but consisting mostly of leaves, were also relatively high in these elements (Smith, 2010). Average concentrations of $\mathrm{P}$, other elements, and suspended sediments in composite samples of highway runoff were reported to be 3 to 11 times greater in winter runoff compared to runoff during warmer months (Smith, 2010). The large difference between winter and nonwinter runoff concentrations in highway runoff was attributed primarily to the application of maintenance sand. Although maintenance sand constituent concentrations were small, the large amount of sand applied during the winter resulted in large increases of many elements in runoff, including a 94-percent increase in winter P concentrations (Smith, 2010). Low temperatures, increased vehicle component wear, and entrained material in snowbanks are all additional sources of increased winter loading. Smith (2010) reported exhaust emissions from gasoline engines at highway speeds represented less than 3 percent of $P$ concentrations in stormwater runoff, background soils accounted for about 37 percent of the median $\mathrm{P}$ concentration, and that erosion or presence of soils onto the paved surface could be a large source of $\mathrm{P}$ and other elements in stormwater runoff.

Urban and suburban traffic patterns have more frequent stops and accelerations. This type of vehicle operation is associated with less efficient combustion by gasoline engines and increased vehicle component and road wear. These conditions in urban and suburban areas may result in greater concentrations of $\mathrm{Cu}$ and $\mathrm{Zn}$ associated with brake and tire wear (Davis and others, 2000). Average emission rates of $\mathrm{Cr}, \mathrm{Cu}$, Nickel $(\mathrm{Ni})$, and $\mathrm{Pb}$ were similar to major particulate-associated polyaromatic hydrocarbon (PAH) emission rates, but $\mathrm{P}, \mathrm{Fe}$, and $\mathrm{Zn}$ were about 6 to 38 times greater than their respective PAH emission rates (Cadle and others, 2001).

Median concentrations of organic carbon, $\mathrm{P}$, and 31 other elements in street-solid composite samples from multifamily and commercial streets in Cambridge, Mass., were normalized by the mass of the respective grain-size fraction. Median total-recoverable concentrations and respective standard deviations of all CTC composite samples of street solids for each grain-size fraction for the two land-use types are listed in table 9 (in back of report). Concentrations of organic carbon and 12 elements were greater in composite samples collected from multifamily streets than in composite samples collected from commercial streets. Median concentrations of organic carbon and total $\mathrm{P}$ were about 35 and 29 percent greater than the median concentrations calculated for composite samples collected from commercial streets. Individual total-recoverable concentrations of street-solid composite samples for streets in 


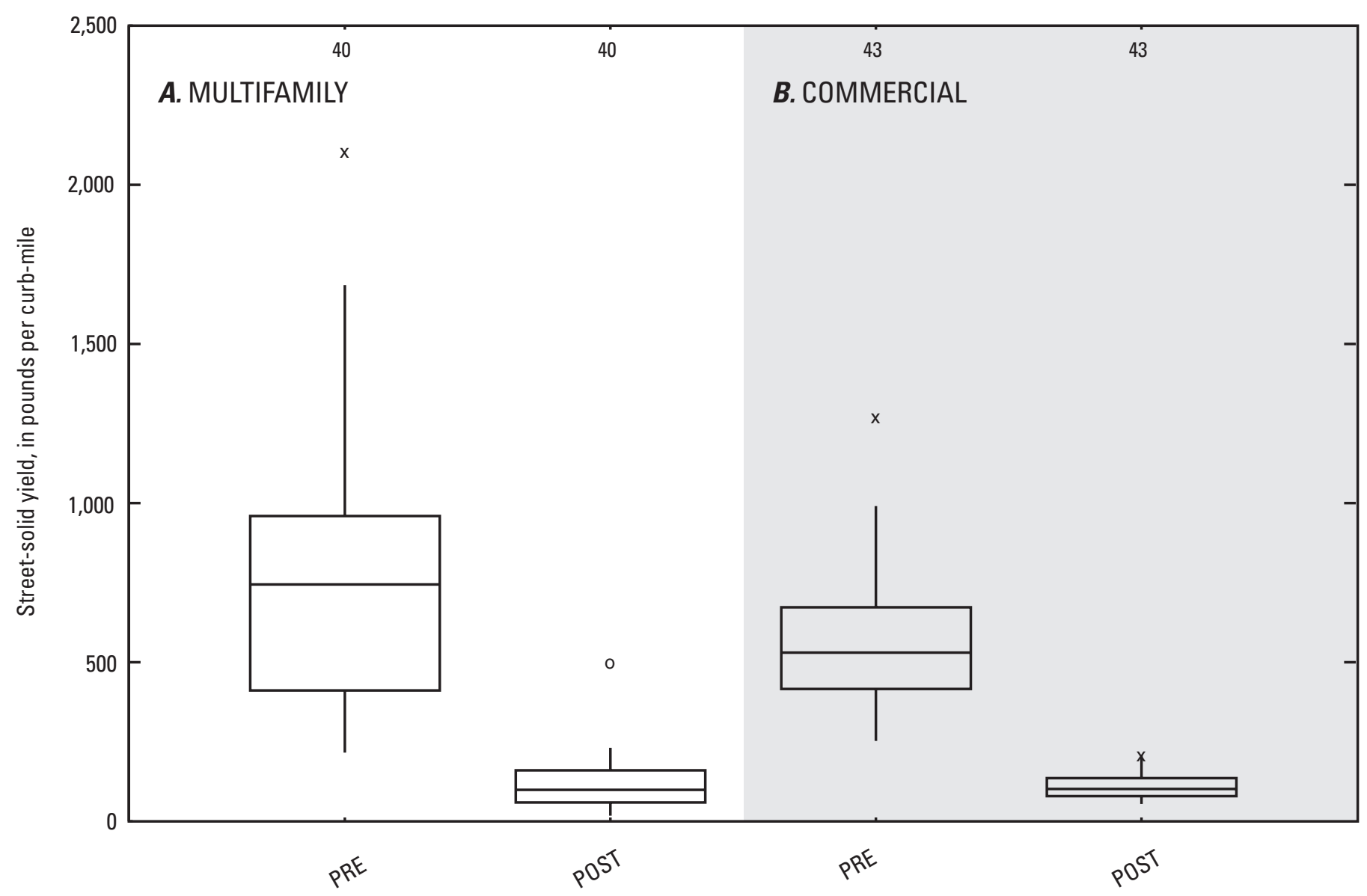

Figure 13. Street-solid yields before (PRE) and after (POST) a single pass of a regenerative-air street cleaner on streets in $A$, multifamily and $B$, commercial land-use types, Cambridge, Massachusetts.

both multifamily and commercial land-use types are seen in appendix tables $1-17$ and $1-18$, respectively (on CD-ROM at back of report).

The total mass of constituents in composite samples collected from multifamily streets also were somewhat greater than the total mass of constituents in composite samples collected from commercial streets (table 9, in back of report). The total mass of constituents generally increased with decreasing grain size, except for organic carbon, $\mathrm{Ca}, \mathrm{K}, \mathrm{Mg}$, $\mathrm{P}$, and strontium $(\mathrm{Sr})$, in samples from streets in both land-use types. These constituents had higher concentrations in the coarse size fraction.

Concentrations of organic carbon, $\mathrm{Ca}$, and $\mathrm{K}$, from the medium fraction also were greater than concentrations in the fine fraction, although the difference was slightly greater in the multifamily street solid composite samples. Concentrations of organic carbon, $\mathrm{Ca}, \mathrm{K}, \mathrm{P}$ in samples of unwashed leaves collected from residential streets were higher than finer grain-size fractions of street solids. Similar concentrations of these constituents also were found in bulk samples greater than $0.250 \mathrm{~mm}$ in diameter, consisting predominantly of leaves, collected at the outlet of a catch basin along Massachusetts highways (Smith, 2010). About 13.3 and 1.5 percent of the total $P$ mass is within the finest fraction (less than $0.125 \mathrm{~mm}$ ) for multifamily and commercial land-use types, respectively. The total mass of organic carbon and $\mathrm{P}$ in composite samples of street solids from multifamily streets was about 68 and 75 percent greater than the mass of the constituents in composite samples collected from commercial land-use streets, respectively. The mass of $\mathrm{P}$ on multifamily streets was greater than that on commercial streets by about 1.4 and 11.5 times in the medium and fine grain-size fractions, respectively. Total $\mathrm{P}$ on commercial streets was about 0.8 times (or about 20 percent) greater than total $\mathrm{P}$ on multifamily streets within the coarse grain-size fraction. About 87 and 98 percent of the total P mass was observed within material greater than very fine sand (greater than $0.125 \mathrm{~mm}$ in diameter), for streets in multifamily and commercial, landuses, respectively. 


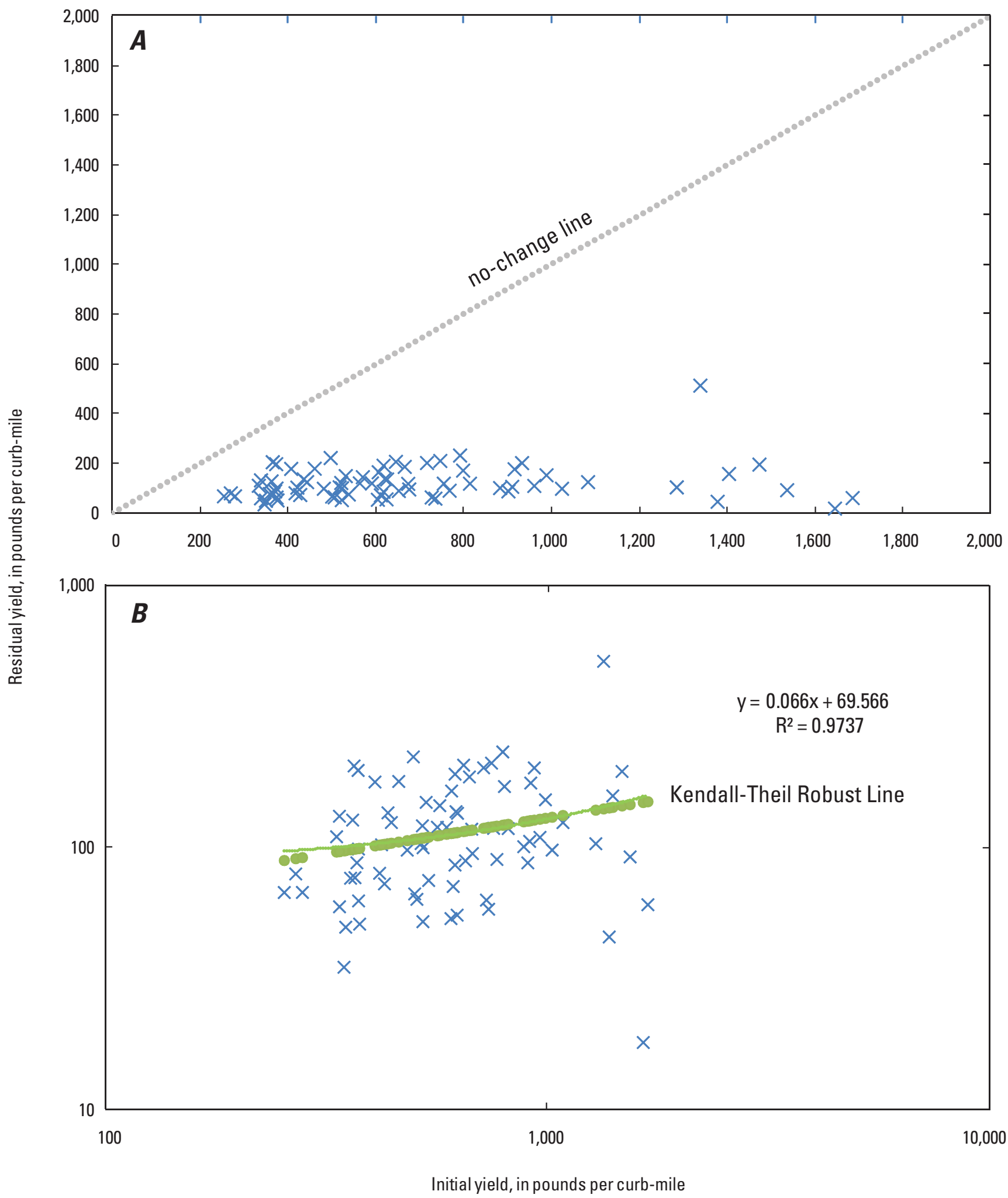

Figure 14. A, Removal efficiency plot of a regenerative-air street cleaner making a single pass on streets with smooth to rough street-surface conditions and heavy on-street parking with monthly parking controls, in multifamily and commercial land-use types Cambridge, Massachusetts. All data below the 1:1 no-change line represent reductions in street-solid yields. $B$, Productivity function (green dotted line) of the regenerative-air street cleaner using the Kendall-Theil Robust Line (KTRLine version 1.0), where 0.066 is the slope and 69.566 is the $y$-intercept. 
Total P yields (fig. 15, table 10) generally follow the pattern of street solid yields (fig. 8, table 10). Following spring cleaning, $P$ yields are reduced to low levels by street cleaning and washoff events during the spring and summer. Yields of $P$ increase in autumn during leaf-fall season and maximum yields of $\mathrm{P}$ were measured on streets in both land-use areas at this time (fig. 15, table 10); however, median yields of $\mathrm{P}$ were highest at the EOW in March 2011 (fig. 15).

\section{Accumulation Rate Estimates of Organic Carbon and Elements}

Accumulation rate estimates were calculated for concentrations of organic carbon, total $\mathrm{P}$, and 31 elements by first normalizing by mass to determine the load of constituents in grams. The resulting mass was then used to determine the yield of each constituent in lbs/curb-mi using the process described in the "Street-Solid Mass" section. Resulting yields were divided by the total number of days between sampling events to further obtain estimates of constituent accumulation rates in lbs/curb-mi/day. Average, median, maximum, and minimum accumulation rates for each constituent in streetsolid samples were estimated for each grain-size fraction by land-use type (table 11, in back of report). Sample concentrations from commercial streets do not include Mount Auburn Street data. Median concentrations of organic carbon and element accumulation rates for the multifamily land-use type are greater than those observed on commercial land-use streets for 24 of the 33 constituents for the coarse and fine fractions, and for 14 of the 33 constituents for the medium fraction. Median accumulation rates from coarse to fine in samples from the multifamily land-use type were greater than those from streets in the commercial land use for 31,24 , and 16 of the 33 constituents, respectively (table 9 , in back of report).

Accumulation rates of most constituents were generally smallest within the coarse grain-size fraction, except for yields of organic carbon. The largest accumulation rates for most constituents appear to vary between the medium and fine grain-size fractions (table 10). Accumulation rates from streets in multifamily land-use areas were generally greater than streets in commercial land-use areas. In particular, the median accumulation rates of $\mathrm{Cr}, \mathrm{Cu}, \mathrm{P}$ and $\mathrm{Pb}$ in total solids from streets in multifamily areas were about 1.9, 1.4, 5.0, and 12.7 times greater than those from streets in commercial areas, respectively; however, median accumulation rates of $\mathrm{Cd}, \mathrm{Ni}$, and $\mathrm{Zn}$ from streets in commercial areas were greater than the those from multifamily streets by about 2.0, 1.9, and 1.5 times, respectively. Kaufman and others (2011) also reported high concentrations of metals including $\mathrm{Pb}$ in residential as compared to commercial land-use types in urban areas.

The median accumulation rate estimated for organic carbon for all grain-size fractions from multifamily streets was $1.4 \mathrm{lbs} /$ curb-mi/day and ranged between about -10 to $17 \mathrm{lbs} /$ curb-mi/day. The median accumulation rate and range for organic carbon for all grain-size fractions in commercial data was $0.067 \mathrm{lbs} /$ curb-mi/day, and ranged between about -12 to $4 \mathrm{lbs} /$ curb-mi/day. Accumulation rates of organic carbon were highest within the medium grain-size fraction, followed by the coarse grain-size fraction for both land-use types reflecting the dominant effect of larger organic debris within the coarser fractions.

The median total $\mathrm{P}$ accumulation rate for total solids in multifamily data was $0.002 \mathrm{lbs} / \mathrm{curb}-\mathrm{mi} /$ day and ranged between about -0.017 and $2.36 \mathrm{lbs} / \mathrm{curb}-\mathrm{mi} / \mathrm{day}$. Accumulation rates of $\mathrm{P}$ increased from coarse to fine grain-size fractions. From coarse to fine, multifamily median accumulation rates of $\mathrm{P}$ are about $0.001,0.004$, and $0.010 \mathrm{lbs} /$ curb-mi/day, respectively. The median accumulation rate for total $\mathrm{P}$ for total solids in commercial data was $0.0004 \mathrm{lbs} /$ curb-mi/day, or about 5 times less than the multifamily accumulation rate, and ranged between about -0.003 to $0.030 \mathrm{lbs} / \mathrm{curb}-\mathrm{mi} /$ day. Median commercial accumulation rates of total $\mathrm{P}$ in the coarse to fine grain-size fractions are about $0.0001,0.004$, and $0.0001 \mathrm{lbs} /$ curb-mi/day, respectively. Although the accumulation rate of total $\mathrm{P}$ for the medium size fraction was nearly the same on streets in both land-use types, the accumulation rate on multifamily streets in the coarse and fine size fractions were about 11 and 82 times greater than those on commercial streets.

\section{Washoff Estimates of Organic Carbon and Elements}

The amount of washoff for each constituent was determined by multiplying the element concentrations by their respective mass of each grain-size fraction from the six composite sample pairs. Table 12 (in back of report) shows the average, median, maximum, and minimum percent washoff of organic carbon and 32 elements for each grain-size fraction within the multifamily and commercial land-use types. Median percent washoff for organic carbon and elements on streets in multifamily land-use areas was greater than those on commercial land-use streets for 24 of the 33 constituents in the coarse and fine grain-size fractions, and for 14 of the 33 constituents in the medium grain-size fraction. Negative washoff was observed for several rainstorms in all grain-size fractions, but was most common in the coarse and fine grain-size fractions. These rainstorms likely are associated with organic debris and "washon" from other source areas onto the streets.

Median total washoff for total P on streets in multifamily areas was 58 percent and ranged between about $-1,120$ to 93 percent. Median percent washoff of total $\mathrm{P}$ from streets in multifamily areas was about 39 percent for the two coarser fractions greater than $0.125 \mathrm{~mm}$, and about 76 percent for the fine grain-size fraction. Median washoff of total $\mathrm{P}$ from streets in commercial areas was about 48 percent and ranged between about -214 to 99 percent. Median washoff of P from coarse to fine grain-size fractions are about 34,51 , and 77 percent, respectively. 

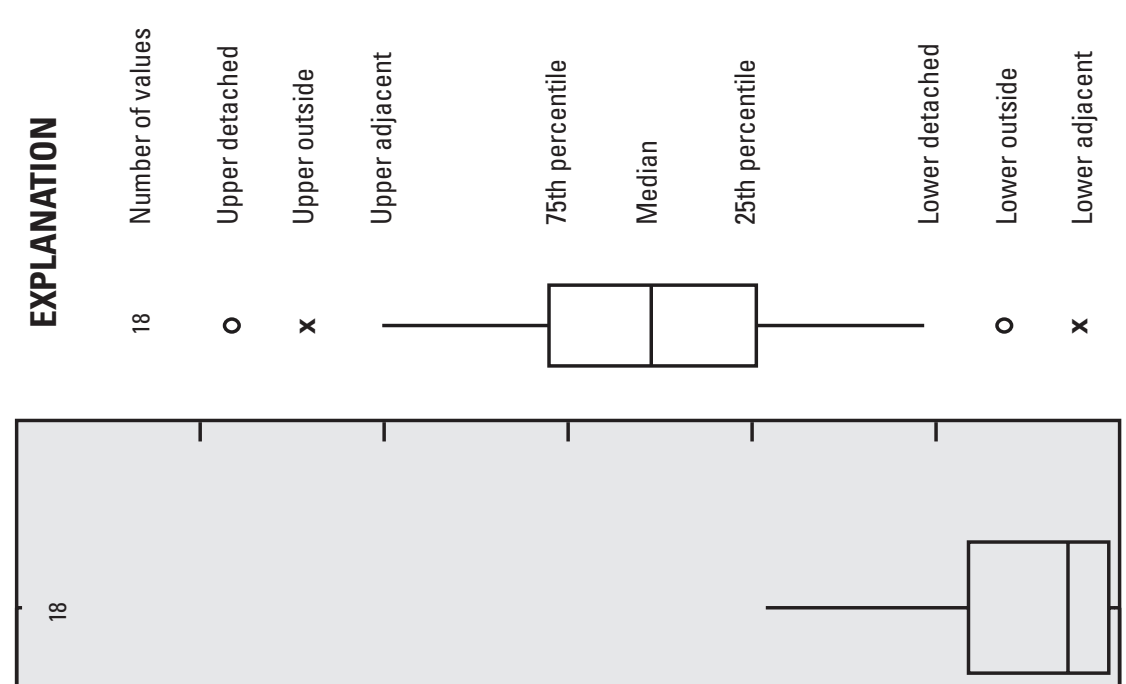

3

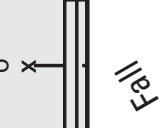

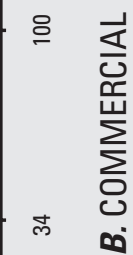

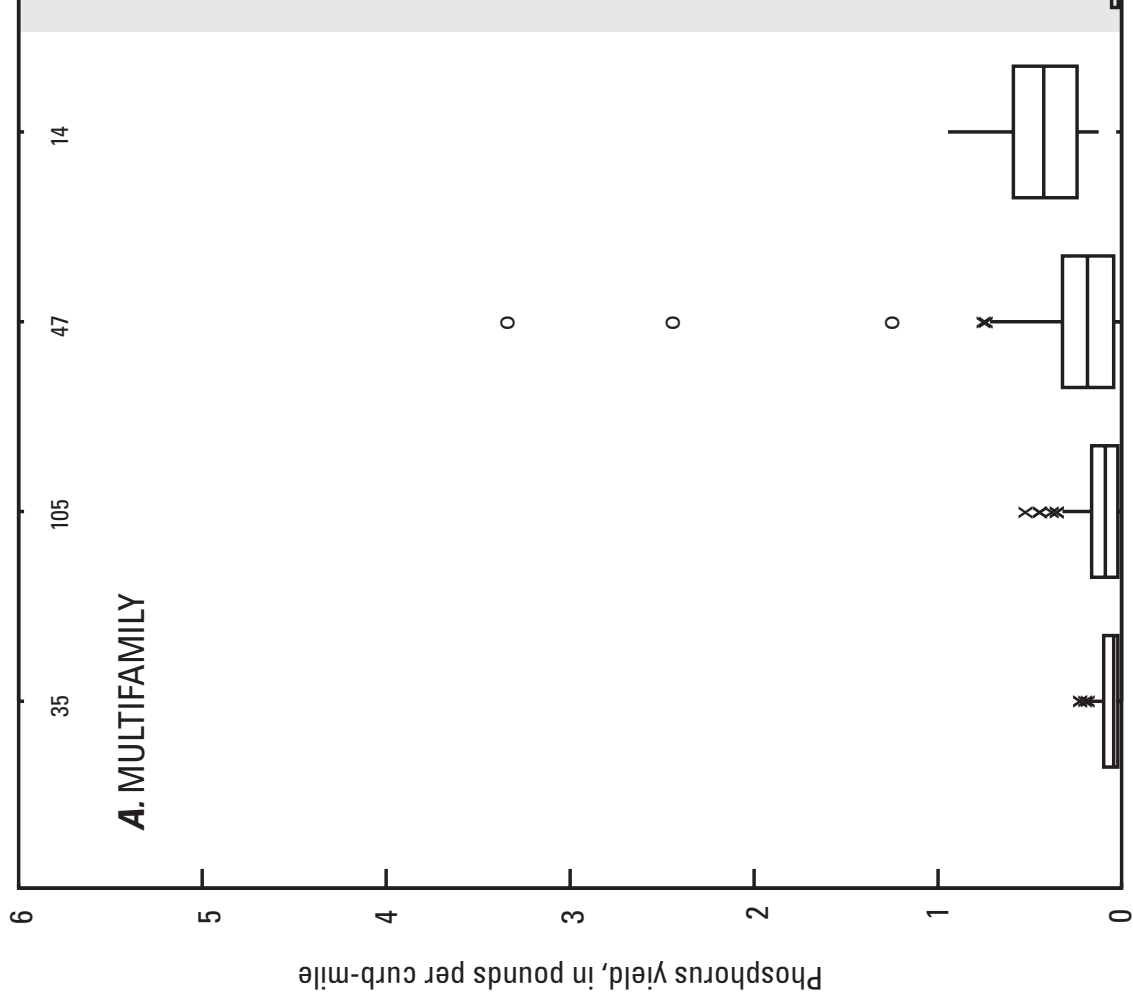

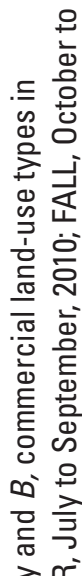

츨

些引

ह

丈음

竞导

.

흥 욱 $\frac{0}{2} \sum^{\pi}$

言

Ф)

竞

힝. 물

要

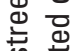

E 巳

焉

동

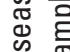

文究

बi

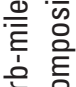

竞

㐫

空

힌

응

.$\subseteq$ 은

ง ำ

.

is 1

홀

은

옹르

음 흥 흠

퓸

年

노 흉 힝

인 틍

+ 
Table 10. Street-solid composite sample collection dates, sample type, antecedent rain conditions, sampled storm volume, street-solid yield, and total phosphorus yields from streets in Cambridge, Massachusetts.

[Street-solid yields from single-side (SS) sample composites are estimated; in, inches; lb/curb-mi, pounds per curb-mile; P, phosphorus; SS, single side; CTC, curb-to-curb; --, no data]

\begin{tabular}{|c|c|c|c|c|c|c|c|c|c|}
\hline \multirow[b]{2}{*}{$\begin{array}{c}\text { Sample } \\
\text { date }\end{array}$} & \multirow[b]{2}{*}{$\begin{array}{c}\text { Sample } \\
\text { type }\end{array}$} & \multirow{2}{*}{$\begin{array}{l}\text { 24-hour } \\
\text { precipita- } \\
\text { tion depth } \\
\quad \text { (in) }\end{array}$} & \multirow{2}{*}{$\begin{array}{l}\text { 48-hour } \\
\text { precipita- } \\
\text { tion depth } \\
\text { (in) }\end{array}$} & \multirow{2}{*}{$\begin{array}{l}\text { 72-hour } \\
\text { precipita- } \\
\text { tion depth } \\
\text { (in) }\end{array}$} & \multirow[b]{2}{*}{$\begin{array}{c}\text { Sampled } \\
\text { storm depth } \\
\text { (in) }\end{array}$} & \multirow{2}{*}{$\begin{array}{c}\text { Multifamily } \\
\begin{array}{c}\text { Street-solid } \\
\text { yield }\end{array} \\
\text { (lb/curb-mi) }\end{array}$} & \multirow{2}{*}{$\begin{array}{c}\text { Commercial } \\
\begin{array}{c}\text { Street-solid } \\
\text { yield }\end{array} \\
\text { (lb/curb-mi) }\end{array}$} & \multirow{2}{*}{$\begin{array}{l}\text { Multifamily } \\
\text { Total P yield } \\
\text { (lb/curb-mi) }\end{array}$} & \multirow{2}{*}{$\begin{array}{l}\text { Commercial } \\
\text { Total P yield } \\
\text { (Ib/curb-mi) }\end{array}$} \\
\hline & & & & & & & & & \\
\hline $05 / 11 / 10$ & $\mathrm{SS}$ & 0.00 & 0.00 & 0.00 & 0.00 & $1,077.6$ & -- & -- & -- \\
\hline $05 / 12 / 10$ & SS & 0.00 & 0.00 & 0.00 & 0.00 & 286.2 & -- & -- & -- \\
\hline $05 / 13 / 10$ & SS & 0.00 & 0.00 & 0.00 & 0.00 & -- & 529.9 & -- & -- \\
\hline $05 / 14 / 10$ & SS & 0.45 & 0.00 & 0.00 & 0.00 & -- & 198.2 & -- & -- \\
\hline $05 / 18 / 10$ & CTC & 0.00 & 0.00 & 0.00 & 0.00 & 476.1 & 388.8 & -- & -- \\
\hline 05/19/10 & CTC & 1.48 & 0.00 & 0.00 & 1.54 & 233.0 & 198.6 & -- & -- \\
\hline 06/08/10 & SS & 0.00 & 0.00 & 1.38 & 0.00 & 630.2 & -- & -- & -- \\
\hline 06/09/10 & SS & 0.05 & 0.00 & 0.00 & 0.00 & 220.0 & -- & -- & -- \\
\hline $06 / 11 / 10$ & SS & 0.00 & 0.13 & 0.05 & 0.00 & -- & 529.2 & -- & -- \\
\hline $06 / 12 / 10$ & SS & 0.33 & 0.00 & 0.13 & 0.00 & -- & 162.1 & -- & -- \\
\hline $06 / 24 / 10$ & CTC & 0.21 & 0.11 & 0.00 & 0.00 & 504.4 & 466.2 & 0.28 & 0.14 \\
\hline $06 / 24 / 10$ & CTC & 0.21 & 0.11 & 0.00 & 0.32 & 298.8 & 306.1 & 0.21 & 0.12 \\
\hline 07/07/10 & CTC & 0.00 & 0.00 & 0.00 & 0.00 & 819.7 & 565.3 & 0.57 & 0.21 \\
\hline 07/08/10 & SS & 0.00 & 0.00 & 0.00 & 0.00 & -- & 553.0 & -- & -- \\
\hline 07/09/10 & SS & 0.00 & 0.00 & 0.00 & 0.00 & -- & 182.2 & -- & -- \\
\hline 07/13/10 & SS & 0.14 & 0.01 & 0.05 & 0.00 & 568.4 & -- & -- & -- \\
\hline $07 / 14 / 10$ & SS & 0.01 & 0.05 & 0.14 & 0.00 & 179.3 & -- & -- & -- \\
\hline $07 / 28 / 10$ & CTC & 0.00 & 0.00 & 0.00 & 0.00 & 839.4 & 628.2 & 0.54 & 0.23 \\
\hline 07/29/10 & CTC & 0.05 & 0.00 & 0.00 & 0.05 & 637.3 & 419.2 & 0.37 & 0.12 \\
\hline 08/10/10 & SS & 0.06 & 0.00 & 0.00 & 0.00 & 760.1 & -- & -- & -- \\
\hline $08 / 11 / 10$ & SS & 0.00 & 0.06 & 0.00 & 0.00 & 185.0 & -- & -- & -- \\
\hline $08 / 12 / 10$ & SS & 0.00 & 0.00 & 0.06 & 0.00 & -- & 692.8 & -- & -- \\
\hline $08 / 13 / 10$ & SS & 0.00 & 0.00 & 0.00 & 0.00 & -- & 195.4 & -- & -- \\
\hline $08 / 26 / 10$ & CTC & 0.00 & 3.38 & 1.01 & 0.00 & 379.6 & 542.0 & 0.02 & 0.02 \\
\hline $08 / 27 / 10$ & CTC & 0.00 & 0.00 & 3.38 & 0.00 & 268.6 & 274.9 & 0.01 & 0.01 \\
\hline 08/30/10 & CTC & 0.00 & 0.00 & 2.39 & 0.00 & 613.1 & 664.7 & 0.03 & 0.03 \\
\hline 09/01/10 & CTC & 0.00 & 0.00 & 0.00 & 0.00 & 697.8 & 635.7 & 0.04 & 0.03 \\
\hline 09/03/10 & CTC & 0.00 & 0.00 & 0.00 & 0.00 & 752.7 & 937.5 & 0.47 & 0.37 \\
\hline $09 / 05 / 10$ & CTC & 0.00 & 0.54 & 0.00 & 0.54 & 747.6 & 720.3 & 0.46 & 0.30 \\
\hline 09/08/10 & SS & 0.48 & 0.00 & 0.00 & 0.00 & 410.2 & -- & -- & -- \\
\hline 09/09/10 & SS & 0.00 & 0.48 & 0.00 & 0.00 & 98.2 & 667.6 & -- & -- \\
\hline 09/10/10 & SS & 0.00 & 0.00 & 0.48 & 0.00 & -- & 160.6 & -- & -- \\
\hline $09 / 27 / 10$ & CTC & 0.12 & 0.00 & 0.00 & 0.00 & 618.9 & 356.3 & 0.49 & 0.19 \\
\hline 09/29/10 & CTC & 0.98 & 0.12 & 0.00 & 1.10 & 542.8 & 248.7 & 0.35 & 0.11 \\
\hline $10 / 02 / 10$ & CTC & 0.95 & 0.02 & 0.00 & 0.95 & 667.6 & 387.7 & 0.42 & 0.21 \\
\hline $10 / 08 / 10$ & SS & 0.00 & 0.00 & 1.66 & 0.00 & -- & 639.0 & -- & -- \\
\hline $10 / 09 / 10$ & SS & 0.00 & 0.00 & 0.00 & 0.00 & -- & 138.7 & -- & -- \\
\hline $10 / 12 / 10$ & SS & 0.06 & 0.00 & 0.00 & 0.00 & $1,264.9$ & -- & -- & -- \\
\hline $10 / 13 / 10$ & SS & 0.00 & 0.06 & 0.00 & 0.00 & 213.9 & -- & -- & -- \\
\hline $11 / 04 / 10$ & CTC & 1.07 & 0.00 & 0.00 & 0.00 & $2,433.6$ & $1,015.9$ & 2.96 & 2.39 \\
\hline $11 / 06 / 10$ & CTC & 0.00 & 0.64 & 1.07 & 0.00 & $1,445.4$ & 567.3 & 0.98 & 0.29 \\
\hline $11 / 16 / 10$ & CTC & 0.05 & 0.00 & 0.00 & 0.00 & 505.3 & 508.9 & 0.48 & 0.22 \\
\hline $11 / 18 / 10$ & CTC & 0.03 & 1.23 & 0.05 & 1.28 & 727.2 & 489.2 & 0.76 & 0.25 \\
\hline $11 / 30 / 10$ & CTC & 0.00 & 0.00 & 0.00 & 0.00 & 871.3 & 716.1 & 0.92 & 0.32 \\
\hline $12 / 02 / 10$ & CTC & 0.57 & 0.00 & 0.00 & 0.57 & 666.6 & 289.1 & 0.53 & 0.10 \\
\hline $12 / 08 / 10$ & SS & 0.00 & 0.00 & 0.00 & 0.00 & 808.6 & 652.2 & -- & -- \\
\hline $12 / 09 / 10$ & SS & 0.00 & 0.00 & 0.00 & 0.00 & 127.7 & 146.8 & -- & -- \\
\hline $03 / 04 / 11$ & CTC & 0.00 & 0.00 & 0.00 & 0.00 & $2,588.1$ & $4,310.1$ & 1.24 & 1.24 \\
\hline 03/08/11 & CTC & 0.00 & 0.71 & 0.00 & 0.71 & $2,639.4$ & $5,266.7$ & 1.52 & 1.61 \\
\hline
\end{tabular}




\section{Estimates of Regenerative-Air Street Cleaner Removal of Organic Carbon and Elements}

Percent reductions of constituent load on streets, as a result of a single pass from the RA street cleaner, were estimated by using the median values of each constituent measured in 48 to 72 pre- and post-RA street cleaner composite samples of street solids formulated to represent the constituent mass for spring, summer, and fall street-solids (table 9, in back of report). The median percent reduction in total yields and three grain-size fractions for organic carbon and 32 elements from seasonal samples of pre- and poststreet cleaner operation composite samples for multifamily and commercial, respectively, is shown in table 13 (in back of report). Percent reductions generally decrease with decreasing grain size, with slightly less removal of constituent mass during the spring and summer months. This likely is a reflection of lower street-solid yields available for removal during the summer compared to the larger EOW cleanup and autumn leaf-fall yields. Percent reductions for total samples are greater on multifamily streets in all seasons for all or nearly all constituents. Percent reductions from multifamily streets were greater than those on commercial streets in all seasons for nearly all constituents in coarse and medium grainsize fractions with the exception of the coarse size fraction in the spring and the medium size fraction in the fall where about one-half of constituent reductions are greater on commercial streets. Nearly all constituent reductions are greater on commercial streets in the fine grain-size fraction for summer and fall composites, and for about two-thirds of constituents in the spring fine fraction. Negative values indicate an increase in the mass of a constituent following street cleaner use, and are seen almost entirely in the less than $0.125 \mathrm{~mm}$ grain-size fraction from multifamily streets in the fall composite results (table 13, in back of report). Net increases within the fine grain-size fraction are seen for tin $(\mathrm{Sn}), \mathrm{Pb}, \mathrm{Ni}, \mathrm{Cu}$, chromium $(\mathrm{Cr})$ and arsenic (As). The range of reductions on multifamily streets for all constituents is between 50 and 98 percent during the spring, -37 and 100 percent for the summer, and $-1,050$ and 99 percent for the fall. Commercial street reductions indicated one negative value for cobalt $(\mathrm{Co})$ within the coarse grain-size fraction for the spring. Spring, summer, and fall reductions of all constituents ranged between -8 to 98,14 to 99 , and 60 to 99 percent, respectively.

Median total P reductions for total samples were 82 and 62 percent on streets in multifamily and commercial land-use types, respectively. Percent reductions generally increased with increasing grain size for both land-use types. Multifamily street reductions from coarse to fine were about 94,86 , and 64 percent in spring composites, 100, 99, and 97 percent in summer composites, and 96, 93, and 66 percent in fall composites. Reductions of total $\mathrm{P}$ on commercial streets from coarse to fine grain-size fractions were 96,73 , and 63 percent, respectively, in the spring, and 99, 97, and 98 and 97, 89, and 79 percent, respectively, in summer and fall. Total-recoverable concentrations for pre- and post-street cleaner seasonal composite samples for streets in both multifamily and commercial land-use types are seen in appendix tables 1-19 and $1-20$, respectively (on CD-ROM at back of report).

\section{Potential Reductions of Street Solids and Phosphorus Achievable by Street Cleaning}

Potential reductions in $\mathrm{P}$ associated with various street cleaning practices were simulated for a predominantly commercial land-use subcatchment in Cambridge, Mass., that ultimately drains to the lower Charles River. Street-solid data collected as part of this study and geographic information provided by the city of Cambridge and other sources were used to develop the model specifically for the study area. Street-solid washoff and total P concentration data collected as part of this study were not used in the model.

The Source Loading and Management Model for Microsoft Windows (WinSLAMM, referred to as SLAMM) version 9.4.0 (Pitt and Voorhees, 2002) is capable of continuously simulating stormwater runoff volume, loads of suspended sediments and other constituents, and the effects of stormwater-control measures. SLAMM has been successfully used to evaluate the performance of many types of stormwater control measures, including street cleaning, in locations across the United States and Canada. A more complete description of SLAMM and the input data used for the following simulations are in appendix 1 (included in accompanying CD-ROM).

Version 9.4.0 of SLAMM does have several limitations, including the inability to simulate base flow or snowmelt conditions, evaluate in-stream processes that affect constituent mass, or model erosion from pervious areas and construction sites. The model also uses simplified drainage system routing compared to the detailed water routing through certain stormwater control measures such as grass swales or detention ponds, and it cannot currently (ver 9.4.0) simulate rural areas effectively or run design storm analyses. The model has limited particle size information representing leaf matter and other organic debris and model runs appeared insensitive to seasonal effects such as leaf-fall.

\section{Description of Commercial Land-Use Subcatchment}

The subcatchment representing mostly commercial land use was selected for this study because of the existing level, flow, and constituent loading data at its outfall that was available from previous USGS studies (Breault and others, 2002; Zarriello and others, 2002) and is shown in figure 16. In addition, street-solid data were collected from streets in and around this subcatchment (fig. 2). Massachusetts Avenue and Mount Auburn Street are the two major routes that cross the basin, 
231,700 231,800 231,900 232,000 232,100 232,200

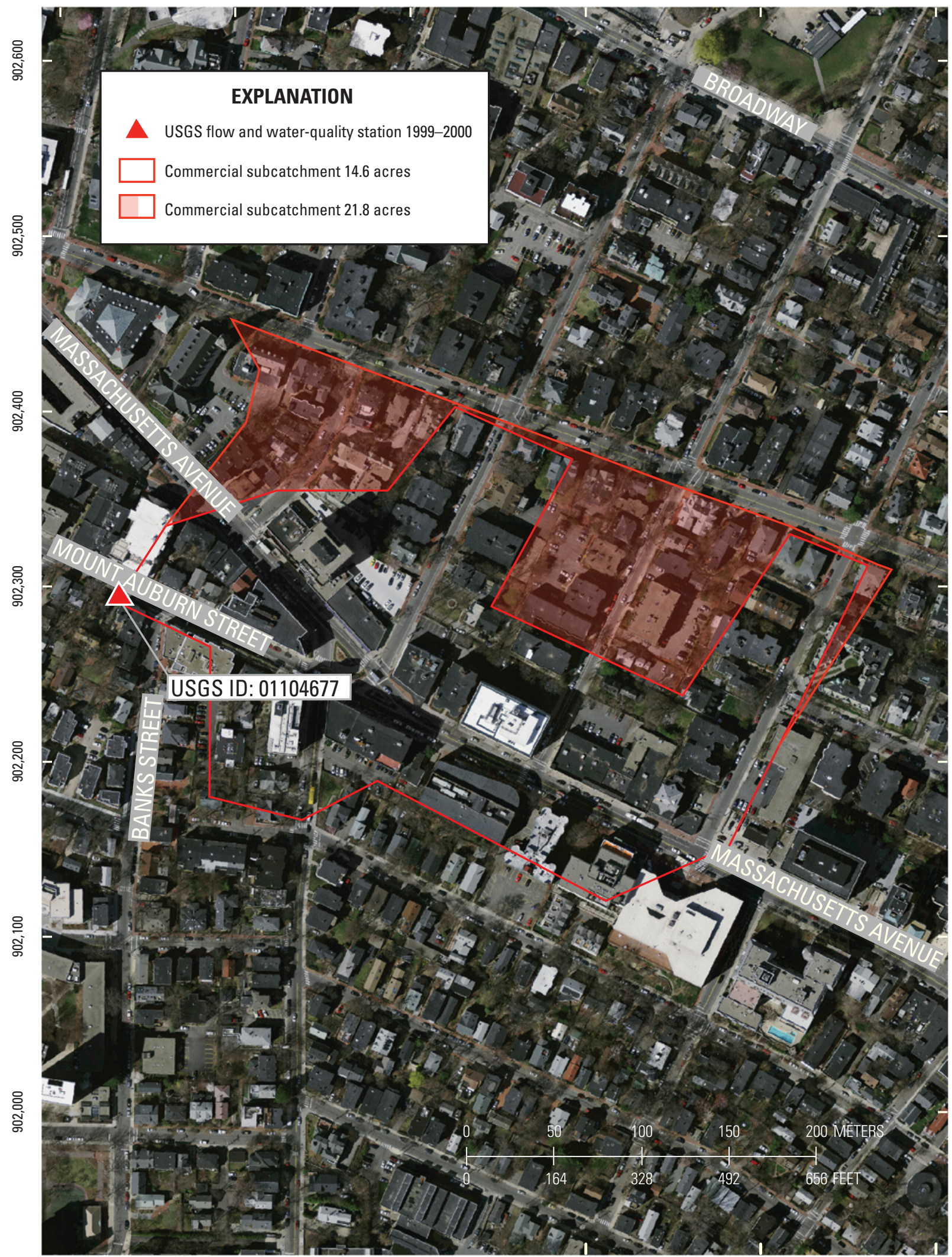

Northings and eastings in state plane meters. Basemap source, Mass GIS

Figure 16. Predominantly commercial land-use subcatchment in Cambridge, Massachusetts, and U.S. Geological Survey flow and water-quality monitoring station (USGS ID: 01104677), over a 0.5-meter color orthophoto obtained from MassGIS. 
and 24-hour traffic counts from 2002 were 11,670 and 9,860, respectively (city of Cambridge, written commun., 2009). Areas of Massachusetts Avenue are swept daily and weekly. The southern side of Mount Auburn Street has a dedicated bicycle lane that is typically swept weekly, while the northern side is swept monthly following the schedule for Streetcleaning district $\mathrm{E}$ (fig. 2). The street-cleaning schedule for both sides of Mount Auburn Street was changed to monthly between May and December 2010.

The outfall monitoring location for the commercial landuse station (USGS ID: 01104677) was a 3-ft diameter concrete storm drain located on Mount Auburn Street near Banks Street representing about 77 percent commercial land use and about 24 percent multifamily land use (fig. 16). During 1999 and 2000, 14 dry- and 10 wet-weather sample events were collected from the 14.6 acre $\left(0.023 \mathrm{mi}^{2}\right)$ subbasin (Breault and others, 2002); however, other areas may have contributed additional runoff to the monitoring location during some storm events and the resulting total area increased to 21.8 acres (Zarriello and Barlow, 2002). Zarriello and Barlow (2002) also determined the commercial subbasin contained about 86 percent effective impervious area (EIA). Multifamily and institutional land-use types also are present in the 21.8 acre subcatchment; however, the model treats commercial and institutional land-uses similarly, therefore the effective commercial land-use area is about 64 percent (appendix 2, table 2-1).

Several limitations need to be considered when using the previous data: (1) level and velocity records from the site were incomplete, and estimation techniques were needed to fill these data gaps (Zarriello and Barlow, 2002); (2) Zarriello and Barlow (2002) used the limited level and discharge data from the commercial subbasins to develop rainfall-runoff relations from low-intensity storms with rainfall-runoff coefficients less than 1.0; (3) water-quality samples were collected in a flow proportional manner from a fixed location pointing downstream on the bottom of the drainage pipe. Under these conditions sand-sized particles (greater than $0.063 \mathrm{~mm}$ ) generally form a vertical gradient (Smith, 2002; Bent and others, 2000), and sampling in this manner potentially resulted in a large positive bias in total suspended-sediment concentrations and other constituents associated with high concentrations of coarse-grained sediment concentrations, such as $\mathrm{P}$, also were potentially affected by the vertical gradient formed within the water column at the time of sampling.

\section{Source Loading and Management Model}

The general order of calibration begins with runoff, followed by particulate solids, and then constituents. Initial SLAMM simulations were evaluated using the special *.RAN file to guide modifications to the *.RSV file to match existing runoff data from 2000 (appendix 2, table 2-2). Only after acceptable agreement between simulated and observed runoff was achieved, were evaluations of simulated and observed street-solid yields from 2009-2011 possible.

\section{Relative Contributions of Source Areas}

The special *.RAN file based on 62 years of precipitation record at Boston Logan Airport (COOP ID: 190770, appendix 2, table 2-2) yielded relative runoff contribution data seen graphically as cumulative columns for each of the three landuse types in the subcatchment in figure 17A-C. Multifamily (fig. 17A) runoff is dominated by roof source areas, which contribute about 35 to 55 percent of the total runoff for this land-use type. Paved parking areas represent the next largest fraction of runoff ( 25 to 30 percent), followed by streets (20 to 15 percent), sidewalks and walkways (about 15 percent), and landscaped areas (about 7 percent). Landscaped areas, and to a much lesser extent, roof runoff disconnected from the drainage system (draining onto about $20 \mathrm{ft}$ or more of pervious area), contribute small amounts of runoff during small storms, but contribute substantially more runoff when storms are greater than 1 inch.

The relative contribution of institutional land-use runoff (fig. 17B), although treated in the same manner as commercial land use by the model, has a runoff distribution similar to multifamily land use; however, the overall contribution of paved parking areas is greater and they are the dominant runoff source area for storm less than 0.3 inches. Walkways and landscaped areas contribute less to institutional runoff as compared to runoff in multifamily land use. Disconnected roof runoff is also much lower compared to runoff from multifamily land use.

The commercial land-use percent contribution is seen in figure 17C. Rooftops contributed between about 23 to 48 percent, street surfaces and paved parking areas contribute similar amounts of runoff, but both source areas contribute greater volumes in storms less than 0.3 inches. Walkway percent contribution was similar to that in multifamily land use. Commercial land use contained only a small amount of landscaped area and such pervious surfaces do not appear to contribute any runoff. Disconnected rooftops also are not a contributor of runoff.

Available runoff data were collected for storm depths between 0.25 and $2.0 \mathrm{in}$., and model runoff estimates outside of this range are associated with greater uncertainty. Modifications to runoff coefficients were, therefore, based only on simulation results between these precipitation depths. Modifications were made in a stepwise manner beginning with runoff coefficients from source areas with the greatest relative contribution and ending with those areas contributing the least.

\section{Model Output Compared to 1999-2000 Runoff and Water-Quality Data}

The 13 runoff observations from 2000 were first evaluated to determine the quality of the data for comparisons with simulated runoff. Plots of rainfall depth as compared to runoff depth and runoff coefficient as compared to rainfall depth, respectively, are shown in figures $18 \mathrm{~A}$ and B. Although 

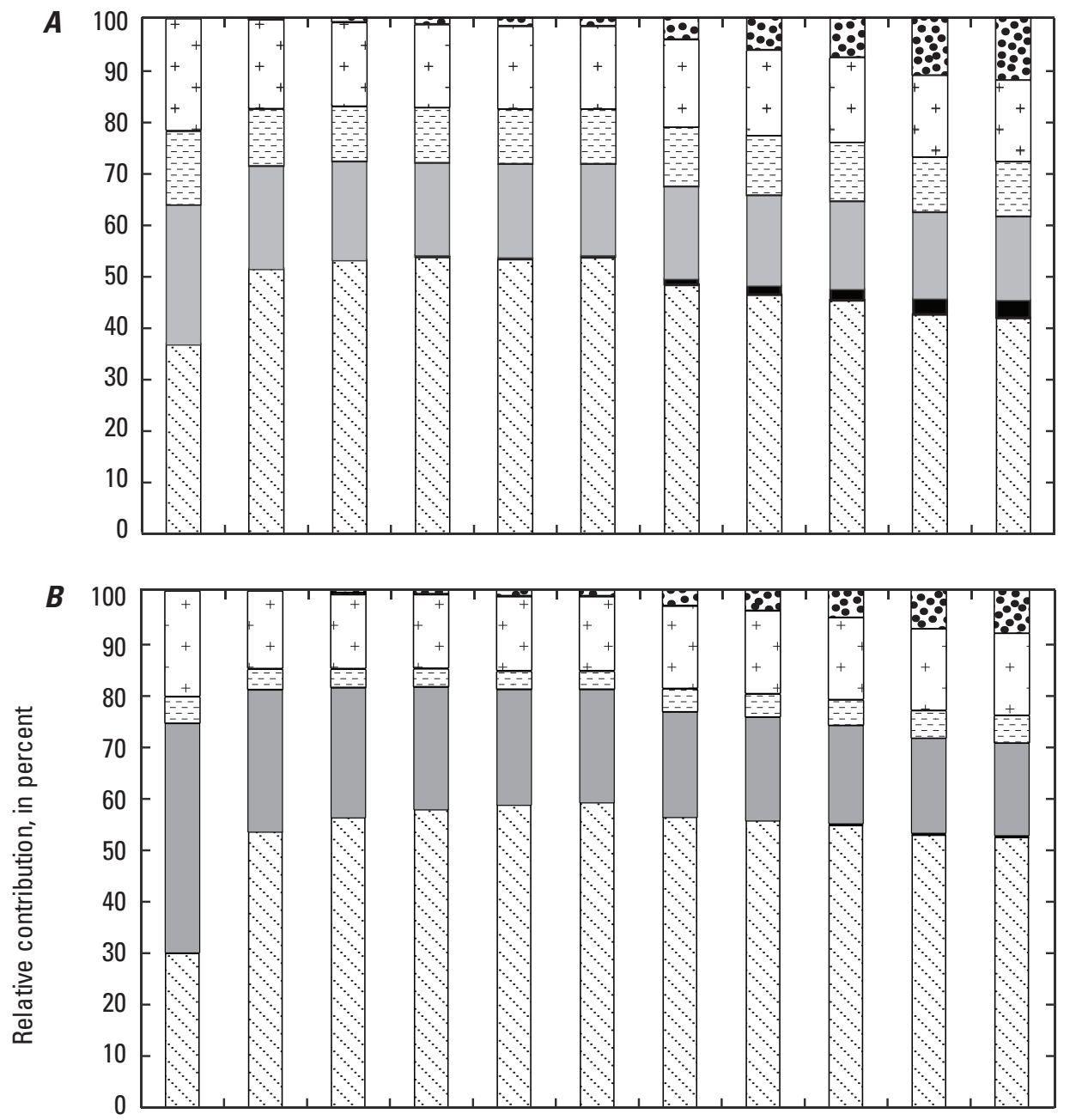

EXPLANATION

: Landscaped areas

+ Streets

Walkways

$\square$ Paved parking

Disconnected roofs

Connected roofs

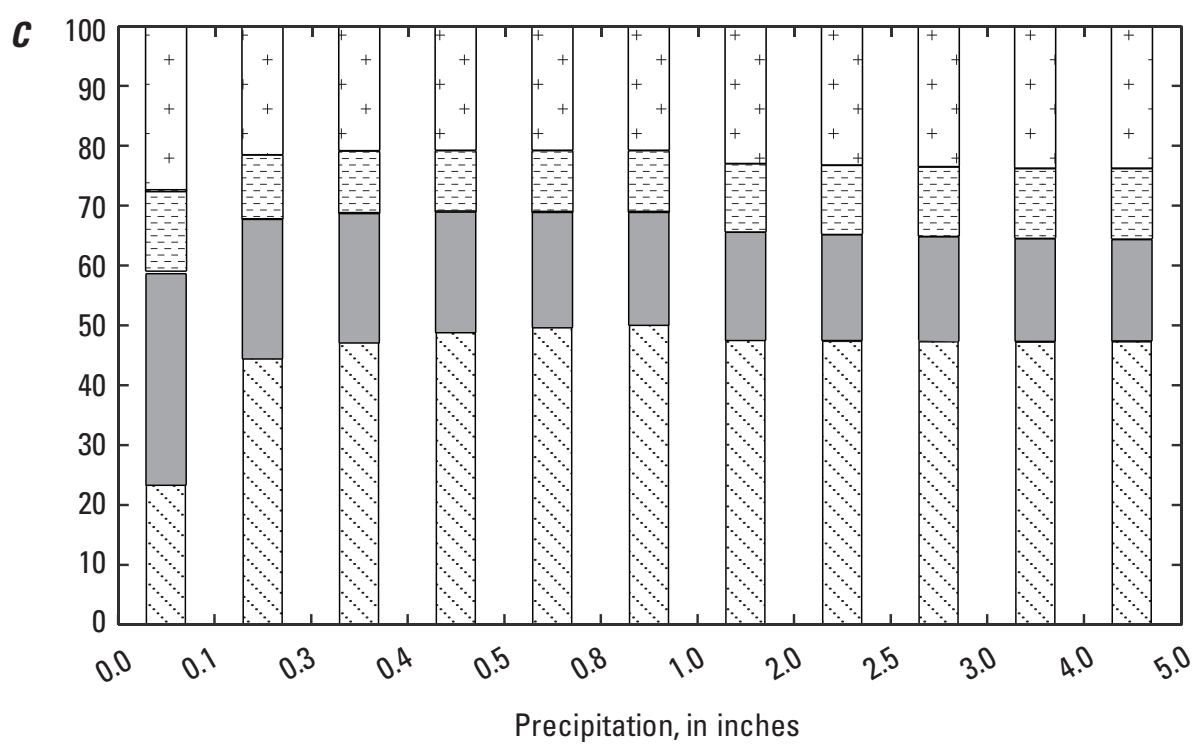

Figure 17. Cumulative relative percent contributions of major source areas within the $A$, multifamily, $B$, institutional, and $C$, commercial land-use types contained in the modeled commercial subcatchment, Cambridge, Massachusetts. 

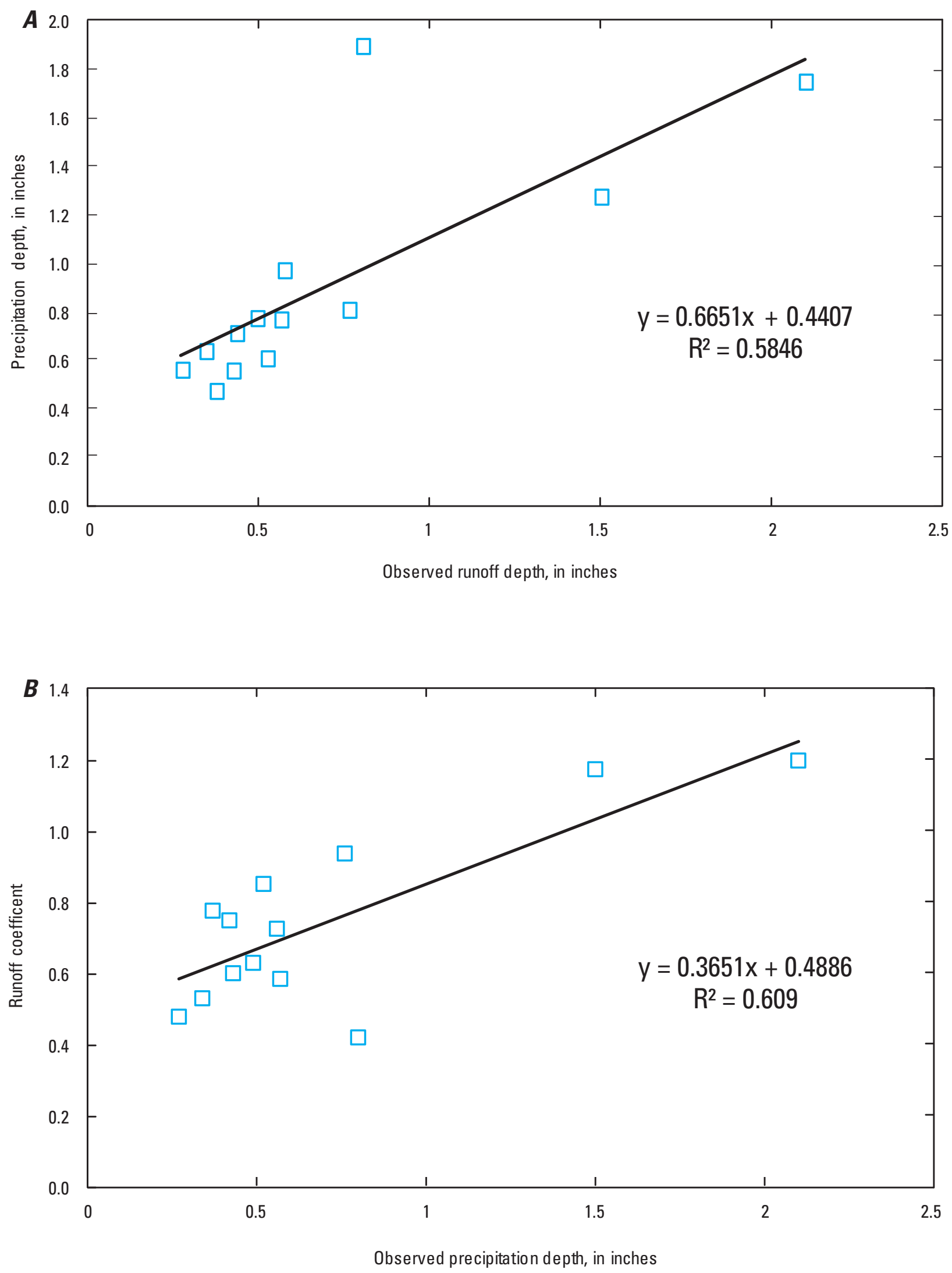

Figure 18. Plots of $A$, rainfall depth as compared to runoff depth, and $B$, runoff coefficient as compared to rainfall depth from commercial subcatchment observations, March to December 2000, Cambridge, Massachusetts (USGS ID: 01104677). 
there is some scatter, the general trend appears reasonable for mostly directly connected areas associated with the subcatchment.

Initial SLAMM simulations were run using the parameter files provided with SLAMM and 10 years of Boston Logan Airport data, and resulted in a mean runoff depth percent error between simulated and observed runoff of about 33 percent and the sum of the percent differences was about 28 percent. Following examination of the relative contribution plots seen in figure 17 , the selected *.RSV file was modified in a stepwise manner until an acceptable agreement was obtained between simulated runoff and the 13 observations from 1999-2000.

The observed runoff as compared to simulated runoff of commercial subcatchment is shown in figure 19. Despite the scatter about the 1:1 line, the mean runoff depth percent error improved to about -11 percent and the sum of the percent differences was -2.31 percent. The comparison of simulated runoff data to observed runoff data is shown in figure 20 .

Initial simulations of particulate solid concentrations and loads resulted in mean percent error between simulated and measured total suspended solids (TSS) of about -43 and -140 percent, respectively. Simulations using the modified *.RSV file resulted in a minor improvement in particulate solid concentrations to about -40 percent and further decreased in particulate solids loads to about -163 percent. Because of the potential high bias in the measured TSS values, and the high number and quality of the particulate solids concentration data contained in the WI_AVG01.PSC (Roger Bannerman, Wisconsin Department of Natural Resources, oral commun., 2011), there was little support for modifications to the *.PSC file to further improve the particulate solid simulation results.

In terms of particulate $\mathrm{P}$, the initial model resulted in mean percent error between simulated and observed particulate P loads of about 54 percent. Simulations using the modified *.RSV file resulted in an improved mean percent error between simulated and observed particulate P loads of about 16 percent.

\section{Model Output Compared to 2009-2011 Street- Solid Yield Data}

The base model equipped with the modified *.RSV file was run using 3 years of precipitation data from the Cambridge DPW and the USGS to match street-solid sampling between August 2009 to March 2011. Resulting simulated street-solid output data were compared to streetsolid observations as a form of verification of model performance. Productivity function coefficients $\mathrm{M}=0.07$ and $\mathrm{B}=70$ corresponding to the RA street cleaner were input and the model was run. A plot of simulated street-solid yields compared to observed street-solid yields for streets in areas characterized as multifamily and commercial land use with the 2010 data only is shown in figure 21. Average percent error between simulated and measured yields of street-solids for the multifamily land-use streets is about 22 percent, and for the commercial land-use streets is about -13 percent. The sum of the percent differences between simulated and measured was about -7 and 11 percent for multifamily and commercial streets, respectively. Removal of data collected in November during the highest periods of leaf-fall from both land-use types improved the mean percent error for multifamily and commercial streets to about 6.4 and 6.5 percent, respectively. However, the sum of the percent differences between simulated and observed street-solid loads for multifamily streets increased to about -19 percent, although commercial streets decreased to less than -2 percent. A time series plot of multifamily and commercial/institutional land use streetsolid yield simulations compared with their respective field observations is shown in figure 22. Gaps in simulated data correspond to street-solid sampling dates not simulated by the model. These plots show reasonable agreement between some simulated and observed points. However, the model under simulates the autumn period of leaf-fall, which is associated with some of largest street-solid loadings. Elevated street-solid loadings under simulated by the model during summer months are perhaps associated with construction track out, deposition of organic material, the highly variable nature of the street material, or some combination of these.

\section{Model Simulations}

The SLAMM model was used to estimate potential reductions of total solids and total $\mathrm{P}$ resulting from various street-cleaning technologies and frequencies. Mechanicalbrush and vacuum-assisted street cleaners were simulated using productivity function coefficients supplied with SLAMM. Simulations using a second "vacuum-assisted" street cleaner using productivity function coefficients developed from the removal efficiency experiments described in the Regenerative-Air Street Cleaner Removal Efficiency section represented the regenerative-air street cleaner.

\section{Street-Cleaning Program Performance}

The five average years *.RAN file was used to simulate mechanical-brush, vacuum-assist, and regenerative-air street cleaners at the following frequencies: monthly, bi-monthly, weekly, and 3 days per week. Mechanical-brush and vacuumassist productivity function coefficients were generated by SLAMM based on long-term, on-street parking conditions with parking controls specified. Mechanical-brush street cleaner productivity function coefficients were $\mathrm{M}=0.73$ and $\mathrm{B}=310$. Vacuum-assist coefficients were $\mathrm{M}=0.70$ and $B=41$. Coefficients for the RA street cleaner evaluated on Cambridge streets were the same as those used to match simulated street solids to observed street solids: $\mathrm{M}=0.07$ and $\mathrm{B}=70$. 


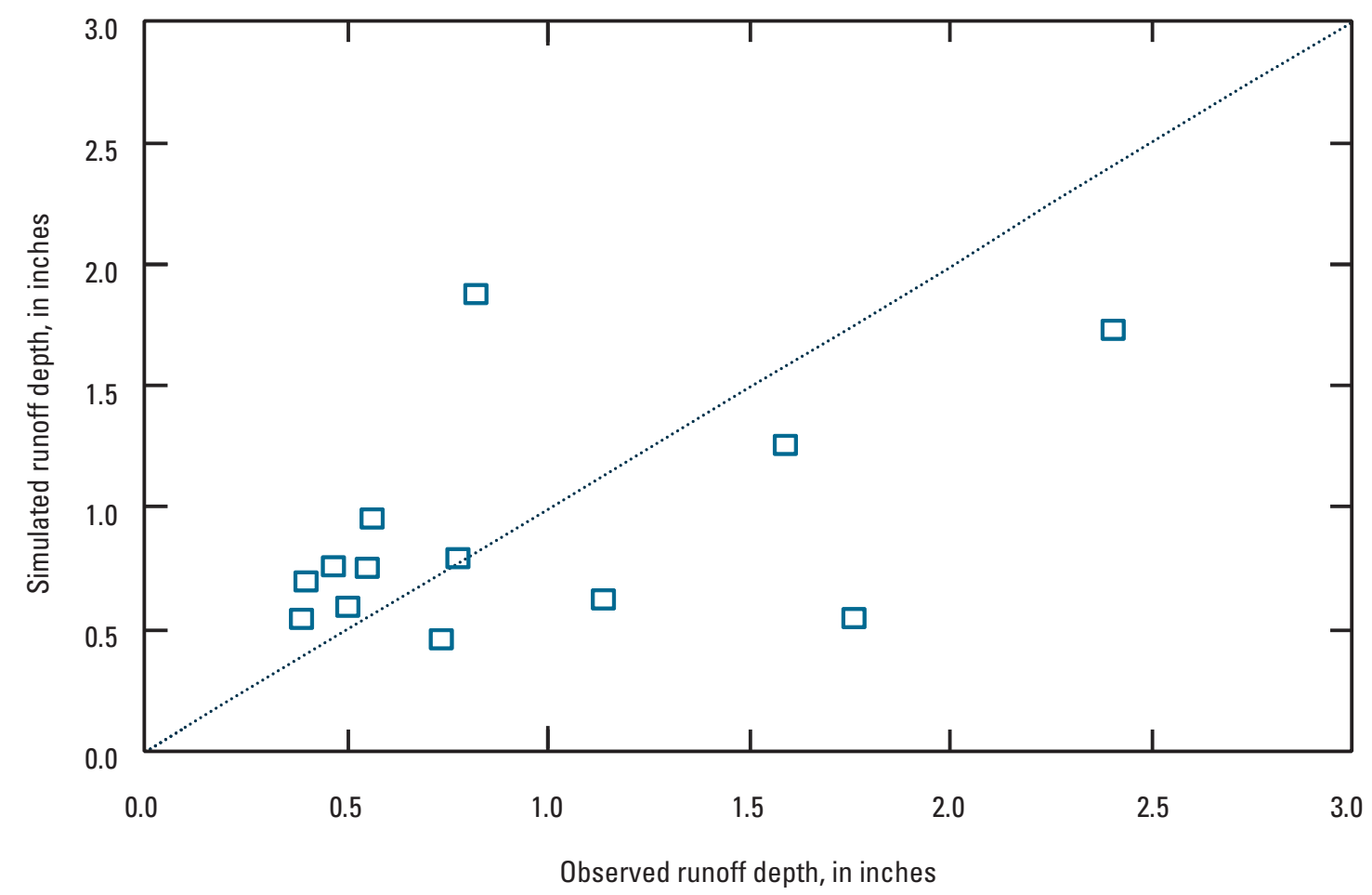

Figure 19. Simulated runoff depth as compared to observed runoff depth, March to December 2000, Cambridge, Massachusetts (USGS ID: 01104677).

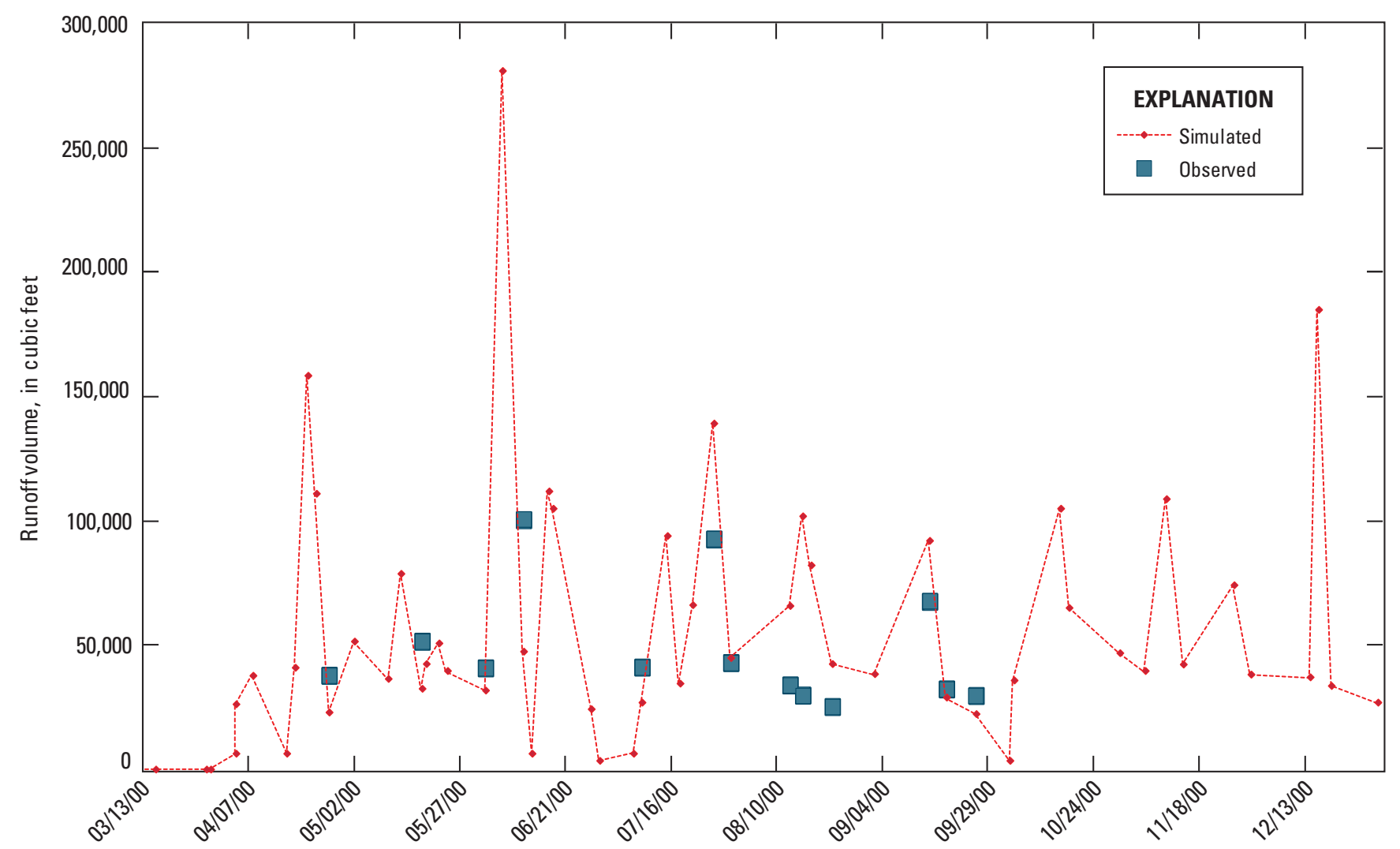

Figure 20. Time series of simulated outfall discharge from the commercial land-use subcatchment as compared to observed runoff volume, March to December 2000, Cambridge, Massachusetts (USGS ID: 01104677). 


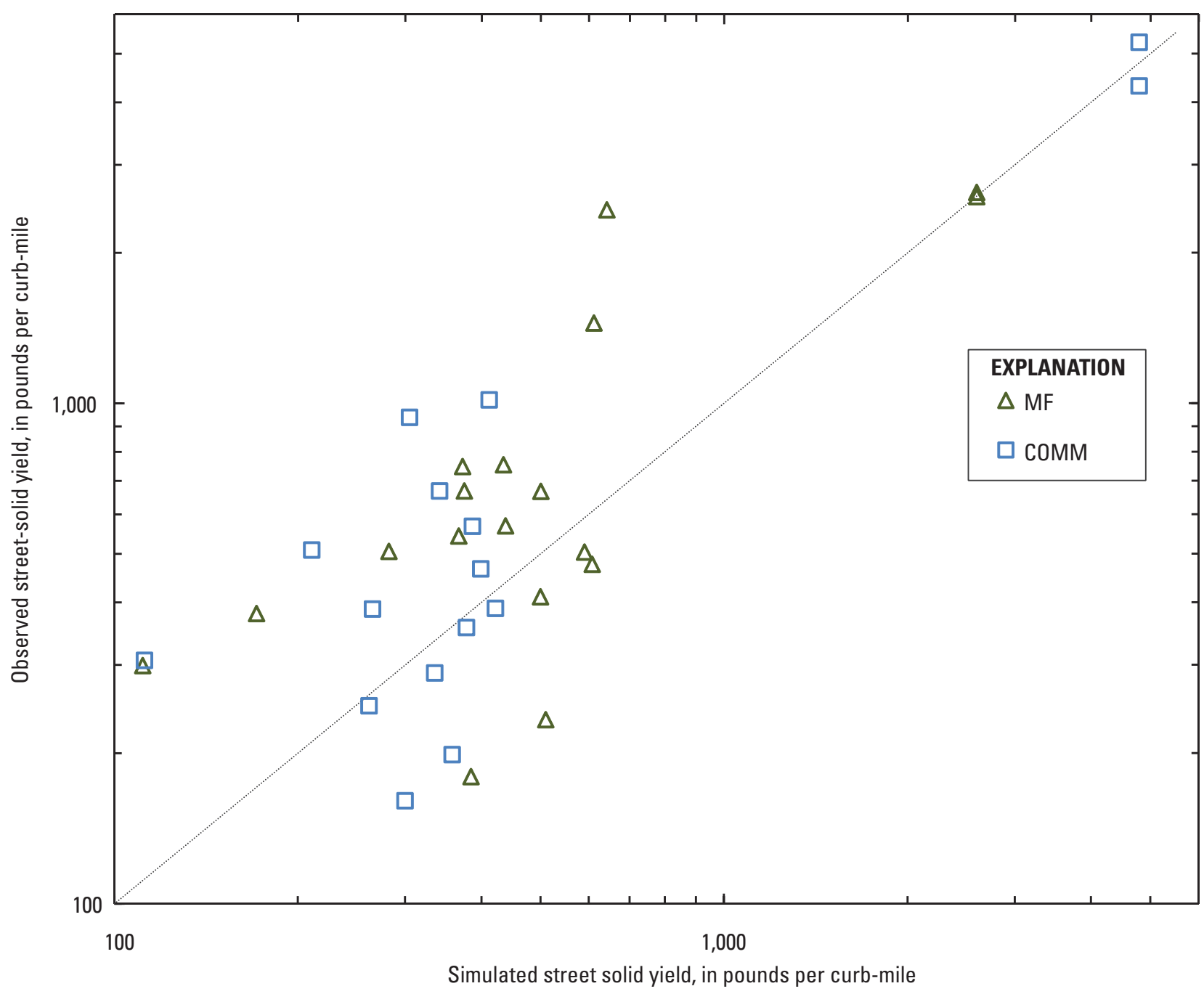

Figure 21. Simulated as compared to observed street-solid yields for multifamily (MF) and commercial (COMM) land-use areas, Cambridge, Massachusetts (2010 data only). 


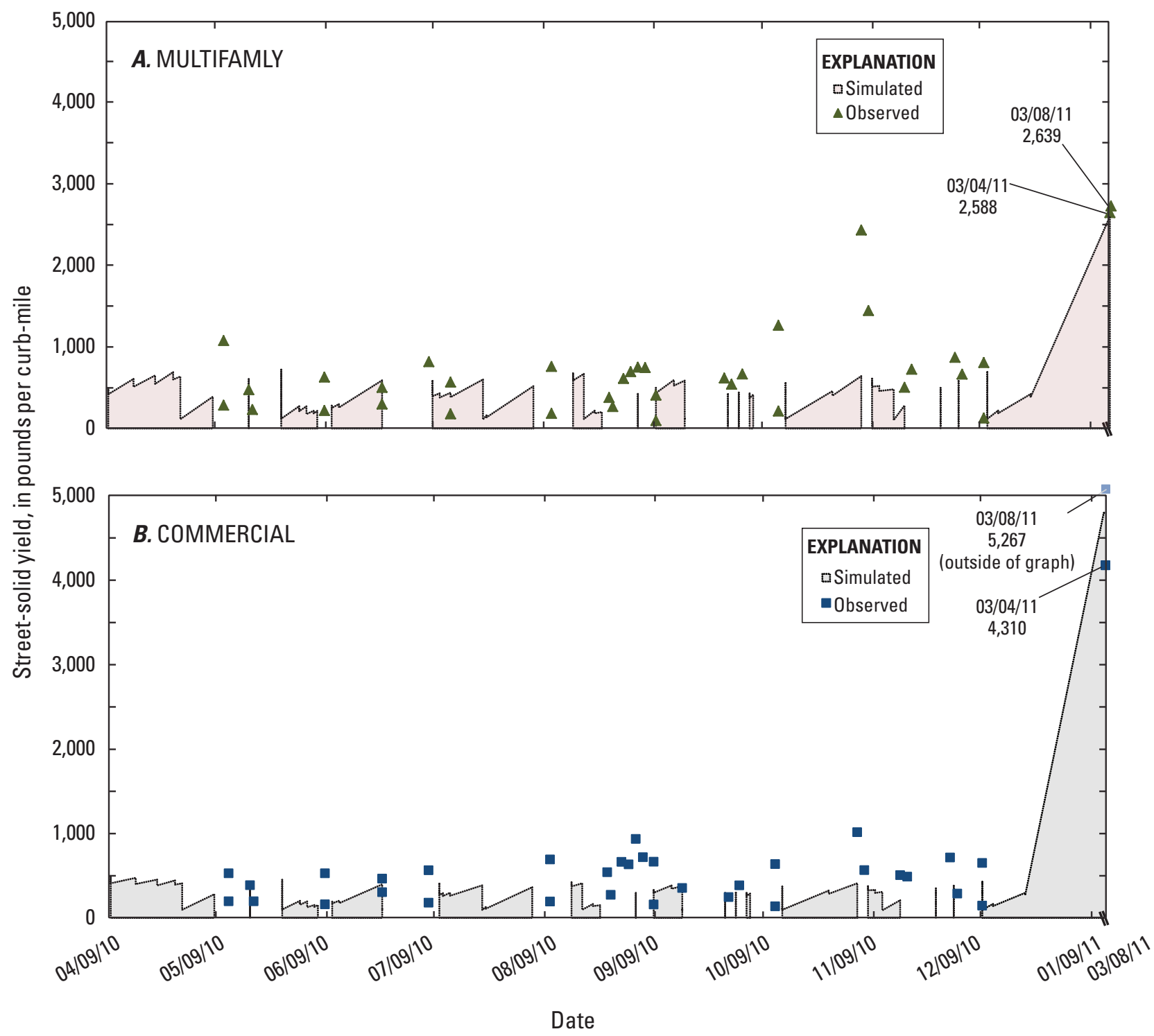

Figure 22. Simulated and observed street-solid yields, April 2010 to March 2011 for $A$, multifamily and $B$, commercial land-use types within the modeled subcatchment, Cambridge, Massachusetts. 
The estimated percent reduction of total and particulate solids, and total and particulate $\mathrm{P}$ following singles passes from each street cleaner type under each operational frequency are summarized in table 14. The percent reduction of total and particulate solids, and P as estimated by SLAMM is for the entire subcatchment at its outfall rather than a percent reduction of solids and $\mathrm{P}$ as measured specifically on only street surfaces. The model appears insensitive to leaf-fall effects and could be underestimating the total P load reductions from street cleaning programs, particularly in multifamily areas where tree density was greatest. Simulations of monthly mechanical-brush street cleaning resulted in reductions of total and total particulate solids and of about 2.7 and 4.2 percent, respectively. Total and particulate $\mathrm{P}$ reductions were about 1.4 and 2 percent, respectively. Estimated reductions

Table 14. Source Loading and Management Model (SLAMM) estimated percent reductions of total and particulate solids and phosphorus using single passes by three different streetcleaning technologies at various frequencies in a predominantly commercial subcatchment, Cambridge, Massachusetts.

\begin{tabular}{|c|c|c|c|}
\hline Constituent & $\begin{array}{l}\text { Mechani- } \\
\text { cal brush } \\
\text { street- } \\
\text { cleaning } \\
\text { percent } \\
\text { reduction }\end{array}$ & $\begin{array}{l}\text { Vacuum- } \\
\text { assist } \\
\text { street- } \\
\text { cleaning } \\
\text { percent } \\
\text { reduction }\end{array}$ & $\begin{array}{c}\text { Regener- } \\
\text { ative-air } \\
\text { street- } \\
\text { cleaning } \\
\text { percent } \\
\text { reduction }\end{array}$ \\
\hline \multicolumn{4}{|c|}{ Monthly street cleaning } \\
\hline Total solids & 2.7 & 5.2 & 16 \\
\hline Total particulate solids & 4.2 & 8.2 & 27 \\
\hline Total phosphorus & 1.4 & 2.7 & 8.0 \\
\hline Total particulate phosphorus & 2.0 & 4.0 & 12 \\
\hline \multicolumn{4}{|c|}{ Bimonthly street cleaning } \\
\hline Total solids & 3.3 & 7.0 & 18 \\
\hline Total particulate solids & 5.1 & 11 & 30 \\
\hline Total phosphorus & 1.7 & 3.7 & 8.3 \\
\hline Total particulate phosphorus & 2.5 & 5.4 & 12 \\
\hline \multicolumn{4}{|c|}{ Weekly street cleaning } \\
\hline Total solids & 4.2 & 9.6 & 18 \\
\hline Total particulate solids & 6.6 & 15 & 31 \\
\hline Total phosphorus & 2.1 & 5.0 & 8.7 \\
\hline Total particulate phosphorus & 3.1 & 7.5 & 13 \\
\hline \multicolumn{4}{|c|}{ Street cleaning three times per week } \\
\hline Total solids & 6.0 & 14 & 19 \\
\hline Total particulate solids & 9.5 & 24 & 32 \\
\hline Total phosphorus & 3.0 & 7.4 & 9.3 \\
\hline Total particulate phosphorus & 4.5 & 11 & 14 \\
\hline
\end{tabular}

resulting from mechanical-brush street cleaning 3-times per week resulted in total and particulate solids of about 6 and 9.5 percent, respectively, and total and particulate $P$ reduction estimates of about 3.0 and 4.5 percent, respectively.

Simulated reductions of total and particulate solids associated with monthly use of vacuum-assist street cleaning technology were about 5.2 and 8.2 , respectively. Total and particulate $\mathrm{P}$ reductions were about 2.7 and 4.0 percent, respectively. Simulated reductions in total and particulate solids and total and particulate $\mathrm{P}$ associated with a vacuum-assist street cleaner with 3-times per week frequency were about 14 and 24, and 7.4 and 11 percent, respectively.

Estimated reductions of total and particulate solids using RA street cleaning technology at a monthly frequency were about 16 and 27 percent, respectively. Monthly total and particulate $\mathrm{P}$ estimated monthly reductions were about 8 and 12 percent, respectively. RA street cleaning three-days per week resulted in estimated reductions of total and particulate solids of about 19 and 32 percent, respectively. Total and particulate P percent reductions were about 9.3 and 14 percent, respectively.

\section{Summary and Conclusions}

In 2009, the U.S. Geological Survey, in cooperation with the city of Cambridge, Massachusetts, the Massachusetts Department of Environmental Protection, and the U.S. Environmental Protection Agency, conducted a study to better understand the physical and chemical nature of the material on street surfaces, evaluate the performance of a regenerativeair street cleaner, and estimate potential reductions of total particulate solid and total phosphorus loading to the Lower Charles River expected from various street cleaning practices.

Street-solid composite samples from the three streets within each land-use type provided an average value for Cambridge, Mass., asphalt streets characterized by heavy on-street parking, monthly parking controls, intermediate surface texture, and fair surface condition within multifamily and commercial land-use areas. Street-solid samples included gravel and asphalt, and all organic material up to about 50 millimeters in diameter.

The median yield of street solids on multifamily and commercial streets between May and December 2010, was about 602 and 467 pounds per curb-mile, respectively. Including the large amounts observed in March 2011, following the winter season, median yields increased to about 616 and $498 \mathrm{lbs} /$ curb-mi, respectively. Average streetsolid yields on multifamily and commercial land-use streets between May and December 2010, were about 1.9 and 1.7 times the national average, respectively, and about 2 to 3 times the national average when including large endof-winter street-solid yields in March 2011. Street-solid yields were greatest during leaf-fall and end-of-winter for multifamily and commercial streets, respectively. 
Street-solid samples were separated into three grainsize fractions: (1) coarse, (2) medium, and (3) fine. About 86 percent of all street-solids were greater than the fine grainsize fraction (or very fine sand) for each land-use type. The coarse solid fraction was higher on multifamily streets and likely from increased tree density on these streets. Routine on-street parking in Cambridge likely causes a more even distribution of material on the streets compared to areas without on-street parking, and as much as 96 percent of the material was measured within 9 feet of the curb.

Median accumulation rate estimates of total street solids were about 33 and 23 pounds per curb-mile per day for multifamily and commercial land-use streets, respectively, but ranged widely from -43 to $308 \mathrm{lbs} / \mathrm{curb}-\mathrm{mi} / \mathrm{day}$. Median accumulation rates by grain-size fraction were also similar between land-use types, and the medium grain-size fraction accumulated the most rapidly. Accumulation was also slightly greater on multifamily streets for the two coarser grain-size fractions. Results indicate that street solids in Cambridge, Mass., can recover within 1 to 3 days after a rainstorm or street cleaning.

Washoff sample pairs were collected for storms between 0.32 and 1.71 inches and rainfall intensities between 0.027 and $0.185 \mathrm{in} / \mathrm{hr}$. Median average washoff from streets in multifamily and commercial land-use types were similar at about 35 and 40 percent, respectively. The distribution of street solids in the washoff also was similar for all streets in magnitude. Washoff generally increased with decreasing grain size; however, observed net increases of street solids were attributed to overland flow and transport of organic debris from source areas other than streets. Net increases of street solids following rainfall events were largest in the coarse grain-size fraction on multifamily streets and in the fine grain-size fraction on commercial streets.

Median concentrations of organic carbon and total $\mathrm{P}$ on multifamily streets were determined to be 35 and 29 percent greater, respectively, than those commercial streets. Median concentrations of organic carbon and total $\mathrm{P}$ were highest within the fine grain-size fraction on streets in both land-use types, followed by the coarse and medium grain-size fractions. Median total masses of organic carbon and total $\mathrm{P}$ on multifamily streets were determined to be 68 and 75 percent greater, respectively, than those on commercial streets. About 87 and 98 percent of the mass of total $\mathrm{P}$ was determined to be within the two larger grain-size fractions for multifamily and commercial streets, respectively. The median total accumulation rate of total $\mathrm{P}$ on streets in multifamily land use was about 5 times greater than on commercial streets. The largest total $\mathrm{P}$ accumulation rate by grain-size fraction was within the medium grain-size fraction and was the same for streets within both land-use types at $0.004 \mathrm{lbs} /$ curb-mi/day. Accumulation rates within the coarse and fine grain-size fractions on multifamily streets were about 11 and 82 times greater than those on the commercial streets, respectively. Multifamily and commercial median washoff of total $\mathrm{P}$ was 58 and 39 percent, respectively, and ranged widely from $-1,120$ to 99 percent.
Median washoff of total P by grain-size fraction was also similar between both land-use types.

Median street-solid removal efficiencies of a regenerative-air street cleaner were 82 and 78 percent for multifamily and commercial land-use types, respectively. Removal efficiency decreased with decreasing grain size of the street solids. Median removal efficiency of solids by the regenerative-air street cleaner by grain-size fraction was also similar between land-use types. Negative values, or net increases in material, were occasionally observed within the fine grainsize fraction, and typically occurred on streets with rough and damaged surfaces. Increases in street solids following a street cleaner pass is likely the result of the wet gutter broom of the cleaner dislodging coarser material from inside cracks and holes within the street surface and exposing finer materials, as well as pasting fine materials back onto the street surface, which would then be available for washoff. The regenerativeair street cleaner tested left a consistent median residual yield regardless of the initial yield on the streets of both land-use types of about $100 \mathrm{lbs} /$ curb-mi. Total P median reductions resulting from a single pass of a regenerative-air street cleaner on streets in multifamily and commercial land-use types were about 82 and 62 percent, respectively, decreased with decreasing grain-size, and were similar in magnitude for the three grain-size fractions on streets in both land-use types. Constituent mass reductions as a result of regenerative-air street cleaning generally decreased with decreasing grain size, and reductions were slightly less during the spring and summer months, likely a result of lower available street-solid yields. Net increases of some constituent masses following a single regenerative-air street cleaner pass were seen almost entirely in the fine grain-size fraction results from multifamily streets.

A Source Loading and Management Model for Microsoft Windows version 9.4.0 was applied to a 21.8 acre subcatchment in Cambridge, Mass., consisting of commercial, institutional and multifamily land-use types to evaluate the potential reductions of phosphorus as a result of street-cleaning practices. The model results were calibrated to runoff and water-quality data collected at the subcatchment outfall in 2000 and street-solid yield data collected in 2010. Rooftop runoff was the dominant source of the total runoff simulated at the subcatchment outfall. Street surfaces in the subcatchment contributed about 20 percent of the total runoff at the outfall in the model.

Productivity function coefficients for mechanical-brush and vacuum-assisted street cleaners were generated by SLAMM based on long-term (24-hour), on-street parking with parking controls. Regenerative-air street cleaner productivity function coefficients were developed from field data under the same conditions. Simulations based on 5 years of average climatic conditions resulted in potential reductions of total solids of about 3 and 5 percent for monthly mechanical-brush and vacuum-assist street cleaner operation, respectively, and about 16 percent for the regenerative-air street cleaner. Estimated total $\mathrm{P}$ reductions for monthly use of mechanical-brush and vacuum-assisted street cleaners were about 1 and 3 percent, 
respectively, and 8 percent for the regenerative-air machine. An operational frequency of three times per week increased potential reductions of total solids for mechanical-brush, vacuum-assist and regenerative-air street cleaners to about 6 , 14 and 19 percent, respectively. Simulated percent reductions of total P were about 3, 7, and 9 percent, respectively, when streets were cleaned 3 times per week.

\section{References Cited}

Bannerman, R., Baun, K.M., Bohn, P.E., and Graczyk, D.A., 1983, Evaluation of urban nonpoint source pollution management in Milwaukee County, Wisconsin: Chicago, Ill., U.S. Environmental Protection Agency, PB 84-114164.

Bender, G.M., and Terstriep, M.L., 1984, Effectiveness of street sweeping in urban runoff pollution control: Science of the Total Environment, v. 33, p. 185-192.

Bent, G.C., Gray, J.R., Smith, K.P., and Glysson, G.D., 2000, A synopsis of technical issues for monitoring sediment in highway and urban runoff: U.S. Geological Survey OpenFile Report 00-497, $51 \mathrm{p}$.

Bent, G.C., Socolow, R.S., and Comeau, L.Y., 2009, Water Resources Data Report, Massachusetts and Rhode Island, Water Year 2009: U.S. Geological Survey Water-Data Report MA-RI-09-1, accessed September 5, 2011, at http://wdr.water.usgs.gov/wy2009/search.jsp.

Breault, R.F., Smith, K.P., and Sorenson, J.R., 2005, Residential street-dirt accumulation rates and chemical composition, and removal efficiencies by mechanical- and vacuum-type sweepers, New Bedford, Massachusetts, 2003-04: U.S. Geological Survey Scientific Investigations Report 2005-5184, 27 p.

Breault, R.F., Sorenson, J.R., and Weiskel, P.K., 2002, Streamflow, water-quality, and contaminant loads in the Lower Charles River watershed, Massachusetts, 19992000: U.S. Geological Survey Scientific Investigations Report 2002-4137, 139 p.

Burton, G.A., Jr., and Pitt, R., 2002, Stormwater effects handbook: A tool box for watershed managers, scientists, and engineers: CRC Press, Inc., Boca Raton, Fla., 911 p.

Cadle, S.H., Mulawa, P., Groblicki, P., Laroo, C., Ragazzi, R.A., Nelson, K., Gallagher, G., and Zielinska, B., 2001, In-use light-duty gasoline vehicle particulate matter emissions on three driving cycles: Environmental Science and Technology, v. 35, no. 1, p. 26-32.

Clausen, J.C., and Spooner, J., 1993, Paired basin watershed study design: U.S. Environmental Protection Agency, Office of Water, EPA-841-F-93-009, 8 p.
County and City Data Book: 2000, Washington, D.C.: U.S. Department of Commerce, Bureau of the Census, Table C -1 .

Davis, A.P., Shokouhian, M., and Ni, S., 2000, Loading estimates of lead, copper, cadmium, and zinc in urban runoff from specific sources, Chemosphere, v. 44, p. 997-1009.

Granato, G.E., 2006, Kendall-Theil Robust Line (KTRLineversion 1.0)-A visual basic program for calculating and graphing robust nonparametric estimates of linearregression coefficients between two continuous variables: Techniques and Methods of the U.S. Geological Survey, book 4, chap. A7, 31 p.

Hansen, J., Sesing, M., Hughes, P., and Graczyk, D., 1984, Evaluation of urban nonpoint source pollution management in Milwaukee County, Wisconsin - Vol III-Study site characteristics, Experimental Methods and Quality Assurance Program: Wisconsin Department of Natural Resources, PB 84-114180, variously paginated.

Helsel, D.R., and Hirsch, R.M., 2002, Statistical methods in water resources-Hydrologic analysis and interpretation: U.S. Geological Survey Techniques of Water-Resources Investigations, chap. A3, book 4, $510 \mathrm{p}$.

Kaufman, M.M., Rogers, D.T., and Murray, K.S., 2011, Urban watersheds: geology, contamination, and sustainable development, Boca Raton, Fla., CRC press, 583 p.

Law, N.L., DiBlasi, K., and Upal, G., 2008, Deriving reliable pollutant removal rates for municipal street sweeping and stormdrain cleanout programs in the Chesapeake Bay Basin: Center for Watershed Protection, $73 \mathrm{p}$.

Maestre, A., and Pitt, R., 2005, The National Stormwater Quality Database, Version 1.1, A compilation and analysis of NPDES stormwater monitoring information: Washington D.C., U.S. Environmental Protection Agency, Water Planning Division, variously paginated.

Massachusetts Department of Environmental Protection and the U.S. Environmental Protection Agency, 2007, Total maximum daily load for nutrients in the Lower Charles River Basin: Massachusetts, CN 301.0, with support from Tetra Tech, $196 \mathrm{p}$.

Massachusetts Office of Geographic Information (MassGIS), 2011, 1-meter impervious surface raster and metadata: Accessed February 12, 2011, at http://www.mass.gov/mgis/ imp.htm. 
Massachusetts Office of Geographic Information (MassGIS), 2011, 0.5-meter color ortho mosaic and metadata: Accessed February 12, 2011, at http://www.mass.gov/anf/researchand-tech/it-serv-and-support/application-serv/office-ofgeographic-information-massgis/datalayers/massgis-datadownload-usgs-color-ortho-imagery-2008-2009.html

National Climatic Data Center, accessed February 12, 2011, at http://cdo.ncdc.noaa.gov/dlyp/DLYP.

National Oceanic and Atmospheric Administration, National Weather Service, accessed July 6, 2011, at http://www.erh. noaa.gov/box/AveragesTotals.shtml

Novotny, V., and Chesters, G., 1981, Handbook of nonpoint pollution sources and management, New York, New York, Van Nostrand Reinhold Company.

Pitt, R.E., 1979, Demonstration of nonpoint pollution abatement through improved street cleaning practices: Washington, D.C., U.S. Environmental Protection Agency, EPA-600/2-79/161, $269 \mathrm{p}$.

Pitt, R.E., 1982, Urban bacteria sources and control in the lower Rideau River watershed: Ottawa Ontario, Ontario Ministry of the Environment, variously paginated.

Pitt, R.E., 1985, Characterizing and controlling urban runoff through street and sewerage cleaning: U.S. Environmental Protection Agency, Storm and Combined Sewer Program, Cincinnati, Ohio, Risk Reduction Engineering Laboratory, EPA/600/S2-85/038, PB 85-186500, variously paginated.

Pitt, R.E., 1987, Small storm urban flow and particulate washoff contributions to outfall discharges: Department of Civil and Environmental Engineering, University of Wisconsin, Madison, Ph.D. dissertation 187 p.

Pitt, R.E., 2008, Calibration of WinSLAMM: PV \& Associates, Madison, Wis., 38 p.

Pitt, R.E., and Amy, G., 1973, Toxic materials analysis of street surface constituents: Washington, D.C., U.S. Environmental Protection Agency, EPA-R2-73-283, 143 p. (Also available from National Technical Information Service, Springfield, VA 22161 and http://www.ntis.gov, item PB 224-677)

Pitt, R.E., Bannerman, R., Clark, S., and Williamson, D., 2005a, Sources of pollutants in urban areas (part I)—older monitoring projects, in Effective modeling of urban water systems: Monograph 13, James, W., Irvine, K.N., McBean, E.A., and Pitt, R.E., eds., CHI, Guelph, Ontario, 465-484 and $507-530 \mathrm{p}$.
Pitt, R.E., Bannerman, R., Clark, S., and Williamson, D., 2005 b, Sources of pollutants in urban areas (part II) - recent sheetflow monitoring results, in Effective modeling of urban water systems: Monograph 13, James, W., Irvine, K.N., McBean, E.A., and Pitt, R.E., eds., CHI, Guelph, Ontario, $485-530 \mathrm{p}$.

Pitt, R.E., and Bozeman, M., 1982, Sources of urban runoff pollution and its effects on an urban creek: Cincinnati, Ohio, U.S. Environmental Protection Agency, EPA-600/ S2-82-090, variously paginated.

Pitt, R.E., Chen, S., Clark, S.E., Swenson, J., and Ong, C.K., 2008, Compaction's impacts on urban storm-water infiltration: Journal of Irrigation and Drainage Engineering, p. 652-658.

Pitt, R.E., and McLean, J., 1984, Humber River pilot watershed project: Toronto, Ontario, Ontario Ministry of the Environment, variously paginated.

Pitt, R.E., and Shawley, G., 1981, Demonstration of nonpoint pollution management on Castro Valley Creek: Washington, D.C., U.S. Environmental Protection Agency, Water Planning Division, variously paginated.

Pitt, R.E., and Voorhees, J., 2000, The source loading and management model (SLAMM): A water quality planning management model for urban storm water runoff, PV \& Associates, Madison, Wis., $587 \mathrm{p}$.

Pitt, R.E., and Voorhees, J., 2002, Field, R., and Sullivan, D., eds., in Wet-weather flow in the urban watershedTechnology and Management: Boca Raton, Fla., CRC Press, p. 103-139.

Pitt, R.E., Williamson, D., and Voorhees, J., 2005c, Review of historical street dust and dirt accumulation and washoff data, in Effective modeling of urban water systems: Monograph 13, James, W., Irvine, K.N., McBean, E.A., and Pitt, R.E., ed., CHI, Guelph, Ontario, 203-246 pp.

Pitt, R.E., Williamson, D., Voorhees, J., and Clark, S., 2004, Review of historical street dust and dirt accumulation and washoff data, chap. 12 of, James, W., Irvine, K.N., McBean, E.A., and Pitt, R.E., eds., Effective modeling of urban water systems: CHI Publishing, Ontario, Canada, $44 \mathrm{p}$.

Sartor, J.D., and Boyd, G.B., 1972, Water pollution aspects of street surface constituents: Washington, D.C., U.S. Environmental Protection Agency, EPA-R2-72-081, p. $458-467$.

Seattle Public Utilities and Department of Transportation, 2009, Seattle streetsweeping pilot study: monitoring report, Herrera Environmental Consultants, 266 p. 
Selbig, W.R., and Bannerman, R.T., 2007, Evaluation of street sweeping as a stormwater-quality-management tool in three residential basins in Madison, Wisconsin: U.S. Geological Survey Scientific Investigations Report 2007-5156, 103 p.

Shelley, P.E., and Gaboury, D.R., 1986, Estimation of pollution from highway runoff-initial results: Conference on urban runoff quality-impact and quality enhancement technology, Henniker, New Hampshire: Urbonas, B., and Roesner, L.A., eds., in Proceedings published by the American Society of Civil Engineering, New York, variously paginated.

Skeehan, J.W., 2001, Roadside geology of Massachusetts: Mountain Press Publishing, Missoula, Mont., 379 p.

Smith, K.P., 2002, Effectiveness of three best management practices for highway runoff quality along the southeast expressway, Boston, Massachusetts: U.S. Geological Survey Scientific Investigations Report 2002-4059, 170 p.

Smith, K.P., 2010, Quality of stormwater runoff discharged from Massachusetts highways, 2005-07: U.S. Geological Survey Scientific Investigations Report 2009-5269, 198 p.

Steuer, Jeffrey, Selbig, William, Hornewer, N.J., and Prey, Jeffrey, 1997, Sources of contamination in an urban basin in Marquette, Michigan, and an analysis of concentrations, loads, and data quality: U.S. Geological Survey WaterResources Investigations Report 97-4242, 25 p.

Terstriep, M.L., Bender, G.M., and Noel, D.C., 1982, Evaluation of the effectiveness of municipal street cleaning in the control of urban storm pollution: Final report-NURP project, Champaign-Urbana, Illinois, State Water Survey Division, Illinois Department of Energy and Natural Resources, variously paginated.

U.S. Census Bureau, Census Summary File, 2010, PL94-171 Massachusetts data file, accessed July 6, 2011, at (http://www.census.gov/rdo/data/2010_census_ redistricting_data_pl_94-171_summary_files.html).
U.S. Department of Agriculture, 1995, Soil Survey Geographic (SSURGO) Data Base, Data Use Information: Natural Resources Conservation Service, National Soil Survey Center, Miscellaneous Publication Number 1527, variously paged.

U.S. Environmental Protection Agency, 1983, Nationwide Urban Runoff Program, Winston-Salem, N.C.-An evaluation of street sweeping as a runoff pollution control: Office of Water Programs, 229 p. (Also available from National Technical Information Service, Springfield, VA 22161 and http://www.ntis.gov, item PB85-102507)

U.S. Environmental Protection Agency, 1986, Quality criteria for water 1986: U.S. Environmental Protection Agency, EPA440/5-86-001, variously paginated.

U.S. Geological Survey, Fresh Pond streamflow monitoring station (USGS ID: 422302071083801).

Waschbusch, R.J., Selbig, W.R., and Bannerman, R.T., 1999, Sources of phosphorus in stormwater and street dirt from two urban residential basins in Madison, Wisconsin, 199495: U.S. Geological Survey Water-Resources Investigations Report 99-4021, 47 p.

Weather Underground, accessed September 16, 2011, at http://www.wunderground.com/US/MA/Cambridge.html

Zarriello, P.J., and Barlow, L.K., 2002, Measured and simulated runoff to the Lower Charles River, Massachusetts: U.S. Geological Survey Water-Resources Investigations Report 02-4129, 89 p.

Zarriello, P.J., Breault, R.F., and Weiskel, P.K., 2002, Potential effects of structural controls and street sweeping on stormwater loads to the Lower Charles River, Massachusetts: U.S. Geological Survey Water-Resources Investigations Report 02-4220, $42 \mathrm{p}$.

Zimmerman, M.J., Barbaro, J.R., Sorenson, J.R., and Waldron, M.C., 2010, Effects of selected low-impact development (LID) techniques on water quality and quantity in the Ipswich River Basin, Massachusetts—Field and modeling studies: U.S. Geological Survey Scientific Investigations Report 2010-5007, 114 p. 
Tables 9, 11, 12, and 13 
Table 9A. Total and grain-size fraction median constituent total-recoverable concentrations and masses constituent masses from composite street-solid samples collected from streets representing $A$, multifamily and $B$, commercial land-use types in Cambridge, Massachusetts.

[Bold italicized values indicate less than one-half the detection limit was used to determine concentration and normalized mass. Note: concentrations converted to milligrams per kilogram and in this case are equivalent to concentrations in parts per million (ppm). n, number of samples; mg/kg, milligrams per kilogram; g, grams; mm, millimeter; coarse, greater than or equal to $2 \mathrm{~mm}$; medium, less than $2 \mathrm{~mm}$ greater than or equal to $0.125 \mathrm{~mm}$; fine, less than $0.125 \mathrm{~mm}$ in diameter]

\begin{tabular}{|c|c|c|c|c|c|c|c|c|c|}
\hline & & \multicolumn{2}{|c|}{$\begin{array}{c}\text { Total } \\
n=225\end{array}$} & \multicolumn{2}{|c|}{$\begin{array}{c}\text { Coarse } \\
n=76\end{array}$} & \multicolumn{2}{|c|}{$\begin{array}{c}\text { Medium } \\
\mathrm{n}=74\end{array}$} & \multicolumn{2}{|c|}{$\begin{array}{c}\text { Fine } \\
n=75\end{array}$} \\
\hline \multicolumn{10}{|c|}{ Multifamily } \\
\hline Analyte & $\begin{array}{l}\text { Detec- } \\
\text { tion limit } \\
(\mathrm{mg} / \mathrm{kg})\end{array}$ & $\begin{array}{c}\text { Median } \\
\text { concentra- } \\
\text { tion } \\
(\mathrm{mg} / \mathrm{kg})\end{array}$ & $\begin{array}{c}\text { Standard } \\
\text { deviation } \\
(\mathrm{mg} / \mathrm{kg})\end{array}$ & $\begin{array}{c}\text { Median } \\
\text { concentra- } \\
\text { tion } \\
(\mathrm{mg} / \mathrm{kg})\end{array}$ & $\begin{array}{c}\text { Standard } \\
\text { deviation } \\
(\mathrm{mg} / \mathrm{kg})\end{array}$ & $\begin{array}{c}\text { Median } \\
\text { concentra- } \\
\text { tion } \\
(\mathrm{mg} / \mathrm{kg})\end{array}$ & $\begin{array}{c}\text { Standard } \\
\text { deviation } \\
(\mathrm{mg} / \mathrm{kg})\end{array}$ & $\begin{array}{c}\text { Median } \\
\text { concentra- } \\
\text { tion } \\
(\mathrm{mg} / \mathrm{kg})\end{array}$ & $\begin{array}{c}\text { Standard } \\
\text { deviation } \\
(\mathrm{mg} / \mathrm{kg})\end{array}$ \\
\hline Organic carbon & 500 & 91,700 & 126,431 & 183,500 & 151,308 & 59,850 & 52,671 & 72,800 & 28,279 \\
\hline Silver & 0.2 & 0.10 & 0.25 & 0.10 & 0.06 & 0.10 & 0.06 & 0.10 & 0.40 \\
\hline Aluminum & 100 & 5,200 & 3,042 & 2,700 & 2,696 & 4,630 & 1,045 & 8,900 & 1,427 \\
\hline Arsenic & 3.0 & 4.0 & 14 & 1.5 & 23 & 4.0 & 2.3 & 10.0 & 3.9 \\
\hline Barium & 1 & 55 & 75 & 31 & 17 & 48 & 27 & 127 & 101 \\
\hline Beryllium & 0.5 & 0.25 & 0.17 & 0.25 & 0.14 & 0.25 & 0.16 & 0.25 & 0.20 \\
\hline Bismuth & 5 & 2.50 & 0.54 & 2.50 & 0.00 & 2.50 & 0.57 & 2.50 & 0.76 \\
\hline Calcium & 100 & 9,400 & 7,462 & 11,732 & 11,360 & 8,150 & 2,906 & 10,200 & 3,642 \\
\hline Cadmium & 1 & 0.50 & 0.41 & 0.50 & 0.08 & 0.50 & 0.64 & 0.50 & 0.31 \\
\hline Cobalt & 1 & 4.0 & 16 & 3.0 & 27 & 4.0 & 1.1 & 8.0 & 1.6 \\
\hline Chromium & 1 & 41 & 65 & 10 & 8 & 41 & 36 & 140 & 39 \\
\hline Copper & 0.5 & 47 & 160 & 14 & 128 & 46 & 217 & 176 & 46 \\
\hline Iron & 100 & 18,600 & 100,001 & 5,650 & 8,010 & 18,000 & 5,722 & 27,800 & 5,534 \\
\hline Potassium & 100 & 1,700 & 1,276 & 2,400 & 1,751 & 1,100 & 552 & 1,800 & 522 \\
\hline Lanthanum & 0.5 & 8.5 & 5.9 & 4.4 & 4.5 & 7.9 & 2.0 & 16.3 & 3.0 \\
\hline Lithium & 1 & 8.0 & 4.6 & 5.0 & 5.0 & 7.0 & 1.8 & 13.0 & 2.3 \\
\hline Magnesium & 0.01 & 0.34 & 0.36 & 0.24 & 0.61 & 0.28 & 0.06 & 0.44 & 0.07 \\
\hline Manganese & 2 & 272 & 131 & 202 & 201 & 247 & 48 & 350 & 39 \\
\hline Molybdenum & 1 & 2.00 & 2.05 & 0.50 & 0.92 & 2.00 & 1.39 & 5.00 & 1.05 \\
\hline Sodium & 0.01 & 0.03 & 0.22 & 0.02 & 0.23 & 0.02 & 0.24 & 0.04 & 0.17 \\
\hline Nickel & 1 & 15 & 21 & 8 & 26 & 14 & 7 & 41 & 8 \\
\hline Phosphorus & 100 & 700 & 461 & 800 & 600 & 500 & 241 & 900 & 389 \\
\hline Lead & 2 & 111 & 247 & 25 & 37 & 110 & 178 & 436 & 242 \\
\hline Antimony & 5 & 2.5 & 3.1 & 2.5 & 5.2 & 2.5 & 0.3 & 2.5 & 0.8 \\
\hline Scandium & 0.5 & 1.2 & 0.9 & 0.3 & 0.9 & 1.1 & 0.4 & 2.1 & 0.5 \\
\hline Tin & 10 & 10 & 146 & 5 & 65 & 5 & 14 & 20 & 240 \\
\hline Strontium & 0.5 & 40 & 21 & 43 & 28 & 34 & 15 & 44 & 12 \\
\hline Titanium & 100 & 500 & 353 & 200 & 216 & 500 & 134 & 1,000 & 199 \\
\hline Vanadium & 2 & 24 & 17 & 12 & 12 & 22 & 6 & 46 & 10 \\
\hline Tungsten & 10 & 5.0 & 1.9 & 5.0 & 0.0 & 5.0 & 2.9 & 5.0 & 1.8 \\
\hline Yttrium & 0.5 & 5.3 & 2.9 & 3.0 & 2.5 & 4.8 & 1.1 & 8.6 & 1.7 \\
\hline Zinc & 0.5 & 169 & 185 & 76 & 79 & 160 & 97 & 427 & 137 \\
\hline Zirconium & 0.5 & 2.7 & 2.8 & 1.2 & 1.9 & 2.7 & 1.5 & 5.9 & 2.8 \\
\hline
\end{tabular}


Table 9A. Total and grain-size fraction median constituent total-recoverable concentrations and masses constituent masses from composite street-solid samples collected from streets representing $A$, multifamily and $B$, commercial land-use types in Cambridge, Massachusetts.-Continued

[Bold italicized values indicate less than one-half the detection limit was used to determine concentration and normalized mass. Note: concentrations converted to milligrams per kilogram and in this case are equivalent to concentrations in parts per million (ppm). n, number of samples; $\mathrm{mg} / \mathrm{kg}$, milligrams per kilogram; $\mathrm{g}$, grams; mm, millimeter; coarse, greater than or equal to $2 \mathrm{~mm}$; medium, less than $2 \mathrm{~mm}$ greater than or equal to $0.125 \mathrm{~mm}$; fine, less than $0.125 \mathrm{~mm}$ in diameter]

\begin{tabular}{|c|c|c|c|c|c|c|c|c|c|}
\hline & & \multicolumn{2}{|c|}{$\begin{array}{c}\text { Total } \\
\mathrm{n}=225\end{array}$} & \multicolumn{2}{|c|}{$\begin{array}{c}\text { Coarse } \\
n=76\end{array}$} & \multicolumn{2}{|c|}{$\begin{array}{c}\text { Medium } \\
\mathrm{n}=74\end{array}$} & \multicolumn{2}{|c|}{$\begin{array}{l}\text { Fine } \\
n=75\end{array}$} \\
\hline \multicolumn{10}{|c|}{ Multifamily } \\
\hline Analyte & $\begin{array}{c}\text { Detection } \\
\text { limit } \\
(\mathrm{mg} / \mathrm{kg})\end{array}$ & $\begin{array}{l}\text { Median } \\
\text { mass } \\
(\mathrm{g})\end{array}$ & $\begin{array}{c}\text { Standard } \\
\text { deviation } \\
\text { (g) }\end{array}$ & $\begin{array}{l}\text { Median } \\
\text { mass } \\
(\mathrm{g})\end{array}$ & $\begin{array}{c}\text { Standard } \\
\text { deviation } \\
\text { (g) }\end{array}$ & $\begin{array}{c}\text { Median } \\
\text { mass } \\
(\mathbf{g})\end{array}$ & $\begin{array}{c}\text { Standard } \\
\text { deviation } \\
\text { (g) }\end{array}$ & $\begin{array}{c}\text { Median } \\
\text { mass } \\
(\mathbf{g})\end{array}$ & $\begin{array}{c}\text { Standard } \\
\text { deviation } \\
\text { (g) }\end{array}$ \\
\hline Organic carbon & 500 & 13 & 92 & 22 & 148 & 19 & 15 & 2.9 & 5.9 \\
\hline Silver & 0.2 & 0.02 & 0.05 & 0.01 & 0.05 & 0.03 & 0.04 & 0.01 & 0.06 \\
\hline Aluminum & 100 & 0.59 & 1.41 & 0.35 & 1.11 & 1.25 & 1.78 & 0.37 & 0.80 \\
\hline Arsenic & 3 & 0.43 & 5.9 & 0.30 & 9.9 & 1.1 & 1.8 & 0.40 & 0.93 \\
\hline Barium & 1 & 7.9 & 17 & 3.6 & 19 & 12 & 18 & 5.6 & 9.4 \\
\hline Beryllium & 0.5 & 0.03 & 0.09 & 0.03 & 0.10 & 0.07 & 0.09 & 0.01 & 0.04 \\
\hline Bismuth & 5 & 0.31 & 1.16 & 0.28 & 0.98 & 0.67 & 1.6 & 0.10 & 0.22 \\
\hline Calcium & 100 & 1.2 & 4.2 & 1.2 & 6.0 & 2.1 & 3.2 & 0.37 & 1.6 \\
\hline Cadmium & 1 & 0.06 & 0.20 & 0.06 & 0.20 & 0.13 & 0.25 & 0.02 & 0.05 \\
\hline Cobalt & 1 & 0.5 & 6.6 & 0.3 & 11 & 1.0 & 1.4 & 0.3 & 0.7 \\
\hline Chromium & 1 & 4.1 & 15 & 1.1 & 4.0 & 12 & 21 & 6.0 & 11 \\
\hline Copper & 0.5 & 6.5 & 48 & 1.5 & 53 & 13 & 62 & 7.6 & 13 \\
\hline Iron & 100 & 1.8 & 5.4 & 0.7 & 2.6 & 4.4 & 7.5 & 1.1 & 2.4 \\
\hline Potassium & 100 & 0.16 & 1.1 & 0.31 & 1.8 & 0.33 & 0.30 & 0.01 & 0.01 \\
\hline Lanthanum & 0.5 & 0.91 & 2.5 & 0.45 & 1.6 & 2.03 & 3.3 & 0.66 & 1.3 \\
\hline Lithium & 1 & 0.91 & 2.4 & 0.50 & 1.7 & 2.02 & 3.2 & 0.57 & 1.5 \\
\hline Magnesium & 0.01 & 0.38 & 0.96 & 0.33 & 1.0 & 0.76 & 1.1 & 0.20 & 0.47 \\
\hline Manganese & 2 & 33 & 88 & 28 & 113 & 67 & 85 & 13 & 28 \\
\hline Molybdenum & 1 & 0.17 & 0.65 & 0.07 & 0.49 & 0.47 & 0.84 & 0.20 & 0.37 \\
\hline Sodium & 0.01 & 0.03 & 2.3 & 0.02 & 1.5 & 0.05 & 3.6 & 0.02 & 0.77 \\
\hline Nickel & 1 & 2.0 & 7.8 & 1.1 & 11 & 4.0 & 6.5 & 1.8 & 3.6 \\
\hline Phosphorus & 100 & 0.08 & 0.29 & 0.08 & 0.45 & 0.14 & 0.15 & 0.03 & 0.08 \\
\hline Lead & 2 & 16 & 29 & 2.1 & 17 & 28 & 34 & 20 & 25 \\
\hline Antimony & 5 & 0.31 & 1.25 & 0.28 & 1.8 & 0.67 & 0.89 & 0.12 & 0.34 \\
\hline Scandium & 0.5 & 0.13 & 0.33 & 0.06 & 0.24 & 0.30 & 0.43 & 0.08 & 0.21 \\
\hline Tin & 10 & 1.6 & 5.7 & 1.4 & 5.1 & 2.7 & 5.7 & 0.71 & 6.2 \\
\hline Strontium & 0.5 & 5.0 & 19 & 4.8 & 28 & 8.5 & 15 & 1.7 & 5.6 \\
\hline Titanium & 100 & 0.05 & 0.16 & 0.02 & 0.08 & 0.12 & 0.22 & 0.04 & 0.09 \\
\hline Vanadium & 2 & 2.72 & 8.2 & 1.31 & 6.6 & 5.5 & 10 & 1.9 & 5.3 \\
\hline Tungsten & 10 & 0.60 & 1.7 & 0.55 & 2.0 & 1.3 & 1.8 & 0.20 & 0.37 \\
\hline Yttrium & 0.5 & 0.54 & 1.67 & 0.35 & 1.52 & 1.23 & 2.09 & 0.37 & 0.80 \\
\hline Zinc & 0.5 & 23 & 45 & 6.5 & 44 & 47 & 47 & 17 & 37 \\
\hline Zirconium & 0.5 & 0.31 & 1.3 & 0.15 & 0.61 & 0.74 & 1.8 & 0.26 & 0.76 \\
\hline
\end{tabular}


Table 9B. Total and grain-size fraction median constituent total-recoverable concentrations and masses constituent masses from composite street-solid samples collected from streets representing $A$, multifamily and $B$, commercial land-use types in Cambridge, Massachusetts.

[Bold italicized values indicate less than one-half the detection limit was used to determine concentration and normalized mass. Note: concentrations converted to milligrams per kilogram and in this case are equivalent to concentrations in parts per million (ppm). n, number of samples; mg/kg, milligrams per kilogram; $\mathrm{g}$, grams; $\mathrm{mm}$, millimeter; coarse, greater than or equal to $2 \mathrm{~mm}$; medium, less than $2 \mathrm{~mm}$ greater than or equal to $0.125 \mathrm{~mm}$; fine, less than $0.125 \mathrm{~mm}$ in diameter]

\begin{tabular}{|c|c|c|c|c|c|c|c|c|c|}
\hline & & \multicolumn{2}{|c|}{$\begin{array}{c}\text { Total } \\
\mathrm{n}=\mathbf{2 2 1}\end{array}$} & \multicolumn{2}{|c|}{$\begin{array}{c}\text { Coarse } \\
n=75\end{array}$} & \multicolumn{2}{|c|}{$\begin{array}{c}\text { Medium } \\
\mathrm{n}=\mathbf{7 3}\end{array}$} & \multicolumn{2}{|c|}{$\begin{array}{c}\text { Fine } \\
\mathrm{n}=73\end{array}$} \\
\hline \multicolumn{10}{|c|}{ Commercial } \\
\hline Analyte & $\begin{array}{l}\text { Detec- } \\
\text { tion limit } \\
(\mathrm{mg} / \mathrm{kg})\end{array}$ & $\begin{array}{l}\text { Median } \\
\text { concentra- } \\
\text { tion } \\
(\mathrm{mg} / \mathrm{kg})\end{array}$ & $\begin{array}{c}\text { Standard } \\
\text { deviation } \\
(\mathrm{mg} / \mathrm{kg})\end{array}$ & $\begin{array}{l}\text { Median } \\
\text { concentra- } \\
\text { tion } \\
(\mathrm{mg} / \mathrm{kg})\end{array}$ & $\begin{array}{c}\text { Standard } \\
\text { deviation } \\
(\mathrm{mg} / \mathrm{kg})\end{array}$ & $\begin{array}{c}\text { Median } \\
\text { concentra- } \\
\text { tion } \\
(\mathrm{mg} / \mathrm{kg})\end{array}$ & $\begin{array}{c}\text { Standard } \\
\text { deviation } \\
(\mathrm{mg} / \mathrm{kg})\end{array}$ & $\begin{array}{c}\text { Median } \\
\text { concentra- } \\
\text { tion } \\
(\mathrm{mg} / \mathrm{kg})\end{array}$ & $\begin{array}{c}\text { Standard } \\
\text { deviation } \\
(\mathrm{mg} / \mathrm{kg})\end{array}$ \\
\hline Organic carbon & 500 & 60,100 & 113,171 & 160,000 & 142,140 & 27,100 & 18,274 & 59,100 & 17,275 \\
\hline Silver & 0.2 & 0.10 & 0.67 & 0.10 & 0.10 & 0.10 & 0.10 & 0.50 & 0.99 \\
\hline Aluminum & 100 & 5,000 & 2,528 & 4,100 & 778 & 4,100 & 778 & 7,800 & 986 \\
\hline Arsenic & 3 & 5.00 & 4.66 & 4.00 & 2.17 & 4.00 & 2.17 & 11.00 & 4.19 \\
\hline Barium & 1 & 54 & 53 & 42 & 28 & 42 & 28 & 128 & 36 \\
\hline Beryllium & 0.5 & 0.25 & 0.15 & 0.25 & 0.04 & 0.25 & 0.04 & 0.25 & 0.17 \\
\hline Bismuth & 5 & 2.5 & 0.0 & 2.5 & 0.0 & 2.5 & 0.0 & 2.5 & 0.0 \\
\hline Calcium & 100 & 8,600 & 5,613 & 6,100 & 1,631 & 6,100 & 1,631 & 10,000 & 3,237 \\
\hline Cadmium & 1 & 0.50 & 0.21 & 0.50 & 0.26 & 0.50 & 0.26 & 0.50 & 0.26 \\
\hline Cobalt & 1 & 5.0 & 29 & 4.0 & 4.6 & 4.0 & 4.6 & 8.0 & 49 \\
\hline Chromium & 1 & 51 & 205 & 47 & 58 & 47 & 58 & 166 & 56 \\
\hline Copper & 0.5 & 71.78 & 125.30 & 66 & 99 & 66 & 99 & 250 & 96 \\
\hline Iron & 100 & 23,000 & 12,239 & 21,700 & 6,797 & 21,700 & 6,797 & 34,200 & 6,005 \\
\hline Potassium & 100 & 1,100 & 878 & 700 & 254 & 700 & 254 & 1,400 & 296 \\
\hline Lanthanum & 0.5 & 9.30 & 5.44 & 7.80 & 1.51 & 7.80 & 1.51 & 16.60 & 2.91 \\
\hline Lithium & 1 & 8.00 & 4.19 & 7.00 & 1.95 & 7.00 & 1.95 & 11.00 & 3.09 \\
\hline Magnesium & 0.01 & 0.33 & 0.20 & 0.26 & 0.07 & 0.26 & 0.07 & 0.40 & 0.07 \\
\hline Manganese & 2 & 270 & 271 & 237 & 64 & 237 & 64 & 358 & 43 \\
\hline Molybdenum & 1 & 3.0 & 3.0 & 2.0 & 1.7 & 2.0 & 1.7 & 7.0 & 1.9 \\
\hline Sodium & 0.01 & 300 & 3,544 & 200 & 1,943 & 200 & 1,943 & 500 & 2,671 \\
\hline Nickel & 1 & 18 & 25 & 15.00 & 31.58 & 15.00 & 31.58 & 48.00 & 9.08 \\
\hline Phosphorus & 100 & 500 & 656 & 400 & 166 & 400 & 166 & 800 & 288 \\
\hline Lead & 2 & 62 & 214 & 61 & 226 & 61 & 226 & 241 & 231 \\
\hline Antimony & 5 & 2.50 & 0.92 & 2.50 & 0.00 & 2.50 & 0.00 & 2.50 & 0.67 \\
\hline Scandium & 0.5 & 1.10 & 0.68 & 0.96 & 0.24 & 0.96 & 0.24 & 1.80 & 0.39 \\
\hline Tin & 10 & 10 & 210 & 5.0 & 11 & 5.0 & 11 & 20 & 361 \\
\hline Strontium & 0.5 & 33.30 & 24.34 & 22.40 & 6.68 & 22.40 & 6.68 & 40.10 & 10.42 \\
\hline Titanium & 100 & 500 & 331 & 400 & 110 & 400 & 110 & 900 & 222 \\
\hline Vanadium & 2 & 23 & 18 & 21 & 3.5 & 21 & 3.5 & 48 & 8.2 \\
\hline Tungsten & 10 & 5.0 & 2.9 & 5.0 & 4.1 & 5.0 & 4.1 & 5.0 & 2.9 \\
\hline Yttrium & 0.5 & 5.6 & 3.1 & 4.7 & 0.9 & 4.7 & 0.9 & 9.0 & 1.5 \\
\hline Zinc & 0.5 & 146 & 219 & 132 & 56 & 132 & 56 & 521 & 147 \\
\hline Zirconium & 0.5 & 3.9 & 4.0 & 3.5 & 1.0 & 3.5 & 1.0 & 8.7 & 2.3 \\
\hline
\end{tabular}


Table 9B. Total and grain-size fraction median constituent total-recoverable concentrations and masses constituent masses from composite street-solid samples collected from streets representing $A$, multifamily and $B$, commercial land-use types in Cambridge, Massachusetts.-Continued

[Bold italicized values indicate less than one-half the detection limit was used to determine concentration and normalized mass. Note: concentrations converted to milligrams per kilogram and in this case are equivalent to concentrations in parts per million (ppm). n, number of samples; $\mathrm{mg} / \mathrm{kg}$, milligrams per kilogram; $\mathrm{g}$, grams; mm, millimeter; coarse, greater than or equal to $2 \mathrm{~mm}$; medium, less than $2 \mathrm{~mm}$ greater than or equal to $0.125 \mathrm{~mm}$; fine, less than $0.125 \mathrm{~mm}$ in diameter]

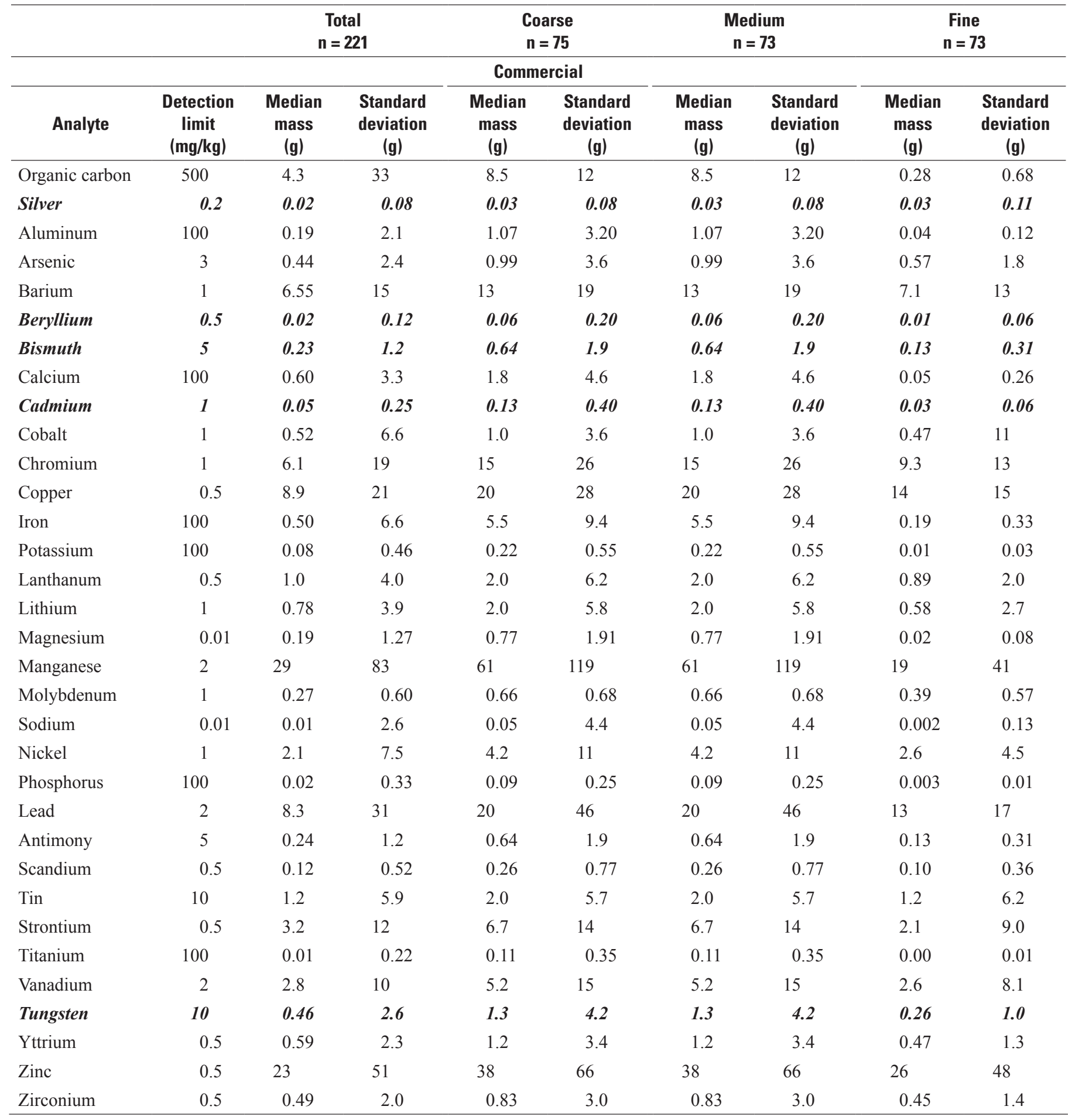




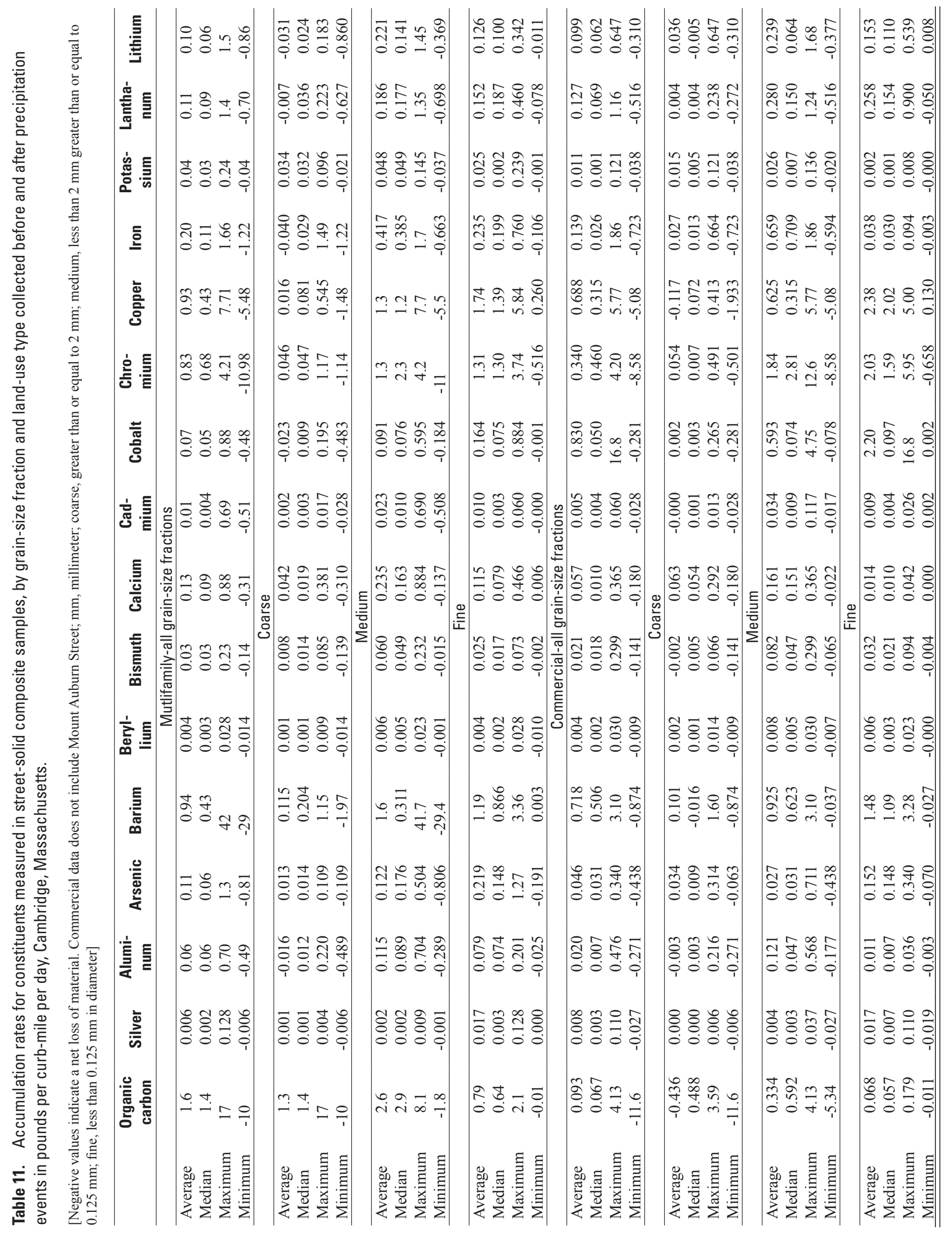




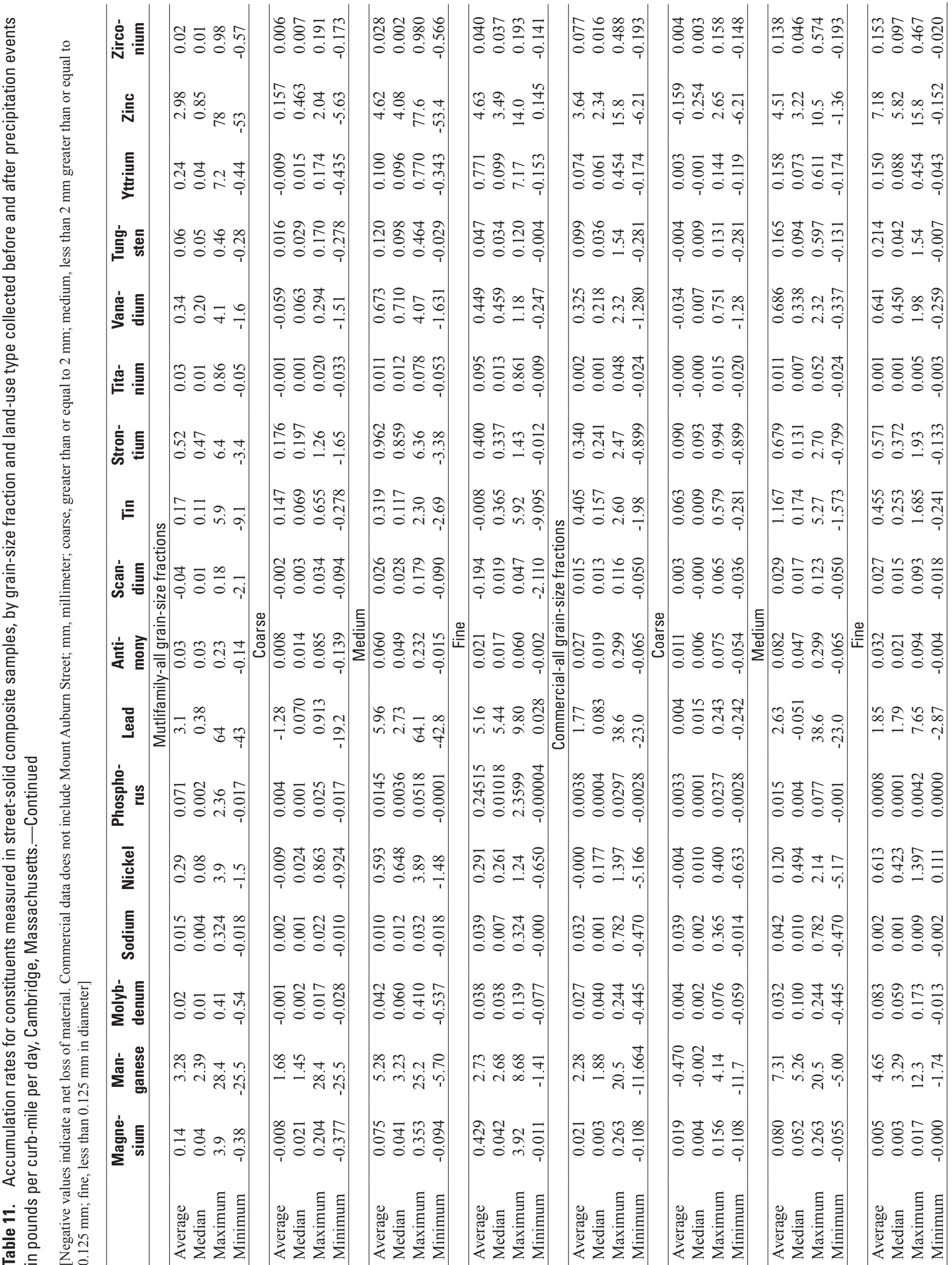


容皆

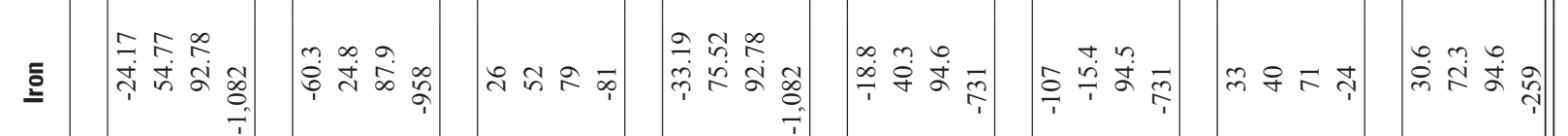

章

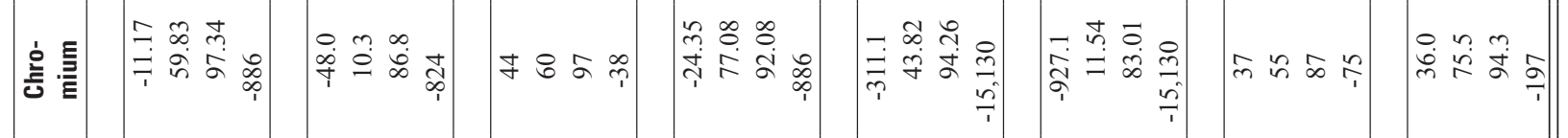

等

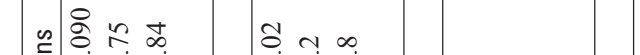

\section{高}

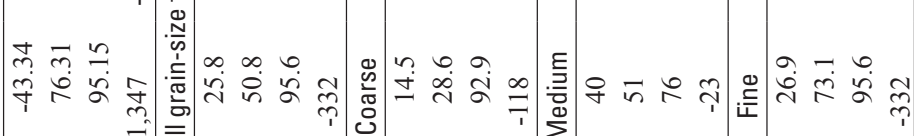

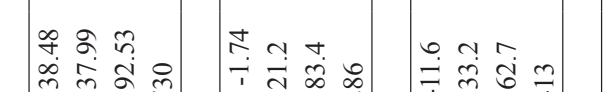

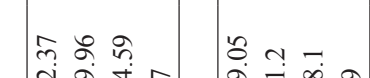
$\lim _{1}$

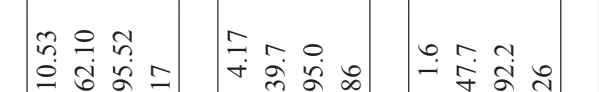

हो

高

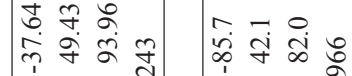

+. $0.0 . \quad$ प

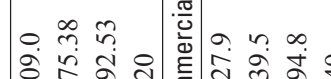

产

$\stackrel{\bar{d}}{\bar{m}}$

\pm ำ

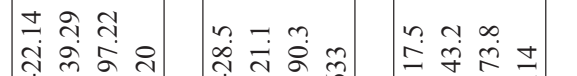

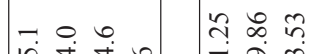




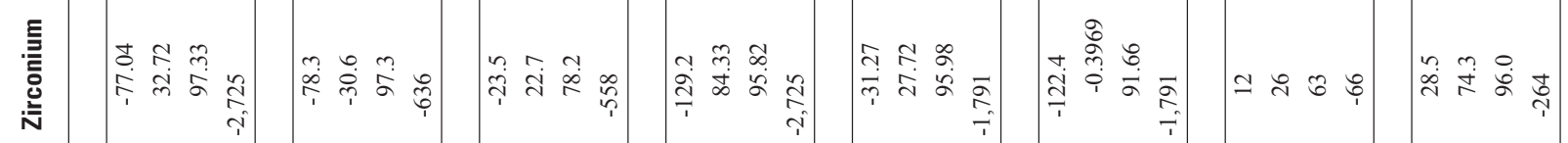

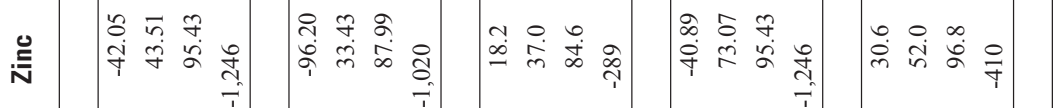

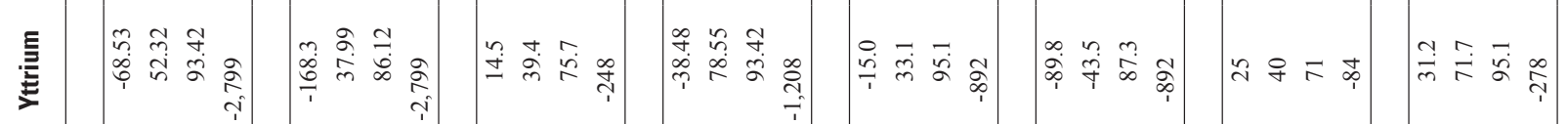

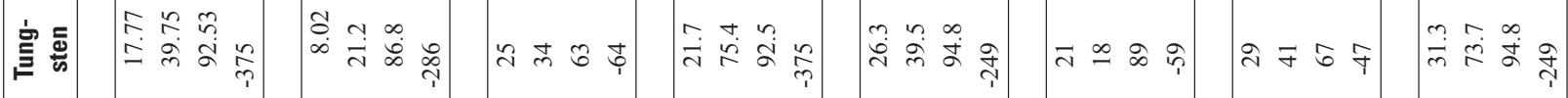

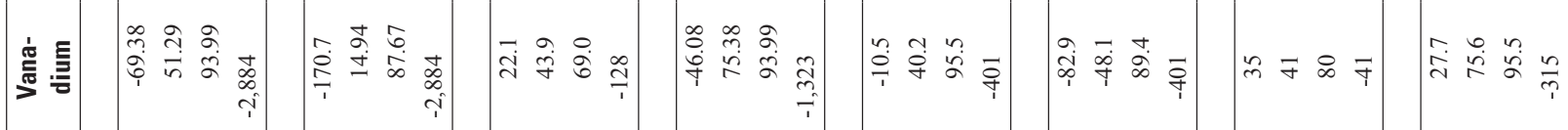

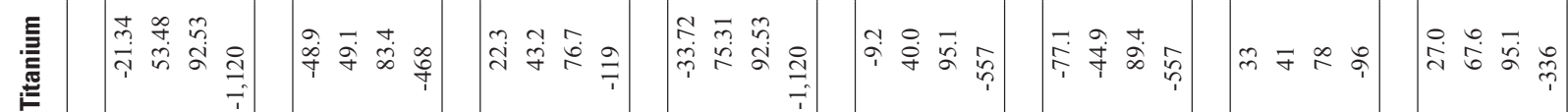

至

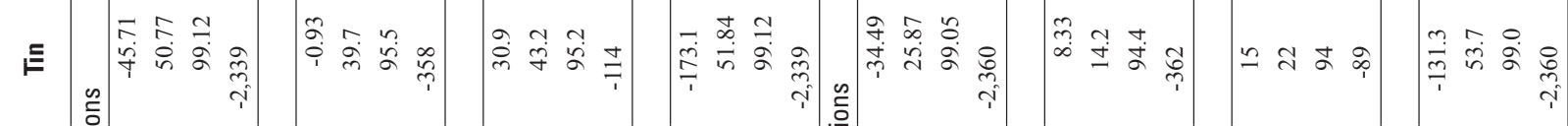

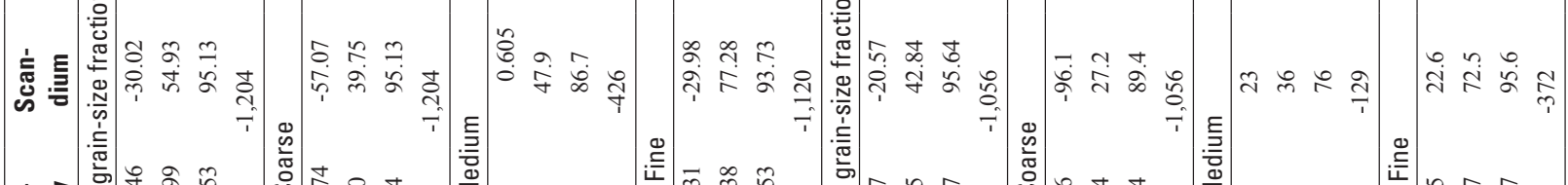

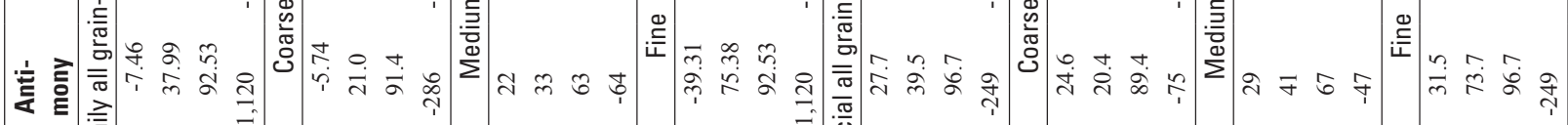

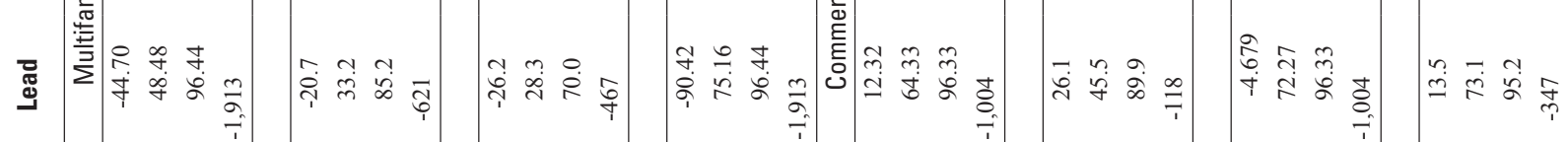

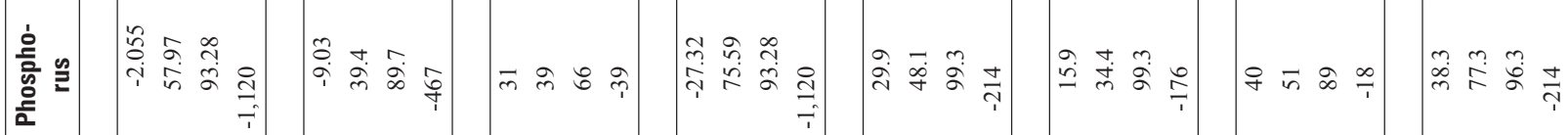

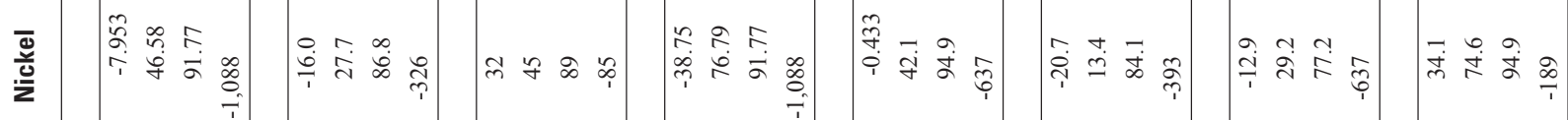

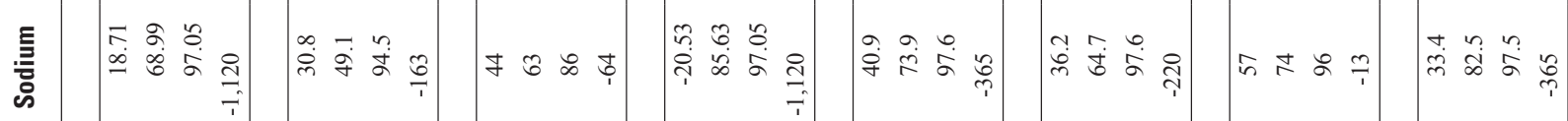

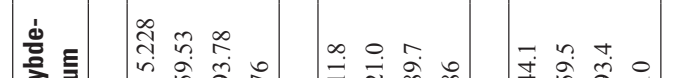

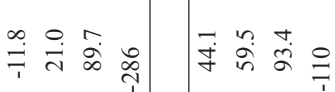

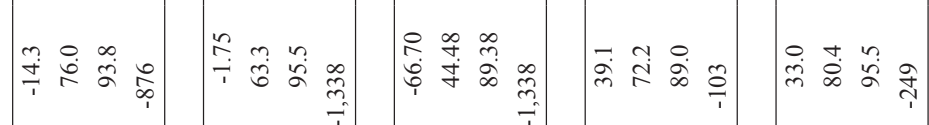

\section{兽}

字.

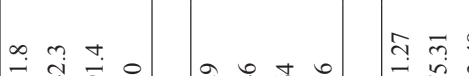

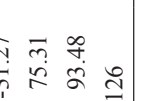

总

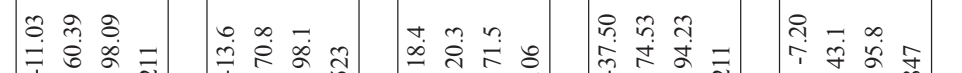

ते बें

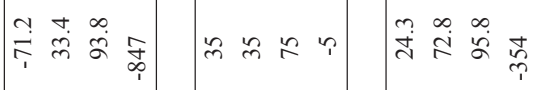


Table 13. Median percent reductions for total and grain-size fractions of constituents measured in seasonal composite of street-solid yields collected before and after a single pass of a regenerative-air street cleaner on streets representing multifamily and commercial land-use types in Cambridge, Massachusetts.

[Bold italicized values indicate less than one-half the detection limit was used to determine concentration and normalized mass. Negative values indicate a potential net increase of a constituent. $\mathrm{n}$, number of samples; $\mathrm{mm}$, millimeter; coarse, greater than or equal to $2 \mathrm{~mm}$; medium, less than $2 \mathrm{~mm}$ greater than or equal to $0.125 \mathrm{~mm}$; fine, less than $0.125 \mathrm{~mm}$ in diameter; spring, May to June, 2010; summer, July to September, 2010; fall, October to December, 2010]

\begin{tabular}{|c|c|c|c|c|c|c|c|c|c|c|c|c|}
\hline \multicolumn{13}{|c|}{ Multifamily } \\
\hline \multirow{2}{*}{ Analyte } & \multicolumn{4}{|c|}{ Spring, $\mathbf{n}=12$} & \multicolumn{4}{|c|}{ Summer, $\mathbf{n}=17$} & \multicolumn{4}{|c|}{ Fall, $n=12$} \\
\hline & Total & Coarse & Medium & Fine & Total & Coarse & Medium & Fine & Total & Coarse & Medium & Fine \\
\hline Organic carbon & 80 & 93 & 87 & 60 & 87 & 93 & 90 & 57 & 94 & 97 & 96 & 81 \\
\hline Silver & 78 & 92 & 83 & 55 & 84 & 93 & 93 & 66 & 94 & 98 & 92 & 66 \\
\hline Aluminum & 78 & 90 & 84 & 60 & 79 & 91 & 87 & 42 & 93 & 98 & 59 & 37 \\
\hline Arsenic & 70 & 98 & 66 & 55 & 77 & 90 & 83 & 11 & 90 & 94 & 73 & -171 \\
\hline Barium & 85 & 91 & 85 & 62 & 80 & 90 & 83 & 12 & 93 & 98 & 92 & 46 \\
\hline Beryllium & 78 & 92 & 83 & 55 & 84 & 93 & 86 & 66 & 94 & 98 & 92 & 66 \\
\hline Bismuth & 78 & 92 & 83 & 55 & 84 & 93 & 86 & 66 & 94 & 98 & 92 & 66 \\
\hline Calcium & 79 & 90 & 88 & 57 & 89 & 96 & 85 & 48 & 93 & 98 & 94 & 78 \\
\hline Cadmium & 78 & 92 & 83 & 55 & 84 & 93 & 86 & 66 & 94 & 98 & 92 & 66 \\
\hline Cobalt & 67 & 85 & 83 & 50 & 84 & 93 & 86 & 31 & 94 & 99 & 59 & 32 \\
\hline Chromium & 55 & 87 & 76 & 60 & 80 & 89 & 82 & 18 & 98 & 97 & 84 & -81 \\
\hline Copper & 74 & 97 & 78 & 70 & 90 & 88 & 92 & 21 & 97 & 99 & 88 & -141 \\
\hline Iron & 75 & 89 & 81 & 58 & 80 & 90 & 86 & 48 & 95 & 95 & 49 & 23 \\
\hline Potassium & 86 & 96 & 87 & 66 & 90 & 96 & 88 & 50 & 94 & 98 & 94 & 69 \\
\hline Lanthanum & 76 & 88 & 81 & 54 & 71 & 88 & 85 & 23 & 92 & 81 & 4 & 11 \\
\hline Lithium & 75 & 86 & 85 & 65 & 82 & 83 & 90 & 59 & 95 & 97 & 59 & 42 \\
\hline Magnesium & 70 & 89 & 84 & 57 & 85 & 93 & 87 & 50 & 94 & 98 & 80 & 51 \\
\hline Manganese & 75 & 88 & 84 & 58 & 81 & 88 & 88 & 57 & 94 & 96 & 87 & 51 \\
\hline Molybdenum & 67 & 96 & 74 & 55 & 84 & 93 & 86 & 43 & 98 & 95 & 84 & 15 \\
\hline Sodium & 85 & 92 & 83 & 67 & 84 & 93 & 72 & -3 & 90 & 91 & 76 & 32 \\
\hline Nickel & 69 & 85 & 77 & 58 & 80 & 90 & 83 & 10 & 95 & 97 & 85 & -88 \\
\hline Phosphorus & 82 & 94 & 86 & 64 & 99 & 100 & 99 & 97 & 94 & 96 & 93 & 66 \\
\hline Lead & 70 & 94 & 62 & 64 & 80 & 85 & 83 & -13 & 93 & 97 & 57 & -18 \\
\hline Antimony & 78 & 92 & 83 & 55 & 84 & 93 & 86 & 66 & 94 & 98 & 92 & 66 \\
\hline Scandium & 72 & 81 & 84 & 62 & 84 & 88 & 86 & 44 & 95 & 98 & 64 & 32 \\
\hline Tin & 94 & 96 & 97 & 70 & 92 & 97 & 44 & -37 & 98 & 98 & 92 & $-1,050$ \\
\hline Strontium & 80 & 92 & 84 & 60 & 85 & 90 & 88 & 45 & 92 & 98 & 94 & 78 \\
\hline Titanium & 82 & 92 & 86 & 60 & 84 & 91 & 86 & 48 & 94 & 98 & 51 & 24 \\
\hline Vanadium & 72 & 87 & 81 & 53 & 79 & 91 & 86 & 31 & 95 & 98 & 63 & 26 \\
\hline Tungsten & 78 & 92 & 83 & 55 & 84 & 93 & 86 & 66 & 94 & 98 & 92 & 66 \\
\hline Yttrium & 78 & 90 & 84 & 54 & 79 & 88 & 86 & 41 & 94 & 91 & 61 & 27 \\
\hline Zinc & 77 & 94 & 81 & 62 & 76 & 95 & 85 & 22 & 95 & 98 & 86 & 13 \\
\hline Zirconium & 78 & 74 & 86 & 52 & 79 & 87 & 82 & 59 & 94 & 98 & 82 & 2 \\
\hline
\end{tabular}


Table 13. Median percent reductions for total and grain-size fractions of constituents measured in seasonal composite of street-solid yields collected before and after a single pass of a regenerative-air street cleaner on streets representing multifamily and commercial land-use types in Cambridge, Massachusetts. - Continued

[Bold italicized values indicate less than one-half the detection limit was used to determine concentration and normalized mass. Negative values indicate a potential net increase of a constituent. $\mathrm{n}$, number of samples; mm, millimeter; coarse, greater than or equal to $2 \mathrm{~mm}$; medium, less than $2 \mathrm{~mm}$ greater than or equal to $0.125 \mathrm{~mm}$; fine, less than $0.125 \mathrm{~mm}$ in diameter; spring, May to June, 2010; summer, July to September, 2010; fall, October to December, 2010]

\begin{tabular}{|c|c|c|c|c|c|c|c|c|c|c|c|c|}
\hline \multicolumn{13}{|c|}{ Commercial } \\
\hline \multirow{2}{*}{ Analyte } & \multicolumn{4}{|c|}{ Spring, $n=12$} & \multicolumn{4}{|c|}{ Summer, $\mathrm{n}=17$} & \multicolumn{4}{|c|}{ Fall, $n=15$} \\
\hline & Total & Coarse & Medium & Fine & Total & Coarse & Medium & Fine & Total & Coarse & Medium & Fine \\
\hline Organic carbon & 70 & 94 & 78 & 59 & 83 & 91 & 79 & 72 & 92 & 96 & 93 & 85 \\
\hline Silver & 37 & 85 & 73 & 82 & 37 & 91 & 35 & 61 & 88 & 96 & 89 & 73 \\
\hline Aluminum & 51 & 47 & 75 & 56 & 74 & 86 & 76 & 68 & 83 & 96 & 87 & 74 \\
\hline Arsenic & 72 & 97 & 62 & 53 & 79 & 82 & 86 & 56 & 79 & 97 & 88 & 73 \\
\hline Barium & 54 & 96 & 60 & 63 & 84 & 88 & 83 & 74 & 84 & 98 & 86 & 76 \\
\hline Beryllium & 69 & 92 & 73 & 58 & 79 & 91 & 78 & 66 & 88 & 96 & 89 & 73 \\
\hline Bismuth & 69 & 92 & 73 & 58 & 79 & 91 & 78 & 66 & 88 & 96 & 89 & 73 \\
\hline Calcium & 54 & 92 & 74 & 61 & 71 & 73 & 82 & 70 & 83 & 98 & 93 & 79 \\
\hline Cadmium & 69 & 92 & 73 & 58 & 79 & 91 & 78 & 66 & 88 & 96 & 89 & 73 \\
\hline Cobalt & 45 & -8 & 66 & 62 & 53 & 85 & 68 & 59 & 86 & 93 & 89 & 73 \\
\hline Chromium & 59 & 80 & 64 & 66 & 66 & 84 & 65 & 68 & 93 & 97 & 87 & 73 \\
\hline Copper & 30 & 90 & 11 & 60 & 31 & 84 & 29 & 62 & 90 & 97 & 87 & 60 \\
\hline Iron & 64 & 82 & 65 & 61 & 74 & 84 & 73 & 62 & 86 & 93 & 86 & 68 \\
\hline Potassium & 72 & 97 & 79 & 62 & 84 & 94 & 78 & 72 & 84 & 98 & 90 & 79 \\
\hline Lanthanum & 68 & 92 & 68 & 60 & 74 & 86 & 73 & 67 & 86 & 87 & 89 & 74 \\
\hline Lithium & 53 & 54 & 73 & 58 & 72 & 85 & 75 & 69 & 83 & 89 & 88 & 73 \\
\hline Magnesium & 55 & 59 & 75 & 57 & 70 & 83 & 77 & 67 & 85 & 93 & 88 & 76 \\
\hline Manganese & 58 & 94 & 71 & 59 & 76 & 83 & 78 & 64 & 87 & 94 & 85 & 72 \\
\hline Molybdenum & 48 & 96 & 31 & 63 & 86 & 91 & 86 & 66 & 94 & 96 & 68 & 73 \\
\hline Sodium & 69 & 96 & 73 & 58 & 79 & 63 & 78 & 81 & 83 & 98 & 89 & 77 \\
\hline Nickel & 64 & 86 & 71 & 66 & 71 & 83 & 70 & 62 & 91 & 95 & 87 & 70 \\
\hline Phosphorus & 62 & 96 & 73 & 63 & 97 & 99 & 97 & 98 & 83 & 97 & 89 & 79 \\
\hline Lead & 73 & 98 & 76 & 66 & 65 & 90 & 63 & 57 & 93 & 98 & 95 & 78 \\
\hline Antimony & 69 & 92 & 73 & 58 & 79 & 91 & 78 & 66 & 88 & 98 & 89 & 73 \\
\hline Scandium & 53 & 54 & 75 & 58 & 77 & 88 & 74 & 66 & 83 & 88 & 87 & 79 \\
\hline Tin & 84 & 92 & 73 & 58 & 58 & 82 & 14 & 66 & 94 & 96 & 89 & 91 \\
\hline Strontium & 66 & 93 & 77 & 64 & 73 & 83 & 75 & 68 & 81 & 97 & 93 & 78 \\
\hline Titanium & 61 & 61 & 73 & 58 & 74 & 77 & 73 & 63 & 80 & 94 & 85 & 77 \\
\hline Vanadium & 61 & 50 & 70 & 58 & 72 & 87 & 75 & 65 & 87 & 94 & 88 & 76 \\
\hline Tungsten & 69 & 92 & 73 & 58 & 79 & 91 & 78 & 66 & 88 & 96 & 89 & 73 \\
\hline Yttrium & 73 & 93 & 77 & 59 & 73 & 87 & 75 & 69 & 86 & 87 & 89 & 75 \\
\hline Zinc & 70 & 96 & 60 & 63 & 75 & 85 & 74 & 73 & 86 & 99 & 88 & 80 \\
\hline Zirconium & 60 & 90 & 71 & 44 & 79 & 89 & 77 & 70 & 88 & 96 & 84 & 71 \\
\hline
\end{tabular}


THIS PAGE INTENTIONALLY LEFT BLANK 


\title{
Appendix 1. Supplemental Data Tables
}

\author{
Tables included on accompanying CD-ROM
}

\section{Tables}

1-1. Curb-to-curb street-solid composite sample collection dates, start times, locations, intake nozzle widths and resulting masses and yields

1-2. Single-sided street cleaner removal efficiency composite sample pair collection dates, start times, locations, intake nozzle widths and resulting masses and yields

1-3. Curb-to-curb street-solid composite sample collection dates, start times, locations, intake nozzle widths and resulting total-recoverable concentrations by grain size for multifamily streets

1-4. Curb-to-curb street-solid composite sample collection dates, start times, locations, intake nozzle widths and resulting total-recoverable concentrations by grain size for commercial streets

1-5. Seasonal mixtures of single-sided street-solid composite samples, locations, and resulting total-recoverable concentrations by grain-size for multifamily streets before and after regenerative-air street cleaner operation

1-6. Seasonal street mixtures of single-sided street-solid composite samples, locations, and resulting total-recoverable concentrations by grain-size for commercial streets before and after regenerative-air street cleaner operation 
THIS PAGE INTENTIONALLY LEFT BLANK 


\section{Appendix 2. Source Loading and Management Model for Windows (WinSLAMM)}

\section{Functional Description of SLAMM}

The Source Loading and Management Model for Windows (WinSLAMM) uses a mass balance approach to track particulate and dissolved constituents associated with as many as six different land-use types and their source areas, taking into account a variety of rainfall conditions and source-area control measures. Runoff, constituent mass discharge and effects of selected control practices are the primary model output. SLAMM also can output other types of information such as the relative contribution of source areas within each land-use type and generation of National Resource Conservation Service (NRCS) curve numbers that represent the modeled land-use and control measures.

The model emphasizes the concept of small storm hydrology and particulate washoff to better simulate stormwater quality. This emphasis follows a major finding of the National Urban Runoff Program (NURP)-era work indicating small rainstorms represent the largest proportion of the annual urban runoff discharge quantities (U.S. Environmental Protection Agency, 1983; Pitt, 1987). The model also takes into account the findings of Maestre and Pitt (2005), where log-transformed constituent concentration data in stormwater generally have a lognormal distribution between the 5th and 95th percentiles. A Monte Carlo option in the model provides the means to determine variations in the constituent concentrations in source area runoff and provide median values used for mass balance calculations. This feature can be deactivated and discrete concentration can be used to allow evaluations of extreme concentrations. SLAMM also can be used with other models such as the Hydrologic Simulation Program Fortran (HSPF) and the StormWater Management Model (SWMM) to improve simulations of stormwater and water-quality controls.

Simulations in SLAMM require six input parameter files, which are based on actual data collected from many different studies across the United States and Canada since the late seventies and continue to be modified as new data become available. It is possible to simulate different stormwater control practices using precipitation data from a single year or several decades. SLAMM simulations can yield accurate predictions of stormwater quality for a drainage area with only limited ancillary information.

Local outfall stormwater quantity and quality data from several watersheds with relatively homogeneous land uses should be collected and used to calibrate SLAMM. Ideally, data from one set of watersheds or subcatchments should be used to calibrate the model, and data from the remaining subcatchments used to verify model performance. Alternatively, a subset of data from a single location can be used for model calibration and any remaining data from the same location used for verification. These approaches assume availability of good quality data. However, available data for this study were limited in number and quality.

\section{Input Data used for Modeling of Land-Use Subcatchments}

Land-use types and their respective source areas as input to SLAMM are provided in appendix table $2-1$. About 36 percent of the commercial subcatchment is considered multifamily or high-density residential land use (referred to as multifamily), about 17 percent institutional, and about 47 percent commercial land use. The model treats institutional and commercial areas the same, so the effective commercial land use is about 64 percent.

Drainage systems and other control practices must also be identified. SLAMM parameter files (table 2-2) must be input and modified as needed following their general order of calibration. Required information and the data contained in the parameter files used for SLAMM simulations of the commercial subcatchment are discussed in the following sections.

\section{Delineation of Land-Use Types and Source- Areas}

Characterization of land-use types and their respective source areas within the model subcatchments were delineated from impervious surface geographic information system (GIS) 2010 coverages generated by the city of Cambridge/MassGIS basemap development project (Cambridge Department of Public Works, written commun., 2011, table 2-1). Using the municipal GIS layers, which provided greater source-area resolution than the 1-meter $(\mathrm{m})$ impervious surface raster layers based on 2005 0.5-m color ortho mosaic index (MassGIS, 2011), all constructed surfaces and areas of man-made compacted soils were considered impervious. All surface waters, wetlands, natural and man-made vegetated areas were considered pervious. Roof, driveway, and other impervious surface drainage were further evaluated in the field to determine connectivity. If runoff drained less than 20 feet of pervious area, the drainage was considered directly connected. 
Table 2-1. Source-area designations and respective areas as input to SLAMM model within the commercial subcatchment, Cambridge, Massachusetts (Based on 2010 land-use coverages, city of Cambridge/MassGIS basemap development project).

$[--$, no data $]$

\begin{tabular}{lccccc}
\hline \multicolumn{1}{c}{ Subcatchment source areas } & $\begin{array}{c}\text { Mutlifamily and high-density } \\
\text { residential land use } \\
\text { (acres) }\end{array}$ & $\begin{array}{c}\text { Commercial } \\
\text { land use } \\
\text { (acres) }\end{array}$ & $\begin{array}{c}\text { Public/urban/insti- } \\
\text { tutional land use } \\
\text { (acres) }\end{array}$ & $\begin{array}{c}\text { Total area } \\
\text { (acres) }\end{array}$ & $\begin{array}{c}\text { Source area } \\
\text { proportion of total } \\
\text { (percent) }\end{array}$ \\
\hline Roofs flat & 1.69 & 3.17 & 1.37 & 6.24 & 28.66 \\
Roofs-flat, disconnected & 0.47 & -- & -- & 0.47 & 2.16 \\
Roofs-pitched & 0.57 & 0.56 & 0.13 & 1.26 & 5.80 \\
Roofs-pitched, disconnected & 0.01 & 0.09 & 0.05 & 0.15 & 0.68 \\
Paved parking/storage & 0.62 & 1.73 & 0.47 & 2.81 & 12.93 \\
Driveways & 0.61 & 0.76 & 0.04 & 1.41 & 6.50 \\
Driveways-disconnected & 0.04 & -- & -- & 0.04 & 0.18 \\
Sidewalks/walks & 0.54 & 1.22 & 0.11 & 1.87 & 8.59 \\
Sidewalks/walks-disconnected & 0.07 & -- & 0.14 & 0.21 & 0.98 \\
Street area & 0.82 & 2.23 & 0.46 & 3.52 & 16.15 \\
Large/small landscaped area & 2.48 & 0.40 & 0.90 & 3.78 & 17.37 \\
& & & & & \\
Total subcatchment area (acres) & 7.93 & 10.16 & 3.67 & 21.76 & \\
Proportion of total area (percent) & 36.45 & 46.70 & 16.86 & & \\
\hline
\end{tabular}

\section{Soils}

Soils in the subcatchment area (Middlesex County) typically are considered disturbed urban glacio-fluvial outwash (U.S. Department of Agriculture, 1995). Despite highly permeable classifications of parent soils, pervious areas were represented as "silty" rather than "sandy" within the model to account for the effects of compression and buildup of fugitive dust that substantially reduce native soil permeability (Pitt and others, 2008).

\section{Control Practices}

The city has a well-defined curb-and-gutter drainage system equipped with about 15 -inch (in.) high granite curbstone set at roughly 90 degrees to the road surface (fig. 4). Catchbasins are incorporated into the drainage system and are cleaned about twice a year. SLAMM version 9.4.0 is unable to simulate catchbasins and street cleaning simultaneously, and catchbasins were not specified. The city uses a monthly street-cleaning program with parking controls between April and December that uses mechanical brush sweepers. The tandem street cleaning approach (mechanical brush followed by vacuum assist) applied during the months of April and November was not simulated. In addition, many commercial areas and city squares that are swept weekly or daily were also not included in the model.
Base model simulations used to compare with flow and water-quality data collected in 1999-2000 were run by specifying monthly mechanical-brush street cleaning in the model. Productivity function coefficients provided with SLAMM for mechanical-brush street cleaners (slope, $\mathrm{M}=0.85$ and y-intercept, $\mathrm{B}=310$ ) were used. Model performance also was evaluated by comparing simulated street-dirt yield to streetdirt observations from 2009-2011. These simulations specified monthly vacuum-assist street cleaning using productivity function coefficients developed from the regenerative-air street cleaner observations in Cambridge.

\section{Street-Solid Accumulation}

The observations of material accumulation on street surfaces in Cambridge collected in 2010-2011 were used to populate SLAMM accumulation coefficients. The average accumulation rate for streets in multifamily areas (M) was set to 30 pounds per curb-mile per day (lbs/curb-mi/day), the intercept load (B) was set to $225 \mathrm{lbs} /$ curb-mi, and the maximum load (C) was set to 3,800 lbs/curb-mi. The endof-winter (EOW) load for residential land-use streets was set at 2,600 lbs/curb-mi. Commercial and institutional land-use accumulation coefficients M, B, C and EOW were set to 20, $225,1,400$, and 4,800, respectively. 


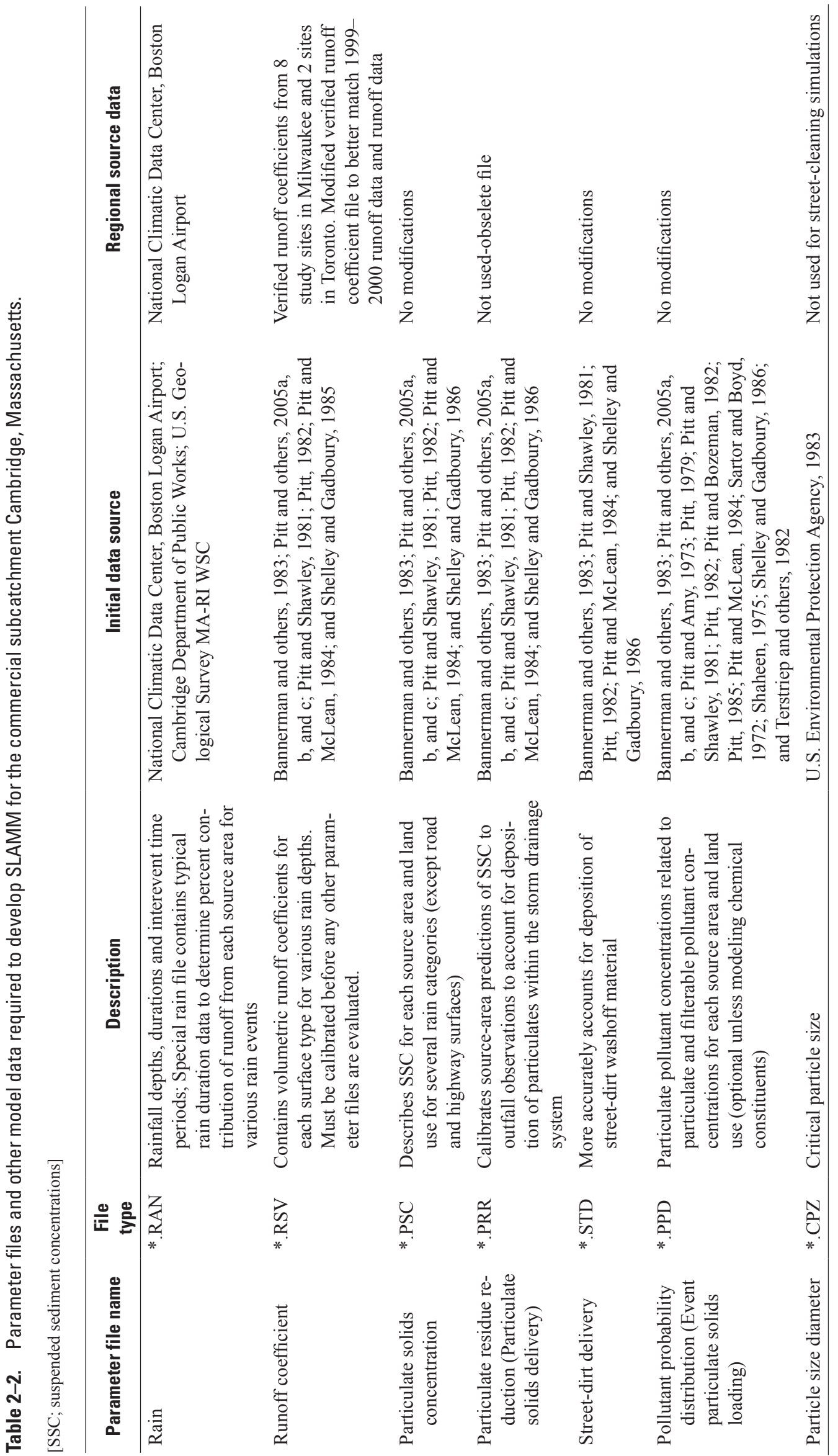




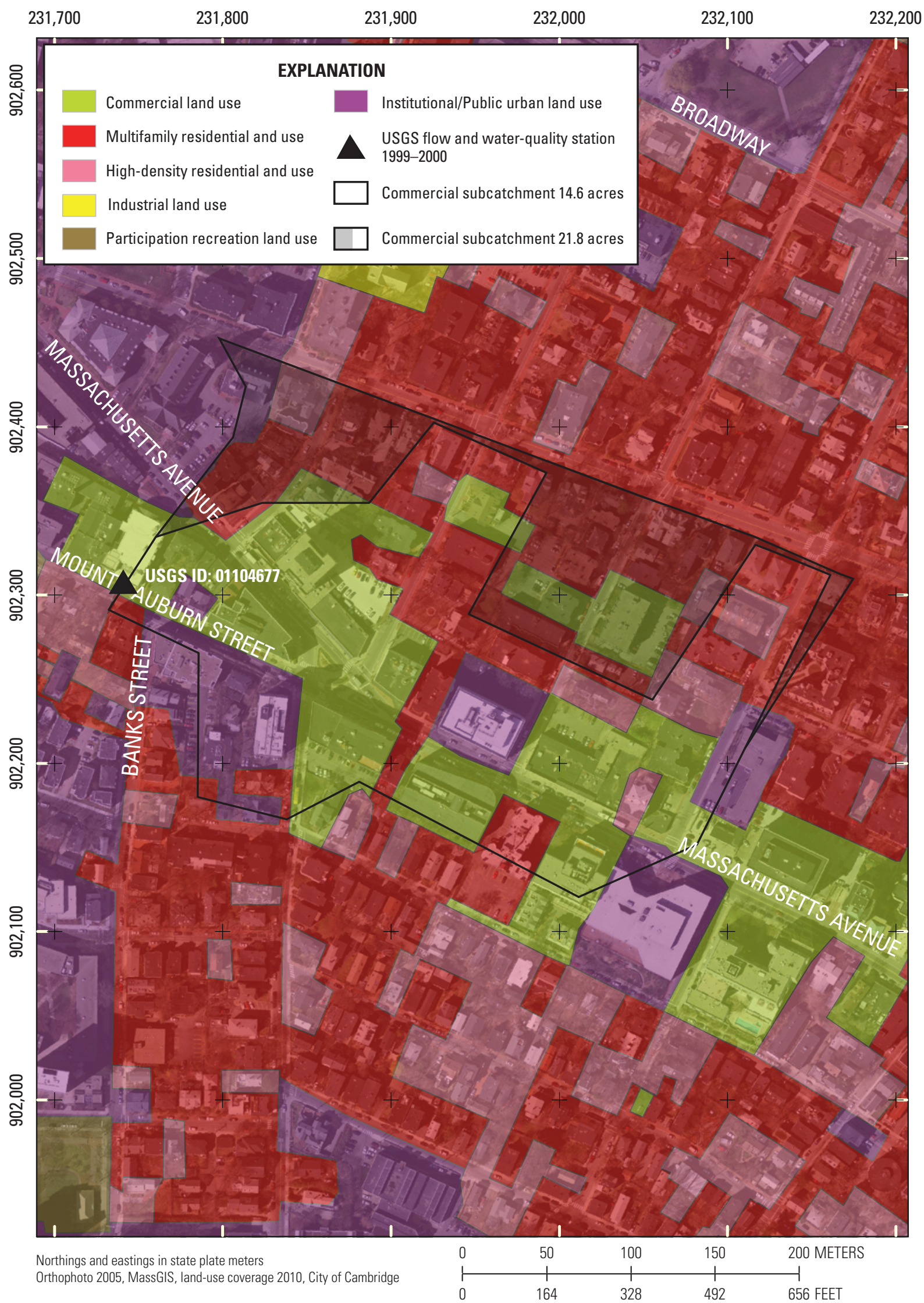

Figure 2-1. Predominantly commercial land-use subcatchment in Cambridge, Massachusetts, and United States Geological Survey flow and water-quality monitoring station (1999-2000; USGS ID: 01104677). Orthophoto 2005, MassGIS, and land-use coverages 2010, based on city of Cambridge/MassGIS basemap development project. 


\section{Rainfall}

Initial model runs used 62 years of rainfall data from Logan Airport in Boston, Massachusetts (1948-2010 COOP ID: 190770) available through the National Climatic Data Center (NCDC, 2011). Storms with rainfall less than 0.1 inch were omitted from all *.RAN files, (that is, only runoff producing storms were considered). A special *.RAN file was created from the long-term Logan Airport data to determine the average storm duration of storm depths between 0.10 to 5.00 in. SLAMM runs using the special *.RAN file estimated the relative contribution of runoff from each source area through the range of storm volumes and provided the basis for any modifications to runoff coefficient *.RSV parameter files. Logan Airport rainfall data were also used to evaluate simulated outfall runoff and loading compared to waterquality data collected in 1999-2000. Additional *.RAN files developed using precipitation records from the Cambridge Department of Public Works (DPW) Hampshire Street gage supplemented by the USGS Fresh Pond gage (USGS ID: 422302071083801) during winter months were used to evaluate model performance in terms of street-dirt loading observations in 2009-2011.

The base model that provided acceptable estimates of runoff and street-dirt loading was run using 5 years of precipitation data from Logan Airport. The five average years were selected by comparison of annual discharges from the USGS Aberjona River at Winchester, Mass. gage (USGS gage ID: 01102500, located about 7 miles north of Cambridge) with the 70-year mean annual flow of 31 cubic feet per second $\left(\mathrm{ft}^{3} / \mathrm{s}\right)$ reported at the gage (Bent and others, 2009). Years with annual average discharge within 4.5 percent of the 70 -year mean annual flow at the USGS Aberjona River at Winchester, Mass. gage were 1948, 1953, 1961, 1986, and 1991. Model runs using a *.RAN file based on these data allowed SLAMM to generate average estimates of street cleaner performance in terms of total and particulate solid and phosphorus (P) reductions.

\section{Runoff}

Runoff coefficient $\left(\mathrm{R}_{\mathrm{v}}\right)$ parameter files $\left({ }^{*}\right.$.RSV) contain ratios of runoff quantity to rainfall volume for all modeled surface types for rain depths measuring from 0.01 to $5 \mathrm{in}$. The WI_SL06 Dec06.RSV file provided with the model initially was used, and examination of the relative contribution of source areas generated by the model run using the special *.RAN file, runoff coefficients were modified in a stepwise manner to improve agreement between simulated results and runoff data from 1999-2000. Runoff coefficient increases between 0.05 and 0.10 were determined to be sufficient to better match simulated and observed outfall flows.

\section{Particulate Solids Concentration}

Suspended solids concentrations (SSCs) associated with source areas from each land use over a range of rain depths is contained in the particulate solids concentrations (*.PSC) file. Build-up and washoff functions directly predict roads and highway surface SSCs, and are not included in the *.PSC file (Pitt and Voorhees, 2000). The WI_AVG01.PSC file (appendix table 2-2) provided with the model is based on data from Madison, Wisconsin, that represents the best average particulate solids information. No new outfall SSC data were collected in Cambridge to support modifications to this *.PSC file, and therefore the WI_AVG01.PSC file was used for calibration and subsequent SLAMM simulations.

Two additional parameter files are used to describe the transport of particulates in SLAMM. The first file is the particulate residue reduction file (*.PRR), and was designed to account for the deposition of particulates in the storm drainage system before the outfall or outfall controls (Pitt, 2008; Pitt and Voorhees, 2000). Particulate deposition in the storm drainage system, however, is now directly calculated, making the *.PRR file obsolete (Pitt, 2008). SLAMM still requires a *.PRR file to be specified, and the file WI_DLV01.PRR, set to zero, was used as a placeholder in the model. The second additional file is the street-dirt delivery file (*.STD). These files account for the fraction reduction in street dirt yield during washoff events measuring from 0.04 to $3.2 \mathrm{in}$. Fraction washoff is applied to street surfaces with textures ranging from smooth to rough within each land-use type. The files WI_Res and Other Urban Dec06.STD, WI_Com Inst Indust Dec06.STD, and Freeway Dec06.STD were used in the model. These files typically show 100-percent washoff for all surface types for storm depths greater than 0.60 inches. Changes to washoff coefficients are not possible in SLAMM version 9.4. Washoff data calculated as part of this study are not used in the following simulations.

\section{Pollutant Concentrations}

The *.PPD file contains particulate and dissolved pollutant concentrations associated with each source area for each land-use type specified in the model. This file only needs to be specified for constituents other than particulate solids. Coefficient of variation (COV) values included for each constituent for Monte Carlo simulations (Pitt, 2008; Pitt and Voorhees, 2000). The WI_GEO01.PPD file (appendix table 2-2) was applied to model the Cambridge commercial subcatchment. The critical particle size file (*.CPZ) is primarily designed to assist evaluations of wet detention ponds and other structural stormwater control measures SCMs. SLAMM comes with several *.CPZ files that describe particle size ranges in areas associated with low to high particulate residue concentrations as well as files that contain the average of the NURP-era studies and a regionally-specific *.CPZ file. The critical particle size parameter file was not necessary for SLAMM simulations of street cleaning in this study, and no *.CPZ file was specified. 


\section{References}

Bannerman, R., Baun, K.M., Bohn, P.E., and Graczyk, D.A., 1983, Evaluation of urban nonpoint source pollution management in Milwaukee County, Wisconsin: Chicago, Ill., U.S. Environmental Protection Agency, PB 84-114164.

Maestre, A., and Pitt, R., 2005, The National Stormwater Quality Database, Version 1.1, A compilation and analysis of NPDES stormwater monitoring information: Washington D.C., U.S. Environmental Protection Agency, Water Planning Division, variously paginated.

Massachusetts Office of Geographic Information (MassGIS), 2011, 0.5-meter color ortho mosaic and metadata: Accessed February 12, 2011, at http://www.mass.gov/anf/researchand-tech/it-serv-and-support/application-serv/office-ofgeographic-information-massgis/datalayers/massgis-datadownload-usgs-color-ortho-imagery-2008-2009.html

National Climatic Data Center, accessed February 12, 2011, at http://cdo.ncdc.noaa.gov/dlyp/DLYP.

Pitt, R.E., 1982, Urban bacteria sources and control in the lower Rideau River watershed: Ottawa Ontario, Ontario Ministry of the Environment, variously paginated.

Pitt, R.E., 1985, Characterizing and controlling urban runoff through street and sewerage cleaning: U.S. Environmental Protection Agency, Storm and Combined Sewer Program, Cincinnati, Ohio, Risk Reduction Engineering Laboratory, EPA/600/S2-85/038, PB 85-186500, variously paginated.

Pitt, R.E., 1987, Small storm urban flow and particulate washoff contributions to outfall discharges: Department of Civil and Environmental Engineering, University of Wisconsin, Madison, Ph.D. dissertation, 187 p.

Pitt, R.E., 2008, Calibration of WinSLAMM, PV \& Associates, Madison, Wis., 38 p.

Pitt, R.E., Bannerman, R., Clark, S., and Williamson, D., 2005a, Sources of pollutants in urban areas (part I) — older monitoring projects, in Effective modeling of urban water systems: Monograph 13, James, W., Irvine, K.N., McBean, E.A., and Pitt, R.E., eds., CHI, Guelph, Ontario, 465-484 and 507-530 p.

Pitt, R.E., Bannerman, R., Clark, S., and Williamson, D., 2005 b, Sources of pollutants in urban areas (part II) - recent sheetflow monitoring results, in Effective modeling of urban water systems: Monograph 13, James, W., Irvine, K.N., McBean, E.A., and Pitt, R.E., eds., CHI, Guelph, Ontario, 485-530 p.
Pitt, R.E., and Bozeman, M., 1982, Sources of urban runoff pollution and its effects on an urban creek: Cincinnati, Ohio, U.S. Environmental Protection Agency, EPA-600/ S2-82-090, variously paginated.

Pitt, R.E., Chen, S., Clark, S.E., Swenson, J., and Ong, C.K., 2008, Compaction's impacts on urban storm-water infiltration: Journal of Irrigation and Drainage Engineering, p. $652-658$.

Pitt, R.E., and McLean, J., 1984, Humber River pilot watershed project: Toronto, Ontario, Ontario Ministry of the Environment, variously paginated.

Pitt, R.E., and Shawley, G., 1981, Demonstration of nonpoint pollution management on Castro Valley Creek: Washington, D.C., U.S. Environmental Protection Agency, Water Planning Division, variously paginated.

Pitt, R.E., and Voorhees, J., 2000, The source loading and management model (SLAMM): A water quality planning management model for urban storm water runoff, PV \& Associates, Madison, Wis., 587 p.

Pitt, R.E., Williamson, D., and Voorhees, J., 2005c, Review of historical street dust and dirt accumulation and washoff data, in Effective modeling of urban water systems: Monograph 13, James, W., Irvine, K.N., McBean, E.A., and Pitt, R.E., ed., CHI, Guelph, Ontario, 203-246 pp.

Shelley, P.E., and Gaboury, D.R., 1986, Estimation of pollution from highway runoff-initial results: Conference on urban runoff quality-impact and quality enhancement technology, Henniker, New Hampshire: Urbonas, B., and Roesner, L.A., eds., in Proceedings published by the American Society of Civil Engineering, New York, variously paginated.

Terstriep, M.L., Bender, G.M., and Noel, D.C., 1982, Evaluation of the effectiveness of municipal street cleaning in the control of urban storm pollution: Final report-NURP project, Champaign-Urbana, Illinois, State Water Survey Division, Illinois Department of Energy and Natural Resources, variously paginated.

U.S. Department of Agriculture, 1995, Soil Survey Geographic (SSURGO) Data Base, Data Use Information: Natural Resources Conservation Service, National Soil Survey Center, Miscellaneous Publication Number 1527, variously paged.

U.S. Environmental Protection Agency, 1983, Nationwide Urban Runoff Program, Winston-Salem, N.C.-An evaluation of street sweeping as a runoff pollution control: Office of Water Programs, 229 p. (Also available from National Technical Information Service, Springfield, VA 22161 and http://www.ntis.gov, item PB85-102507) 
Prepared by the Pembroke and Rolla Publishing Service Centers.

For more information concerning this report, contact:

Office Chief

U.S. Geological Survey

New England Water Science Center

Massachusetts-Rhode Island Office

10 Bearfoot Road

Northborough, MA 01532

dc_ma@usgs.gov

or visit our Web site at:

http://ma.water.usgs.gov 


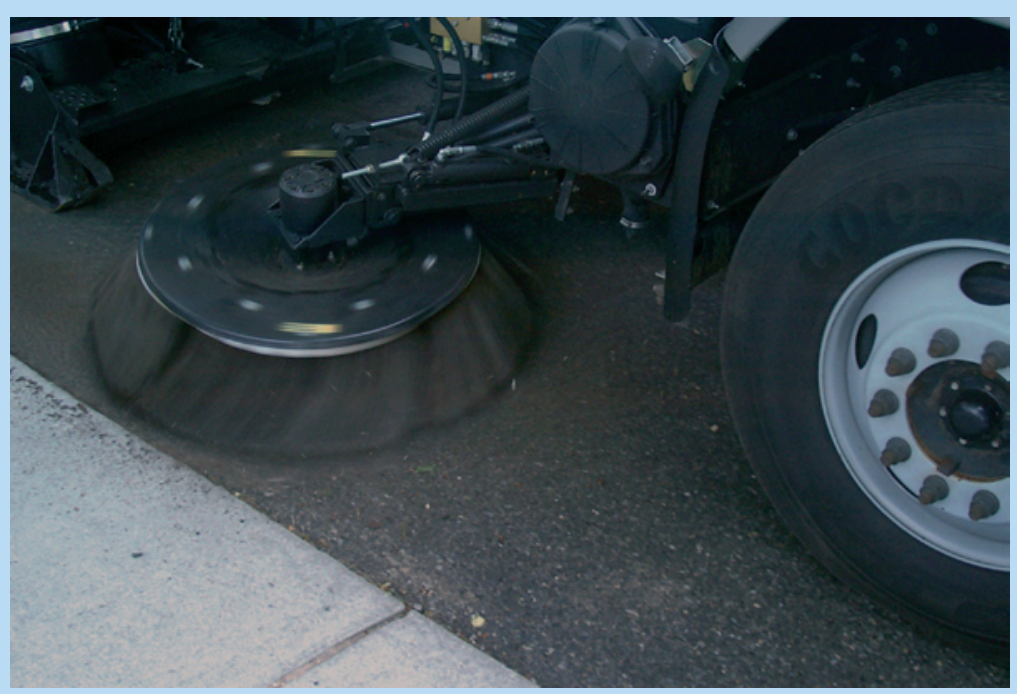

69 Printed on recycled paper 